\title{
Traversing the tightrope between halogen and chalcogen bonds using structural chemistry and theory
}

\author{
Vinu V. Panikkattu, ${ }^{a}$ Anh Tran, ${ }^{b}$ Abhijeet S. Sinha, ${ }^{a}$ Eric W. Reinheimer, ${ }^{c}$ Emilie \\ B. Guidez, ${ }^{b^{*}}$ and Christer B. Aakeröy ${ }^{a^{*}}$
}

aDepartment of Chemistry, Kansas State University, Manhattan, KS 66506;

bepartment of Chemistry, University of Colorado, Denver, CO 80217;

'Rigaku Americas Corporation, 9009 New Trails Drive, The Woodlands, TX 77381.

*Email: emilie.guidez@ucdenver.edu

*Email: aakeroy@ksu.edu

\section{Supplementary information}




\section{Table of Contents}

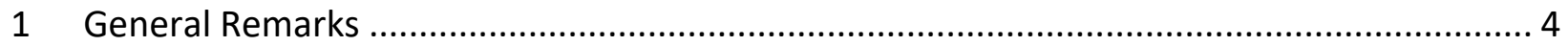

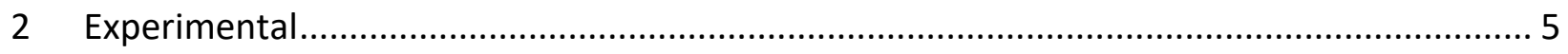

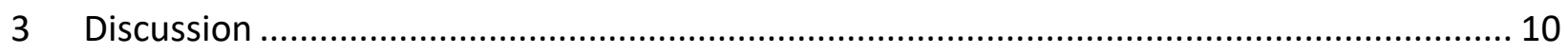

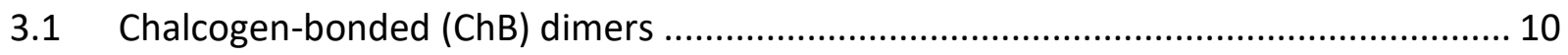

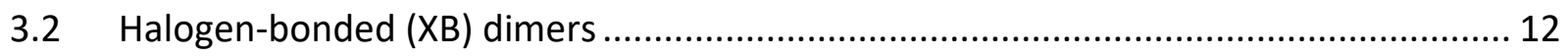

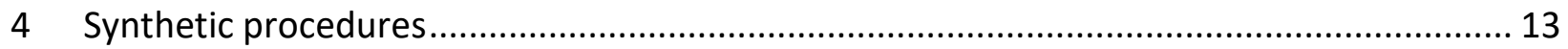

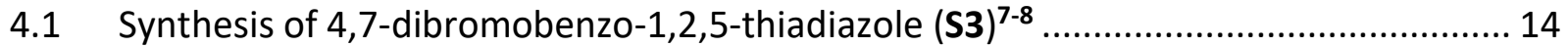

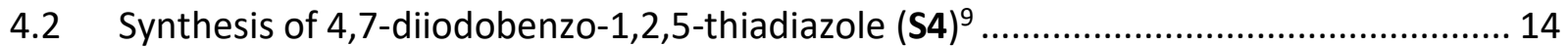

4.3 Synthesis of 4,7-bis((trimethylsilyl)ethynyl)benzo-1,2,5-thiadiazole (ST) ${ }^{10} \ldots \ldots \ldots \ldots \ldots \ldots . . . . .15$

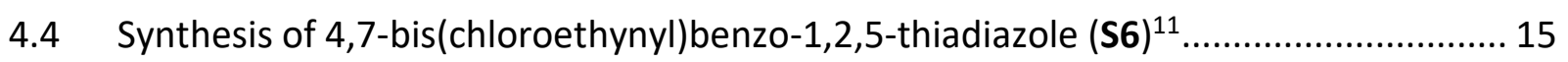

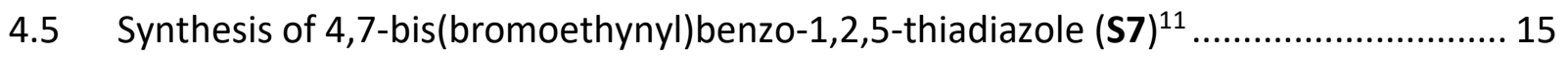

4.6 Synthesis of 4,7-bis(iodoethynyl)benzo-1,2,5-thiadiazole (S8) ${ }^{11}$................................. 16

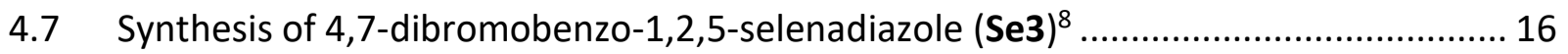

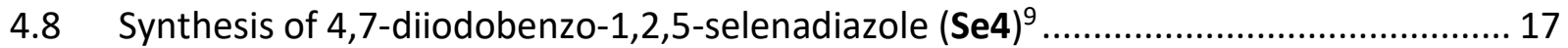

4.9 Synthesis of 3,6-bis((trimethylsilyl)ethynyl)benzene-1,2-diamine (SeT1) ${ }^{12} \ldots \ldots \ldots \ldots \ldots \ldots . . . .17$

4.10 Synthesis of 4,7-bis((trimethylsilyl)ethynyl)benzo-1,2,5-selenadiazole (SeT2) ${ }^{12} \ldots . . . .18$

4.11 Synthesis of 4,7-bis(chloroethynyl)benzo-1,2,5-selenadiazole (Se6) ${ }^{11} \ldots \ldots \ldots \ldots \ldots \ldots \ldots . . . . .18$

4.12 Synthesis of 4,7-bis(bromoethynyl)benzo-1,2,5-selenadiazole (Se7 $)^{11}$.................... 18

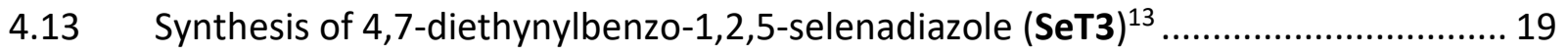

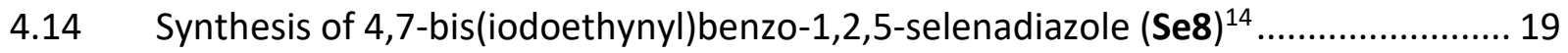

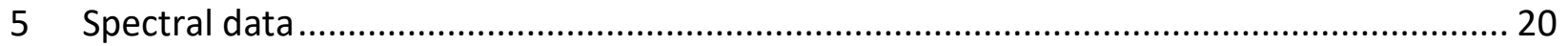

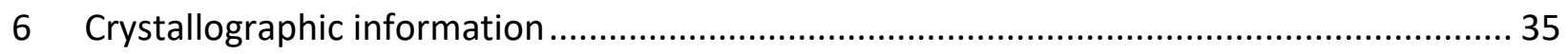

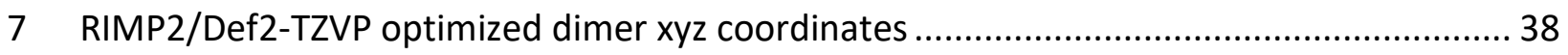

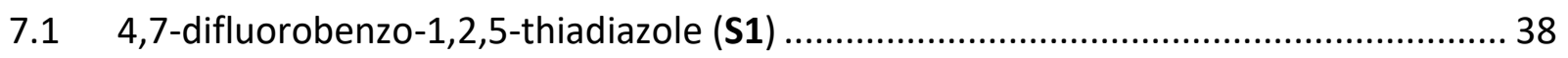

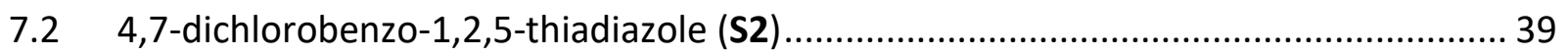

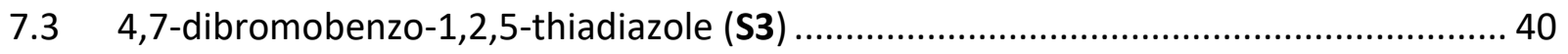

7.4 4,7-diiodobenzo-1,2,5-thiadiazole (S4) .............................................................. 42

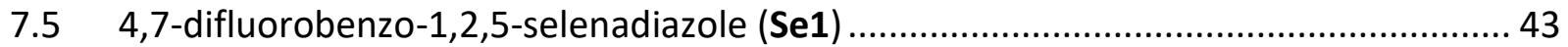

7.6 4,7-dichlorobenzo-1,2,5-selenadiazole (Se2) ........................................................ 44

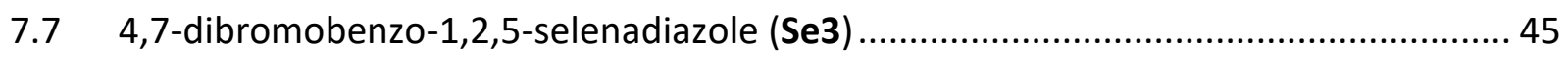

7.8 4,7-diiodobenzo-1,2,5-selenadiazole (Se4) ......................................................... 46 


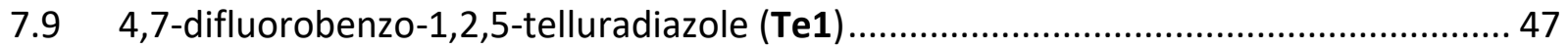

7.10 4,7-dichlorobenzo-1,2,5-telluradiazole (Te2) ................................................. 48

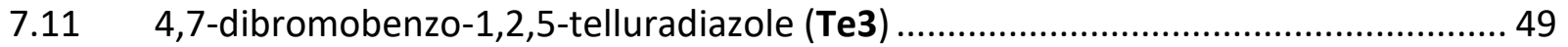

7.12 4,7-diiodobenzo-1,2,5-telluradiazole (Te4) .................................................... 51

7.13 4,7-bis(fluoroethynyl)benzo-1,2,5-thiadiazole (S5) .......................................... 52

7.14 4,7-bis(chloroethynyl)benzo-1,2,5-thiadiazole (S6) ........................................... 54

7.15 4,7-bis(bromoethynyl)benzo-1,2,5-thiadiazole (S7) ....................................... 55

7.16 4,7-bis(iodoethynyl)benzo-1,2,5-thiadiazole (S8) .......................................... 57

7.17 4,7-bis(fluoroethynyl)benzo-1,2,5-selenadiazole (Se5) ........................................ 59

7.18 4,7-bis(chloroethynyl)benzo-1,2,5-selenadiazole (Se6) ..................................... 60

7.19 4,7-bis(bromoethynyl)benzo-1,2,5-selenadiazole (Se7) ....................................... 62

7.20 4,7-bis(iodoethynyl)benzo-1,2,5-selenadiazole (Se8) ......................................... 64

7.21 4,7-bis(fluoroethynyl)benzo-1,2,5-telluradiazole (Te5) ....................................... 65

7.22 4,7-bis(chloroethynyl)benzo-1,2,5-telluradiazole (Te6)....................................... 67

7.23 4,7-bis(bromoethynyl)benzo-1,2,5-telluradiazole (Te7) ..................................... 69

7.24 4,7-bis(iodoethynyl)benzo-1,2,5-telluradiazole (Te8) .......................................... 70

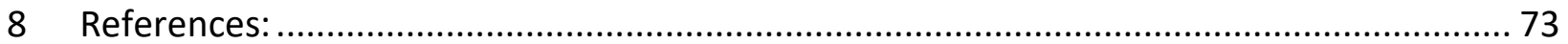




\section{General Remarks}

Commercial reagents were purchased as reagent-grade and used without further purification. All solvents utilized in this study were purchased commercially as technical grade and used as is without further purification. Targets were synthesized by modified versions of previously reported synthetic routes as described when referenced. Melting points were measured using a TA Instruments DSC Q20 differential scanning calorimeter. Nuclear magnetic resonance (NMR) data were collected using either a Bruker Ascend $400 \mathrm{MHz}$ or Varian Unity Plus $400 \mathrm{MHz}$ spectrometer. The residual solvent peak was used as the internal reference for ${ }^{1} \mathrm{H}$ and ${ }^{13} \mathrm{C}$ NMR $(\mathrm{CDCl} 3: \delta \mathrm{H}=7.26 \mathrm{ppm}, \delta \mathrm{C}=77.16 \mathrm{ppm}$; DMSO-d6: $\delta \mathrm{H}=2.50 \mathrm{ppm}, \delta \mathrm{C}=39.52 \mathrm{ppm})$. The residual solvent peak from the ${ }^{1} \mathrm{H}$ spectrum (DMSO-d6: $\delta \mathrm{H}=2.50$ ) was used as reference for the ${ }^{77} \mathrm{Se}$ spectrum. Target signals have been picked and labeled in all spectra, and have also been integrated in ${ }^{1} \mathrm{H}$ spectra. The ${ }^{1} \mathrm{H}$ NMR spectra are reported as follows: chemical shift $\delta$ in ppm relative to TMS $(\delta=0 \mathrm{ppm})$, multiplicity, number of protons. The resonance multiplicity is described as $\mathrm{s}$ (singlet) or $\mathrm{m}$ (multiplet). Broad signals are described with br. (broad). ${ }^{13} \mathrm{C} \mathrm{NMR}$ spectra are reported as follows: chemical shift $\delta$ in ppm relative to TMS $(\delta=0 \mathrm{ppm})$, multiplicity, number of carbon atoms. ${ }^{77} \mathrm{Se}$ NMR spectra are reported as follows: chemical shift $\delta$ in ppm relative to TMS $(\delta=0 \mathrm{ppm})$, multiplicity, number of selenium atoms. Single crystal X-ray diffraction data were collected either using a Rigaku XtaLAB Synergy-S ${ }^{1}$ (S6II, S7) or a Bruker Kappa APEX II ${ }^{2}$ (S6I, S8, Se3-4, Se6-7) diffractometers. Data collection parameters are outlined in crystallographic information table. The structure was solved using Olex $2^{3}$ with the SHELXT ${ }^{4}$ structure solution program using Intrinsic Phasing and refined with the SHELXL ${ }^{5}$ refinement package using Least Squares minimization. 


\section{Experimental}

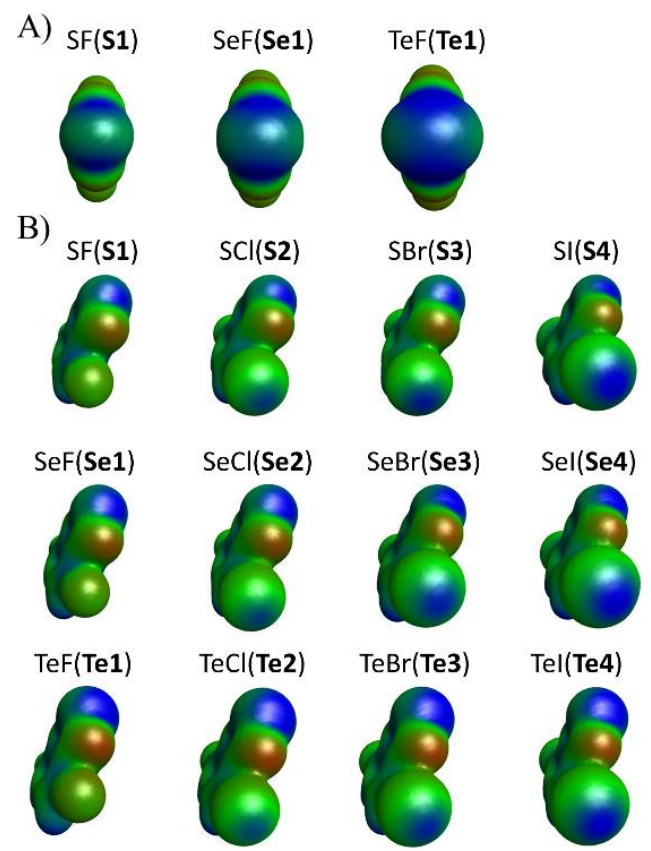

Figure S1. Molecular electrostatic potential surface map of non-activated benzochalcogenadiazole derivatives $\mathrm{ChX}(\mathrm{Ch}=\mathrm{S}, \mathrm{Se}, \mathrm{Te}$ and $\mathrm{X}=\mathrm{F}, \mathrm{Cl}, \mathrm{Br}, \mathrm{I})$. A) Chalcogen view B) Halogen view. Contour value: 0.006. Red indicates an area of negative charge and blue an area of positive charge. Green is neutral.

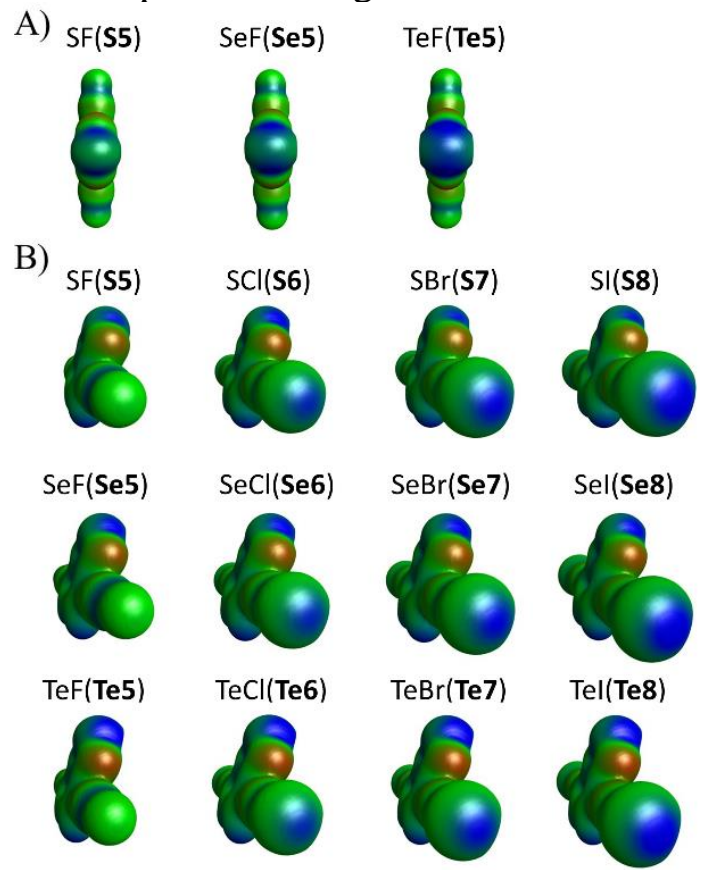

Figure S2. Molecular electrostatic potential surface map of activated benzochalcogenadiazole derivatives $\mathrm{ChX}(\mathrm{Ch}=\mathrm{S}$, Se, Te and $\mathrm{X}=\mathrm{F}, \mathrm{Cl}, \mathrm{Br}, \mathrm{I})$. A) Chalcogen view B) Halogen view. Contour value: 0.006 . Red indicates an area of negative charge and blue an area of positive charge. Green is neutral. 


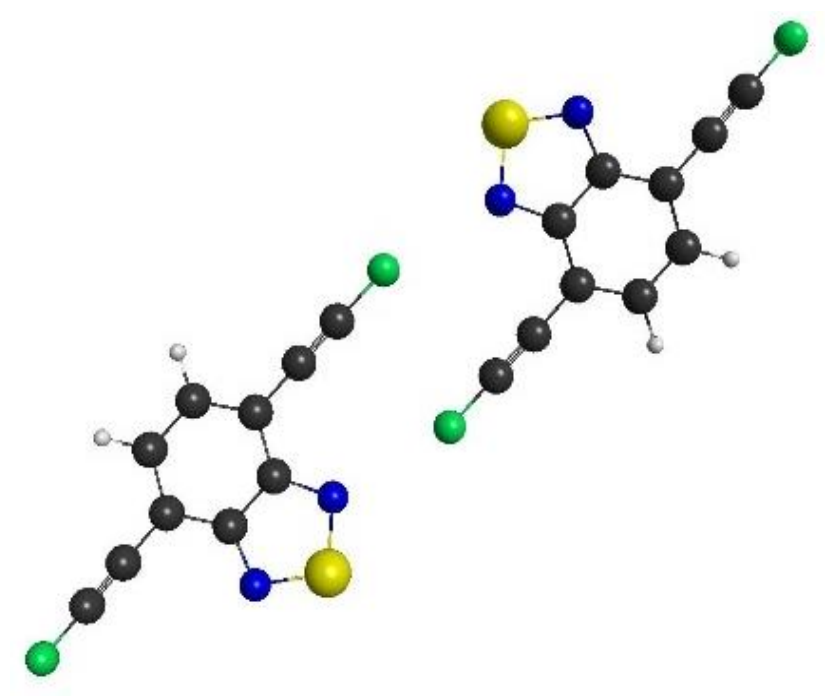

Figure S3. Schematic of the calculated halogen-bonded dimer formed for S5 in-spite of the absence of a $\sigma$-hole on the fluorine atom.

Table S1. CP-corrected MP2/Def2-TZVP energy decomposition analysis of non-activated chalcogen-bonded (ChB) and halogen-bonded (XB) dimers (S1-S4).

\begin{tabular}{|c|c|c|c|c|c|c|c|c|}
\hline & \multicolumn{4}{|c|}{ ChB dimer } & \multicolumn{4}{c|}{ XB dimer } \\
\hline Target & Elec. & Pol. & Ex-rep & Disp. & Elec. & Pol. & Ex-rep & Disp. \\
\hline S1 & -8.60 & -2.42 & 10.88 & -5.44 & N/A & N/A & N/A & N/A \\
\hline S2 & -9.29 & -2.72 & 12.40 & -6.78 & -2.46 & -0.84 & 5.32 & -4.63 \\
\hline S3 & -9.49 & -2.81 & 12.96 & -7.42 & -3.62 & -1.14 & 7.29 & -5.83 \\
\hline S4 & -9.45 & -2.83 & 13.54 & -8.21 & -4.62 & -1.65 & 9.49 & -6.76 \\
\hline
\end{tabular}

Table S2. CP-corrected MP2/Def2-TZVP energy decomposition analysis of non-activated chalcogenbonded (ChB) and halogen-bonded (XB) dimers (Se1-Se4).

\begin{tabular}{|c|c|c|c|c|c|c|c|c|}
\hline & \multicolumn{4}{|c|}{ ChB dimer } & \multicolumn{4}{|c|}{ XB dimer } \\
\hline Target & Elec. & Pol. & Ex-rep & Disp. & Elec. & Pol. & Ex-rep & Disp. \\
\hline Se1 & -17.02 & -6.18 & 21.89 & -8.62 & N/A & N/A & N/A & N/A \\
\hline Se2 & -17.96 & -6.75 & 24.39 & -10.7 & -2.49 & -0.92 & 5.66 & -4.88 \\
\hline Se3 & -17.75 & -6.72 & 24.57 & -11.47 & -3.75 & -1.26 & 7.81 & -6.2 \\
\hline Se4 & -17.04 & -6.44 & 24.55 & -12.32 & -4.68 & -1.79 & 10.09 & -7.2 \\
\hline
\end{tabular}

Table S3. CP-corrected MP2/Def2-TZVP energy decomposition analysis of non-activated chalcogenbonded (ChB) and halogen-bonded (XB) dimers (Te1-Te4).

\begin{tabular}{|c|c|c|c|c|c|c|c|c|}
\hline & \multicolumn{4}{|c|}{ ChB dimer } & \multicolumn{4}{c|}{ XB dimer } \\
\hline Target & Elec. & Pol. & Ex-rep & Disp. & Elec. & Pol. & Ex-rep & Disp. \\
\hline Te1 & -43.72 & -24.87 & 61.48 & -13.63 & N/A & N/A & N/A & N/A \\
\hline Te2 & -40.8 & -23.13 & 59.07 & -16.02 & -2.45 & -1.04 & 6.02 & -5.2 \\
\hline Te3 & -39.37 & -22.22 & 57.81 & -16.92 & -3.86 & -1.43 & 8.47 & -6.69 \\
\hline Te4 & -36.17 & -20.13 & 54.53 & -17.69 & -4.82 & -2.02 & 11.08 & -7.9 \\
\hline
\end{tabular}


Table S4. CP-corrected MP2/Def2-TZVP energy decomposition analysis of activated chalcogenbonded (ChB) and halogen-bonded (XB) dimers (S5-S8).

\begin{tabular}{|c|c|c|c|c|c|c|c|c|}
\hline & \multicolumn{4}{|c|}{ ChB dimer } & \multicolumn{4}{|c|}{ XB dimer } \\
\hline Target & Elec. & Pol. & Ex-rep & Disp. & Elec. & Pol. & Ex-rep & Disp. \\
\hline S5 & -9.14 & -2.68 & 12.87 & -7.35 & -0.21 & -0.22 & 2.09 & -3.03 \\
\hline S6 & -9.61 & -2.78 & 13.54 & -8.72 & -6.15 & -1.72 & 10.25 & -7.83 \\
\hline S7 & -9.89 & -2.89 & 14.1 & -9.43 & -9.48 & -2.89 & 15.51 & -10.31 \\
\hline S8 & -10.32 & -3.11 & 15.2 & -10.4 & -15.54 & -5.96 & 25.62 & -13.49 \\
\hline
\end{tabular}

Table S5. CP-corrected MP2/Def2-TZVP energy decomposition analysis of activated chalcogenbonded (ChB) and halogen-bonded (XB) dimers (Se5-Se8).

\begin{tabular}{|c|c|c|c|c|c|c|c|c|}
\hline & \multicolumn{4}{|c|}{ ChB dimer } & \multicolumn{4}{c|}{ XB dimer } \\
\hline Target & Elec. & Pol. & Ex-rep & Disp. & Elec. & Pol. & Ex-rep & Disp. \\
\hline Se5 & -17.70 & -6.61 & 25.01 & -11.49 & -0.11 & -0.22 & 2.03 & -3.02 \\
\hline Se6 & -18.62 & -6.92 & 26.5 & -13.52 & -6.52 & -1.9 & 11.06 & -8.2 \\
\hline Se7 & -19.19 & -7.21 & 27.67 & -14.47 & -10.37 & -3.29 & 17.27 & -11 \\
\hline Se8 & -19.66 & -7.55 & 28.89 & -15.52 & -17.21 & -6.89 & 28.83 & -14.51 \\
\hline
\end{tabular}

Table S6. CP-corrected MP2/Def2-TZVP energy decomposition analysis of activated chalcogenbonded (ChB) and halogen-bonded (XB) dimers (Te5-Te8).

\begin{tabular}{|c|c|c|c|c|c|c|c|c|}
\hline & \multicolumn{9}{|c|}{ ChB dimer } & \multicolumn{4}{|c|}{ XB dimer } \\
\hline Target & Elec. & Pol. & Ex-rep & Disp. & Elec. & Pol. & Ex-rep & Disp. \\
\hline Te5 & -41.71 & -23.65 & 62.21 & -17.37 & 0.01 & -0.24 & 2.00 & -3.05 \\
\hline Te6 & -42.71 & -24.07 & 63.66 & -19.52 & -7.05 & -2.15 & 12.24 & -8.73 \\
\hline Te7 & -42.79 & -24.13 & 63.98 & -20.4 & -11.54 & -3.82 & 19.52 & -11.84 \\
\hline Te8 & -43.79 & -25.06 & 66.29 & -21.59 & -20.01 & -8.44 & 34.00 & -15.98 \\
\hline
\end{tabular}

Table S7. MP2/Def2-TZVP energy decomposition analysis (no CP correction) of the nonactivated chalcogen and halogen-bonded dimers. All values are given in $\mathrm{kcal} / \mathrm{mol}$.

\begin{tabular}{|c|c|c|c|c|c|c|c|c|c|c|}
\hline & \multicolumn{9}{|c}{ ChB dimer } & \multicolumn{5}{c|}{ XB dimer } \\
Target & Elec. & Pol. & $\begin{array}{c}\text { Ex- } \\
\text { rep }\end{array}$ & Disp. & Total & Elec. & Pol. & $\begin{array}{c}\text { Ex- } \\
\text { rep }\end{array}$ & Disp. & Total \\
\hline S1 & -8.23 & -2.32 & 10.21 & -6.24 & -6.58 & N/A & N/A & N/A & N/A & N/A \\
\hline S2 & -8.85 & -2.63 & 11.63 & -7.72 & -7.57 & -2.12 & -0.88 & 4.81 & -5.21 & -3.40 \\
\hline S3 & -9.07 & -2.72 & 12.19 & -8.37 & -7.98 & -3.34 & -1.19 & 6.80 & -6.44 & -4.17 \\
\hline S4 & -9.12 & -2.72 & 12.86 & -9.22 & -8.20 & -4.56 & -1.64 & 9.22 & -7.54 & -4.51 \\
\hline Se1 & -16.46 & -5.97 & 20.77 & -9.77 & -11.43 & N/A & N/A & N/A & N/A & N/A \\
\hline Se2 & -17.33 & -6.53 & 23.15 & -11.98 & -12.70 & -2.11 & -0.98 & 5.09 & -5.49 & -3.49 \\
\hline Se3 & -17.19 & -6.51 & 23.39 & -12.72 & -13.02 & -3.43 & -1.31 & 7.29 & -6.85 & -4.30 \\
\hline Se4 & -16.68 & -6.23 & 23.62 & -13.63 & -12.92 & -4.62 & -1.78 & 9.82 & -8.02 & -4.60 \\
\hline Te1 & -43.41 & -23.96 & 59.77 & -15.56 & -23.16 & N/A & N/A & N/A & N/A & N/A \\
\hline Te2 & -40.39 & -22.23 & 57.23 & -18.05 & -23.45 & -2.02 & -1.09 & 5.41 & -5.88 & -3.59 \\
\hline Te3 & -39.09 & -21.42 & 56.21 & -18.89 & -23.18 & -3.5 & -1.46 & 7.88 & -7.41 & -4.49 \\
\hline Te4 & -36.07 & -19.43 & 53.31 & -19.67 & -21.86 & -4.74 & -1.99 & 10.78 & -8.80 & -4.76 \\
\hline
\end{tabular}


Table S8. MP2/Def2-TZVP energy decomposition analysis (no CP correction) of the activated chalcogen and halogen-bonded dimers. All values are given in $\mathrm{kcal} / \mathrm{mol}$.

\begin{tabular}{|c|c|c|c|c|c|c|c|c|c|c|}
\hline & \multicolumn{9}{|c|}{ ChB dimer } & \multicolumn{5}{c|}{ XB dimer } \\
\hline Target & Elec. & Pol. & $\begin{array}{c}\text { Ex- } \\
\text { rep }\end{array}$ & Disp. & Total & Elec. & Pol. & $\begin{array}{c}\text { Ex- } \\
\text { rep }\end{array}$ & Disp. & Total \\
\hline S5 & -8.71 & -2.61 & 12.12 & -8.39 & -7.59 & -0.13 & -0.34 & 1.95 & -3.56 & -2.09 \\
\hline S6 & -9.20 & -2.75 & 12.80 & -9.92 & -9.08 & -5.83 & -1.76 & 9.66 & -8.78 & -6.73 \\
\hline S7 & -9.48 & -2.83 & 13.33 & -10.64 & -9.62 & -9.18 & -2.88 & 14.87 & -11.45 & -8.65 \\
\hline S8 & -9.97 & -3.02 & 14.45 & -11.72 & -10.26 & -15.48 & -5.75 & 25.06 & -15.13 & -11.29 \\
\hline Se5 & -17.14 & -6.46 & 23.90 & -12.87 & -12.56 & -0.03 & -0.35 & 1.86 & -3.54 & -2.06 \\
\hline Se6 & -18.16 & -6.81 & 25.48 & -15.09 & -14.57 & -6.14 & -1.94 & 10.38 & -9.19 & -6.90 \\
\hline Se7 & -18.74 & -7.07 & 26.63 & -16.05 & -15.23 & -10.00 & -3.28 & 16.53 & -12.19 & -8.93 \\
\hline Se8 & -19.28 & -7.37 & 27.91 & -17.23 & -15.97 & -17.08 & -6.66 & 28.17 & -16.25 & -11.82 \\
\hline Te5 & -41.48 & -22.96 & 60.80 & -19.57 & -23.20 & 0.10 & -0.36 & 1.81 & -3.60 & -2.04 \\
\hline Te6 & -42.62 & -23.45 & 62.45 & -21.90 & -25.54 & -6.60 & -2.18 & 11.45 & -9.80 & -7.13 \\
\hline Te7 & -42.70 & -23.46 & 62.71 & -22.78 & -26.22 & -11.09 & -3.78 & 18.66 & -13.15 & -9.35 \\
\hline Te8 & -43.73 & -24.32 & 65.01 & -24.09 & -27.13 & -19.83 & -8.12 & 33.19 & -17.91 & -12.68 \\
\hline
\end{tabular}

Table S9. CP-corrected MP2/aug-cc-pVTZ ${ }^{6}$ energy decomposition analysis of the non-activated chalcogen and halogen-bonded dimers. All values are given in $\mathrm{kcal} / \mathrm{mol}$.

\begin{tabular}{|c|c|c|c|c|c|c|c|c|c|c|}
\hline & \multicolumn{9}{|c|}{ ChB dimer } & \multicolumn{5}{c|}{ XB dimer } \\
\hline ChX & Elec. & Pol. & $\begin{array}{c}\text { Ex- } \\
\text { rep }\end{array}$ & Disp. & Total & Elec. & Pol. & $\begin{array}{c}\text { Ex- } \\
\text { rep }\end{array}$ & Disp. & Total \\
\hline S1 & -8.54 & -2.45 & 10.91 & -6.34 & -6.42 & N/A & N/A & N/A & N/A & N/A \\
\hline S2 & -9.23 & -2.75 & 12.43 & -7.90 & -7.44 & -2.44 & -0.84 & 5.38 & -5.51 & -3.42 \\
\hline S3 & -9.42 & -2.84 & 12.99 & -8.57 & -7.84 & -3.63 & -1.17 & 7.30 & -6.66 & -4.16 \\
\hline S4 & -9.39 & -2.86 & 13.57 & -9.48 & -8.15 & -4.63 & -1.69 & 9.56 & -7.81 & -4.57 \\
\hline Se1 & -16.99 & -6.30 & 21.91 & -9.81 & -11.19 & N/A & N/A & N/A & N/A & N/A \\
\hline Se2 & -17.90 & -6.89 & 24.41 & -12.16 & -12.53 & -2.46 & -0.93 & 5.71 & -5.78 & -3.47 \\
\hline Se3 & -17.69 & -6.85 & 24.58 & -12.91 & -12.87 & -3.74 & -1.29 & 7.83 & -7.05 & -4.25 \\
\hline Se4 & -17.00 & -6.57 & 24.60 & -13.87 & -12.84 & -4.69 & -1.83 & 10.17 & -8.26 & -4.60 \\
\hline Te1 & -43.63 & -25.18 & 61.54 & -15.56 & -22.84 & N/A & N/A & N/A & N/A & N/A \\
\hline Te2 & -40.68 & -23.47 & 59.11 & -18.30 & -23.33 & -2.42 & -1.06 & 6.09 & -6.16 & -3.55 \\
\hline Te3 & -39.27 & -22.52 & 57.87 & -19.13 & -23.04 & -3.85 & -1.46 & 8.50 & -7.62 & -4.44 \\
\hline Te4 & -36.09 & -20.44 & 54.64 & -20.02 & -21.90 & -4.83 & -2.07 & 11.18 & -9.08 & -4.79 \\
\hline
\end{tabular}

Table S10. RI-MP2/Def2-TZVP interaction energies. All values are given in $\mathrm{kcal} / \mathrm{mol}$.

\begin{tabular}{|c|c|c|}
\hline $\mathrm{ChX}$ & $\begin{array}{c}\mathrm{ChB} \\
\text { dimer }\end{array}$ & $\begin{array}{c}\mathrm{XB} \\
\text { dimer }\end{array}$ \\
\hline $\mathrm{SF}$ & -6.43 & N/A \\
\hline $\mathrm{SCl}$ & -7.40 & -3.38 \\
\hline $\mathrm{SBr}$ & -7.80 & -4.14 \\
\hline $\mathrm{SI}$ & -8.04 & -4.46 \\
\hline $\mathrm{SeF}$ & -11.05 & $\mathrm{~N} / \mathrm{A}$ \\
\hline
\end{tabular}




\begin{tabular}{|c|c|c|}
\hline $\mathrm{SeCl}$ & -12.30 & -3.47 \\
\hline $\mathrm{SeBr}$ & -12.64 & -4.26 \\
\hline $\mathrm{SeI}$ & -12.57 & -4.54 \\
\hline $\mathrm{TeF}$ & -21.17 & N/A \\
\hline $\mathrm{TeCl}$ & -21.83 & -3.56 \\
\hline $\mathrm{TeBr}$ & -21.63 & -4.44 \\
\hline $\mathrm{TeI}$ & -20.35 & -4.68 \\
\hline
\end{tabular}

Table S11. HF/Def2-TZVP atomic Mulliken charges on $\mathrm{Ch}, \mathrm{N}$ and $\mathrm{X}$ and electrostatic potential at the center of the $\sigma$-hole on $\mathrm{X}$ for the non-activated and activated benzochalcogenadiazole derivatives.

\begin{tabular}{|c|c|c|c|c|c|c|c|c|c|}
\hline \multicolumn{5}{|c|}{ Non-activated systems } & \multicolumn{5}{|c|}{ Activated systems } \\
\hline Target & $\mathrm{Ch}$ & $\mathrm{N}$ & $\mathrm{X}$ & $\begin{array}{c}\text { Electrostatic } \\
\text { potential on } \mathrm{X} \\
(\mathrm{kcal} / \mathrm{mol})\end{array}$ & Target & $\mathrm{Ch}$ & $\mathrm{N}$ & $X$ & $\begin{array}{c}\text { Electrostatic } \\
\text { potential on X } \\
(\mathrm{kcal} / \mathrm{mol})\end{array}$ \\
\hline S1 & 0.4491 & -0.2713 & -0.1848 & -9.39 & S5 & 0.4348 & -0.2633 & -0.1446 & 7.41 \\
\hline S2 & 0.4471 & -0.2694 & -0.0348 & 35.81 & S6 & 0.4355 & -0.2625 & 0.0724 & 57.15 \\
\hline S3 & 0.4460 & -0.2658 & -0.0212 & 48.72 & S7 & 0.4358 & -0.2610 & 0.1322 & 67.88 \\
\hline S4 & 0.4449 & -0.2734 & 0.0414 & 63.85 & S8 & 0.4350 & -0.2600 & 0.2198 & 88.26 \\
\hline Se1 & 0.4956 & -0.2986 & -0.1855 & -11.93 & Se5 & 0.4762 & -0.2893 & -0.1463 & 7.60 \\
\hline $\mathrm{Se} 2$ & 0.4958 & -0.2968 & -0.0394 & 37.23 & Se6 & 0.4774 & -0.2888 & 0.0696 & 59.73 \\
\hline $\mathrm{Se} 3$ & 0.4952 & -0.2933 & -0.0277 & 51.13 & $\mathrm{Se} 7$ & 0.4781 & -0.2875 & 0.1290 & 69.03 \\
\hline Se4 & 0.4940 & -0.3029 & 0.0331 & 68.25 & Se8 & 0.4771 & -0.2861 & 0.2161 & 91.91 \\
\hline Te1 & 0.6607 & -0.3835 & -0.1873 & -13.80 & Te5 & 0.6389 & -0.3697 & -0.1492 & 8.39 \\
\hline $\mathrm{Te} 2$ & 0.6667 & -0.3822 & -0.0472 & 37.78 & Te6 & 0.6414 & -0.3697 & 0.0646 & 62.55 \\
\hline $\mathrm{Te} 3$ & 0.6686 & -0.3794 & -0.0373 & 51.38 & Te7 & 0.6427 & -0.3689 & 0.1234 & 71.29 \\
\hline $\mathrm{Te} 4$ & 0.6684 & -0.3894 & 0.0205 & 69.49 & Te8 & 0.6417 & -0.3673 & 0.2096 & 96.10 \\
\hline
\end{tabular}




\section{Discussion}

\subsection{Chalcogen-bonded (ChB) dimers}

The larger $\sigma$-hole and Mulliken charges on the chalcogen atom in the order $\mathrm{S}<\mathrm{Se}<\mathrm{Te}$ are consistent with the increasing electrostatic/polarization energy in that order, for both the activated and non-activated systems.

For the chalcogen-bonded non-activated systems with $\mathrm{Ch}=\mathrm{S}$, a smooth increase the total interaction energy is observed when going from $\mathrm{X}=\mathrm{F}$ to $\mathrm{X}=\mathrm{I}$. For $\mathrm{Ch}=\mathrm{Se}$, the interaction energy increases when going from $\mathrm{F}$ to $\mathrm{Br}$ and then slightly decreases when going from $\mathrm{Br}$ to I. In addition, the total interaction energy of the Te system decreases when going from $\mathrm{Cl}$ to $\mathrm{I}$. These trends can be attributed to the high steric repulsion between the large chalcogen and halogen atoms (cf Figure S4A). In order to support this hypothesis, the interaction between inactivated monomer $\mathrm{ChX}$ and the FX molecule (Figure S4B) was analyzed. For the module systems in Figure S4B, the halogen atoms $\mathrm{X}$ in brown are $\mathrm{X}=\mathrm{F}, \mathrm{Cl}, \mathrm{Br}, \mathrm{I}$ and the chalcogen atoms $\mathrm{Ch}$ in purple are $\mathrm{Ch}=\mathrm{S}, \mathrm{Se}, \mathrm{Te}$. The $\mathrm{Ch}---\mathrm{X}$ distances represented by the green lines in Figure 4A and 4B are the same. In the model systems, the main contribution to the intermolecular interaction energy comes from the $\mathrm{Ch}---\mathrm{X}$ interaction shown with the green dashed line. The energy decomposition analysis is shown in Table S12.

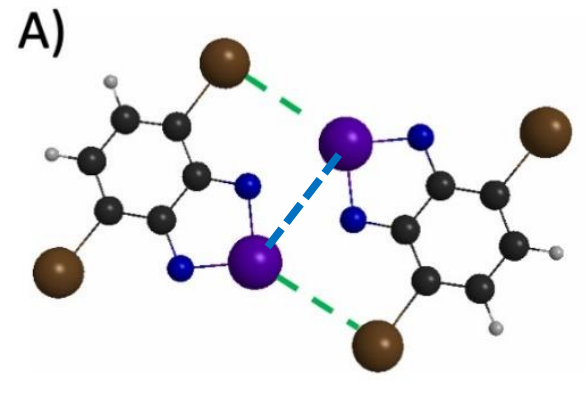

B)

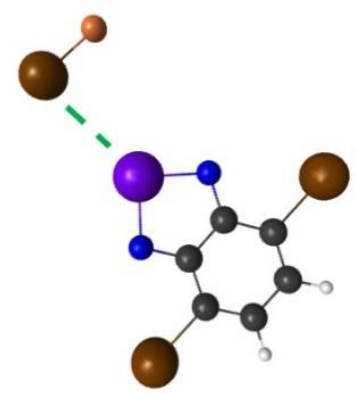

Figure S4. Ch---X interactions (green line) and Ch---Ch interactions (blue line) in A) the optimized non-activated ChB dimer B) the model system. Black: carbon. Blue: nitrogen. Purple: chalcogen atom $\mathrm{Ch}(\mathrm{S}, \mathrm{Se}$ or $\mathrm{Te})$. White: hydrogen. Brown: halogen atom $\mathrm{X}(\mathrm{F}, \mathrm{Cl}, \mathrm{Br}$ or I). Orange: fluorine.

Table S12. CP-corrected energy decomposition analysis of the model systems in Figure S4B at the MP2/Def2-TZVP level of theory.

\begin{tabular}{|l|l|l|l|l|l|l|}
\hline $\begin{array}{l}\text { Model } \\
\text { system } \\
\text { composition } \\
\text { Ch, X }\end{array}$ & $\begin{array}{l}\text { Ch---X } \\
\text { distance } \\
(\AA)\end{array}$ & $\begin{array}{l}\text { Electrostatic } \\
(\mathrm{kcal} / \mathrm{mol})\end{array}$ & $\begin{array}{l}\text { Polarization } \\
(\mathrm{kcal} / \mathrm{mol})\end{array}$ & $\begin{array}{l}\text { Exchange- } \\
\text { repulsion } \\
(\mathrm{kcal} / \mathrm{mol})\end{array}$ & $\begin{array}{l}\text { Dispersion } \\
(\mathrm{kcal} / \mathrm{mol})\end{array}$ & $\begin{array}{l}\text { Total } \\
(\mathrm{kcal} / \mathrm{mol})\end{array}$ \\
\hline $\mathrm{S}, \mathrm{F}$ & 4.22 & -0.04 & 0.00 & 0.03 & -0.20 & -0.20 \\
\hline
\end{tabular}




\begin{tabular}{|l|l|l|l|l|l|l|}
\hline $\mathrm{S}, \mathrm{Cl}$ & 4.10 & -0.11 & -0.03 & 0.38 & -0.64 & -0.40 \\
\hline $\mathrm{S}, \mathrm{Br}$ & 4.09 & -0.19 & -0.06 & 0.73 & -0.92 & -0.45 \\
\hline $\mathrm{S}, \mathrm{I}$ & 4.13 & -0.39 & -0.12 & 1.38 & -1.27 & -0.39 \\
\hline $\mathrm{Se}, \mathrm{F}$ & 3.95 & -0.10 & -0.01 & 0.15 & -0.35 & -0.30 \\
\hline $\mathrm{Se}, \mathrm{Cl}$ & 3.87 & -0.36 & -0.11 & 1.18 & -1.08 & -0.37 \\
\hline $\mathrm{Se}, \mathrm{Br}$ & 3.90 & -0.57 & -0.19 & 1.90 & -1.47 & -0.32 \\
\hline $\mathrm{Se}, \mathrm{I}$ & 3.97 & -0.94 & -0.32 & 3.06 & -1.90 & -0.10 \\
\hline $\mathrm{Te}, \mathrm{F}$ & 3.58 & -0.48 & -0.10 & 1.16 & -0.72 & -0.14 \\
\hline $\mathrm{Te}, \mathrm{Cl}$ & 3.64 & -1.38 & -0.48 & 4.24 & -1.88 & 0.50 \\
\hline $\mathrm{Te}, \mathrm{Br}$ & 3.70 & -1.85 & -0.70 & 5.70 & -2.36 & 0.79 \\
\hline $\mathrm{Te}, \mathrm{I}$ & 3.83 & -2.33 & -1.01 & 7.36 & -2.79 & 1.23 \\
\hline
\end{tabular}

For $\mathrm{Ch}=\mathrm{S}$, attractive forces (electrostatic, polarization, dispersion) between the monomers are larger than the exchange-repulsion forces and the total interaction energy is therefore negative. This observation can be rationalized by the negative belt of the halogen interacts with the positive $\sigma$-hole of the chalcogen atom. We note that the total interaction energy increases by $0.3 \mathrm{kcal} / \mathrm{mol}$ between $\mathrm{X}=\mathrm{F}$ and $\mathrm{X}=\mathrm{Cl}$, but only by $0.06 \mathrm{kcal} / \mathrm{mol}$ between $\mathrm{X}=\mathrm{Br}$ and $\mathrm{X}=\mathrm{Cl}$, and slightly decreases between $X=B r$ and $X=I$. As we go from $X=F$ to $X=B r$, the attractive forces increase more than the repulsive forces. As we go from $\mathrm{X}=\mathrm{Br}$ to $\mathrm{X}=\mathrm{I}$, the opposite occurs due to the very large size of the halogen atom (Table S12).

Similar conclusions can be made for $\mathrm{Ch}=$ Se. However, since selenium atoms are larger than sulfur atoms, the repulsion forces become dominant for a smaller halogen size and a decrease in interaction energy is observe from $\mathrm{X}=\mathrm{Cl}$ to $\mathrm{X}=\mathrm{I}$. The large size of the Te atoms induces an increasingly positive total interaction energy from $X=F$ to $X=I$. In this case, repulsive forces dominate over the attractive forces.

Table S13. Calculated Ch---Ch and Ch---X distances in non-activated dimers from Figure S4A.

\begin{tabular}{|l|c|c|c|c|}
\hline & \multicolumn{2}{|c|}{ Ch--Ch } & \multicolumn{2}{c|}{ Ch--X } \\
\hline & Distance $(\AA)$ & $\begin{array}{c}\text { Van der Waals } \\
\text { reduction }(\%)\end{array}$ & Distance $(\AA)$ & $\begin{array}{c}\text { Van der Waals } \\
\text { reduction }(\%)\end{array}$ \\
\hline $\mathrm{S}, \mathrm{F}$ & 3.85 & -6.9 & 4.22 & -29.1 \\
\hline $\mathrm{S}, \mathrm{Cl}$ & 3.83 & -6.4 & 4.10 & -15.5 \\
\hline $\mathrm{S}, \mathrm{Br}$ & 3.82 & -6.1 & 4.09 & -12.1 \\
\hline $\mathrm{S}, \mathrm{I}$ & 3.79 & -5.3 & 4.14 & -9.5 \\
\hline $\mathrm{Se}, \mathrm{F}$ & 3.86 & -1.6 & 3.95 & -17.2 \\
\hline $\mathrm{Se}, \mathrm{Cl}$ & 3.84 & -1.1 & 3.87 & -6.0 \\
\hline $\mathrm{Se}, \mathrm{Br}$ & 3.83 & -0.8 & 3.90 & -4.0 \\
\hline $\mathrm{Se}, \mathrm{I}$ & 3.82 & -0.5 & 3.97 & -2.3 \\
\hline $\mathrm{Te}, \mathrm{F}$ & 3.86 & 6.3 & 3.58 & -1.4 \\
\hline $\mathrm{Te}, \mathrm{Cl}$ & 3.86 & 6.3 & 3.64 & 4.5 \\
\hline $\mathrm{Te}, \mathrm{Br}$ & 3.86 & 6.3 & 3.70 & 5.4 \\
\hline $\mathrm{Te}, \mathrm{I}$ & 3.86 & 6.3 & 3.83 & 5.2 \\
\hline
\end{tabular}




\subsection{Halogen-bonded (XB) dimers}

Figures S1 and S2 show that for both the non-activated and activated systems, the size of the $\sigma$-hole on the halogen atom increases with increasing halogen atom size. In addition, the electrostatic potential at the center of the $\sigma$-hole on the halogen atom also increases with increasing halogen atom size (Table S11). This behavior is consistent with the increasingly large electrostatic/polarization energy of XB dimers for both activated (Tables S4-S6) and non-activated systems (Tables S1-S3).

For the activated systems, the size of the $\sigma$-hole and magnitude of the electrostatic potential at the center of the $\sigma$-hole are much larger than for the non-activated systems. As a result, the electrostatic and polarization energies computed for the XB dimers are much larger than for the non-activated systems.

The interaction energy $\Delta \mathrm{E}$ between two activated monomers with $\mathrm{Ch}=\mathrm{S}$ and $\mathrm{X}=\mathrm{I}$ was computed at various $\mathrm{C} \equiv \mathrm{C}---\mathrm{I}$ angles (Table $\mathrm{S} 14)$. This table also shows the monomer bending energy, which represents the energy cost to bend the $\mathrm{C} \equiv \mathrm{C}---\mathrm{I}$ angle in a single monomer from the optimized value of $179.60^{\circ}$. Table S14 shows that the interaction energy between the monomers is lowered by $2.47 \mathrm{kcal} / \mathrm{mol}$ upon bending of the $\mathrm{C} \equiv \mathrm{C}---\mathrm{I}$ angle. Without such bending, the interaction energy is $-8.00 \mathrm{kcal} / \mathrm{mol}$, which is higher than the interaction energy of the chalcogen bonded dimer of $-8.63 \mathrm{kcal} / \mathrm{mol}$ (Table 4 ). In addition, we see that the energy cost of distorting the $\mathrm{C} \equiv \mathrm{C}$---I angle for the two monomers is about $1 \mathrm{kcal} / \mathrm{mol}$, which is smaller than the $2.47 \mathrm{kcal} / \mathrm{mol}$ gained through bonding.

Table S14. Interaction energy between two activated monomers with $\mathrm{Ch}=\mathrm{S}$ and $\mathrm{X}=\mathrm{I}$.

\begin{tabular}{|c|c|c|}
\hline $\mathrm{C} \equiv \mathrm{C}-\mathrm{I}$ angle $\left({ }^{\circ}\right)$ & $\Delta \mathrm{E}(\mathrm{kcal} / \mathrm{mol})$ & $\begin{array}{c}\text { Monomer bending } \\
\text { energy }(\mathrm{kcal} / \mathrm{mol})\end{array}$ \\
\hline 171.00 & -10.33 & 0.61 \\
\hline 171.50 & -10.37 & 0.54 \\
\hline $171.67^{\mathrm{a}}$ & -10.47 & 0.52 \\
\hline $179.60^{\mathrm{b}}$ & -8.00 & 0.00 \\
\hline
\end{tabular}

a. $\mathrm{C} \equiv \mathrm{C}---\mathrm{I}$ Angle in the optimized dimer

b. $\mathrm{C} \equiv \mathrm{C}---\mathrm{I}$ Angle in the optimized monomer 

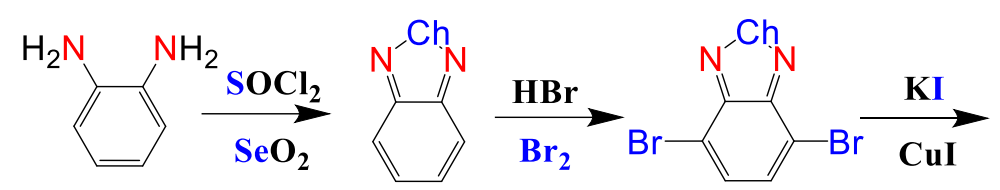

$\underline{\mathrm{S3}}, \underline{\mathrm{Se} 3}$

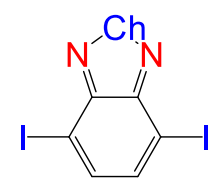

S0, $\underline{\text { Se0 }}$

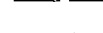

$\underline{\text { S4, Se4 }}$
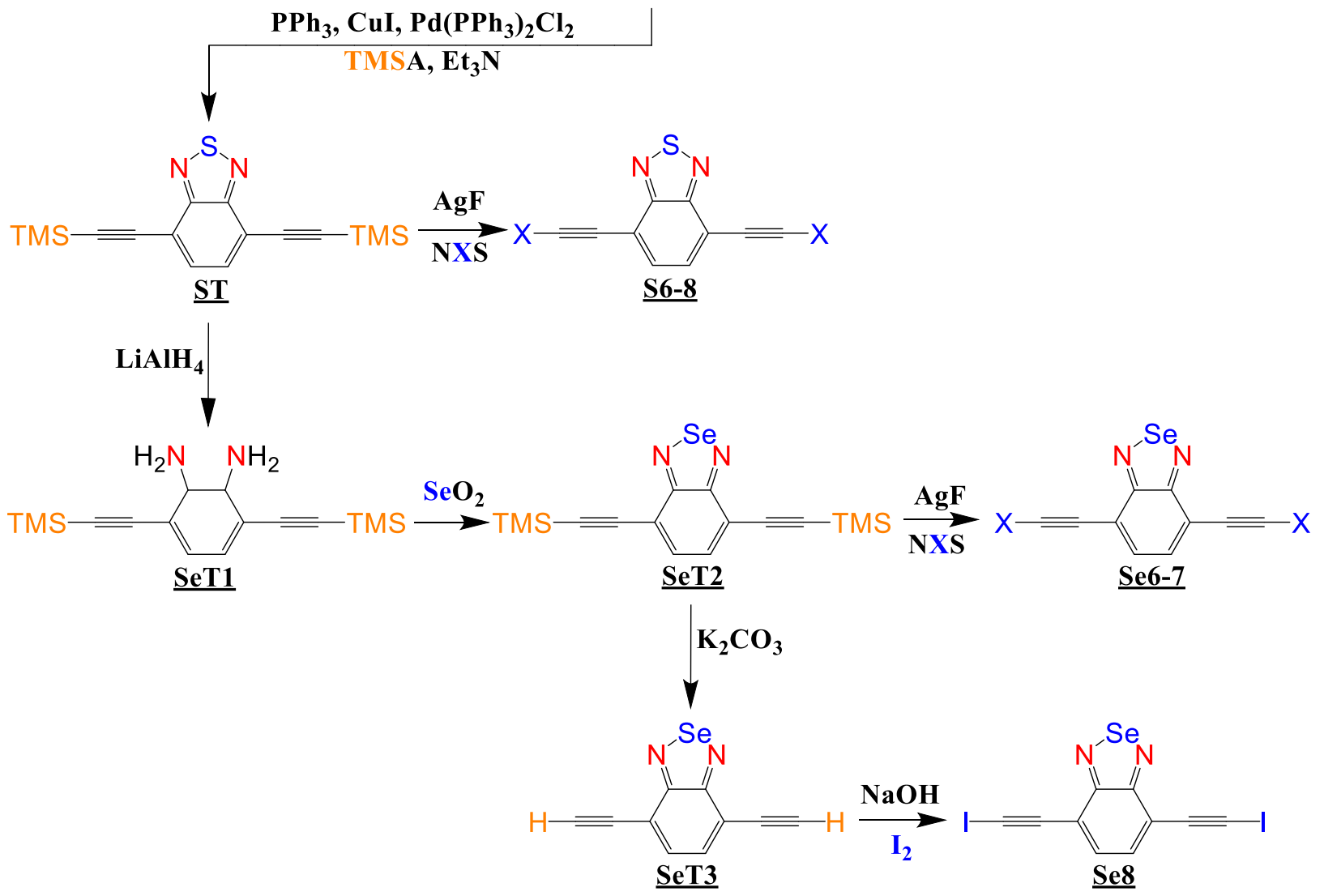

Figure S5. Schematic showing the pathway used to synthesize the targets explored in this study. 


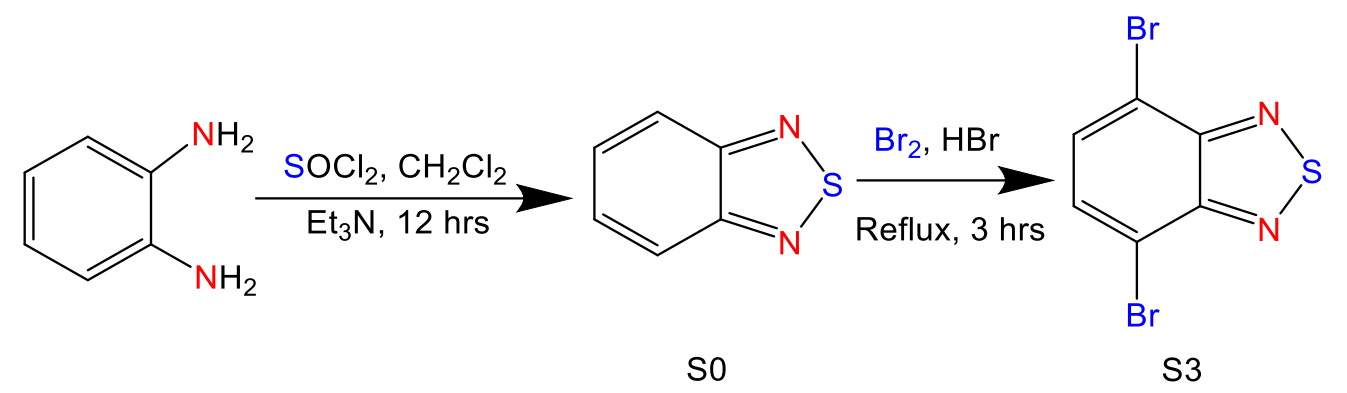

Figure S6. Synthesis of 4,7-dibromo-2,1,3-benzothiadiazole (S3)

$O$-Phenylenediamine ( $60.0 \mathrm{mmol}, 6.49 \mathrm{~g}$ ) is dissolved in $75.0 \mathrm{ml} \mathrm{CH}_{2} \mathrm{Cl}_{2}$, and triethylamine (240 $\mathrm{mmol}, 33.5 \mathrm{ml})$ is added to this solution. This mixture is stirred vigorously while $\mathrm{SOCl}_{2}(180$ $\mathrm{mmol}, 13.0 \mathrm{ml}$ ) is added dropwise, very slowly. After complete addition, the mixture is stirred for 12 hours at room temperature (RT), following which the mixture is washed with water twice and the solvent evaporated under reduced pressure. The resulting brown liquid is steam distilled to yield pure white product benzo-1,2,5-thiadiazole (SO) in 70.4\% yield. Mp: $43.7-44.5^{\circ} \mathrm{C}$ (Reported 43.6-44.4 $\left.{ }^{\circ} \mathrm{C}\right)^{7} .{ }^{1} \mathrm{H}$ NMR $\left(400 \mathrm{MHz}, \mathrm{CDCl}_{3}\right) \delta \mathrm{ppm}: 7.86(\mathrm{dt}, J=6.8,3.5 \mathrm{~Hz}, 1 \mathrm{H}), 7.43(\mathrm{dt}, J=$ $6.8,3.5 \mathrm{~Hz}, 1 \mathrm{H}) .{ }^{13} \mathrm{C}$ NMR $\left(101 \mathrm{MHz}, \mathrm{CDCl}_{3}\right) \delta \mathrm{ppm}: 154.58,129.08,121.35$.

S0 (32 mmol, $4.35 \mathrm{~g}$ ) is first dissolved in $\mathrm{HBr}(120 \mathrm{ml})$ and liquid $\mathrm{Br}_{2}(72 \mathrm{mmol}, 11.5 \mathrm{~g}, 3.70 \mathrm{ml})$ is added dropwise. After complete addition, the mixture is stirred at $120^{\circ} \mathrm{C}$ for 3 hours, during which time the product precipitates out from solution. After completion based no thin layer chromatography (TLC), the mixture is filtered under vacuum to separate solid, which is washed with water twice to remove excess bromine and dried in air followed by recrystallization from ethyl acetate (EtOAc) to yield solid product 4,7-dibromobenzo-1,2,5-thiadiazole (S3) in 91.7\% yield along with 4-bromobenzo-1,2,5-thiadiazole as a minor side product. $\mathrm{Mp}$ : $186.3-188.0^{\circ} \mathrm{C}$ (Reported 187-188 $\left.{ }^{\circ} \mathrm{C}\right)^{7} .{ }^{1} \mathrm{H}$ NMR $\left(400 \mathrm{MHz}, \mathrm{CDCl}_{3}\right) \delta \mathrm{ppm}: 7.73$ (s, 2H). ${ }^{13} \mathrm{C}$ NMR $(101 \mathrm{MHz}$, DMSO-d 6 ) $\delta$ ppm: $152.32,132.85,113.15$.

\subsection{Synthesis of 4,7-diiodobenzo-1,2,5-thiadiazole $(\mathrm{S} 4)^{9}$}

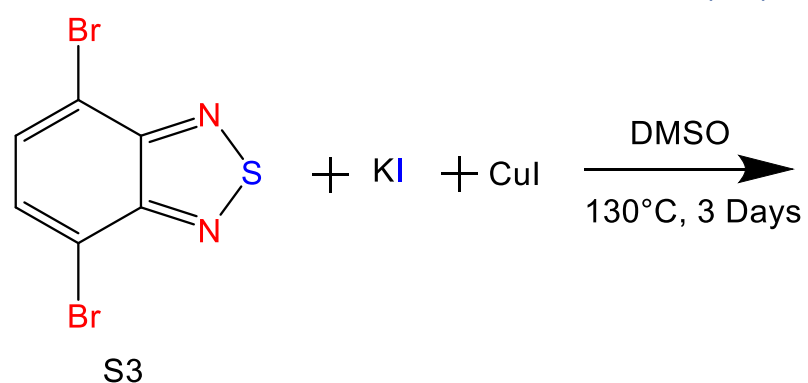

Figure S7. Synthesis of 4,7-diiodo-2,1,3-benzothiadiazole (S4)

S3 $(6 \mathrm{mmol}, 1.76 \mathrm{~g})$ is dissolved in DMSO $(60.0 \mathrm{ml})$, and $\mathrm{CuI}(27 \mathrm{mmol}, 5.22 \mathrm{~g})$ is added followed by $\mathrm{KI}(53 \mathrm{mmol}, 8.77 \mathrm{~g})$. The mixture is stirred at $130^{\circ} \mathrm{C}$ under $\mathrm{N}_{2}$ for 3 days. After completion, this mixture is poured into $200 \mathrm{ml}$ of cold water with ice to precipitate a brown solid, which is then filtered under vacuum. This solid is dispersed in $300 \mathrm{ml} \mathrm{NH} 4 \mathrm{OH}$ and stirred for 12 hours, after which a yellow solid is isolated by filtration, air dried and recrystallized from EtOAc to yield 
product 4,7-diiodobenzo-1,2,5-thiadiazole $(\mathbf{S 4})$ in 71.8\% yield along with 4-iodobenzo-1,2,5thiadiazole as a minor side product. Mp: $190.7-193.4^{\circ} \mathrm{C} .{ }^{1} \mathrm{H}$ NMR $\left(400 \mathrm{MHz}, \mathrm{CDCl}_{3}\right) \delta \mathrm{ppm}: 7.82$ (s, 2H). ${ }^{13} \mathrm{C} \mathrm{NMR}\left(101 \mathrm{MHz}, \mathrm{CDCl}_{3}\right) \delta \mathrm{ppm}: 154.00,139.94,87.91$.

\subsection{Synthesis of 4,7-bis((trimethylsilyl)ethynyl)benzo-1,2,5-thiadiazole (ST) ${ }^{10}$}

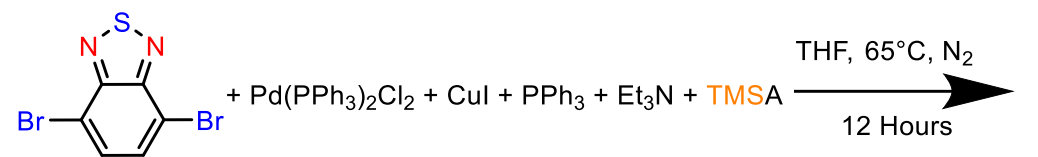

S3

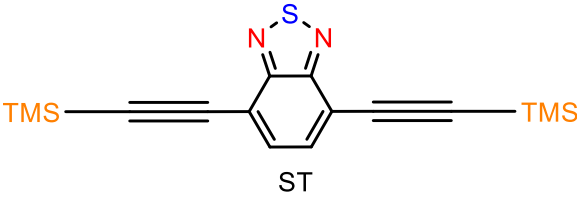

ST

Figure S8. Synthesis of 4,7-bis((trimethylsilyl)ethynyl)benzo-1,2,5-thiadiazole (ST)

S3 $(10 \mathrm{mmol}, 3.07 \mathrm{~g})$ is added to a round bottom (RB) flask along with $\mathrm{Pd}\left(\mathrm{PPh}_{3}\right)_{2} \mathrm{Cl}_{2}(10 \%, 1$ mmol, $0.70 \mathrm{~g}), \mathrm{PPh}_{3}(10 \%, 1 \mathrm{mmol}, 0.26 \mathrm{~g})$ and $\mathrm{CuI}(10 \%, 1 \mathrm{mmol}, 0.19 \mathrm{~g}) . \mathrm{N}_{2}$ bubbled THF $(50 \mathrm{ml})$ and $\mathrm{Et}_{3} \mathrm{~N}(50 \mathrm{ml})$ is added, followed by trimethylsilylacetylene (TMSA) (7Eq, $70 \mathrm{mmol}, 10$ $\mathrm{ml}$ ). The reaction is stirred at $65^{\circ} \mathrm{C}$ under $\mathrm{N}_{2}$ flow for 12 hours, after which the crude mixture is filtered through a frit and the solvent with added silica is evaporated under reduced pressure. The residue is loaded onto a silica column and eluted with pure hexane to yield target as a yellow solid product 4,7-bis((trimethylsilyl)ethynyl)benzo-1,2,5-thiadiazole (ST) in 63.09\% yield. Mp: 105.5$110.7^{\circ} \mathrm{C},{ }^{1} \mathrm{H}$ NMR $\left(400 \mathrm{MHz}, \mathrm{CDCl}_{3}\right) \delta$ ppm: 7.63 (s, 2H), 0.28 (s, 18H). ${ }^{13} \mathrm{C}$ NMR $(101 \mathrm{MHz}$, $\left.\mathrm{CDCl}_{3}\right) \delta$ ppm: $154.21,133.11,117.27,103.58,100.09,-0.03$.

\subsection{Synthesis of 4,7-bis(chloroethynyl)benzo-1,2,5-thiadiazole (S6) $)^{11}$}

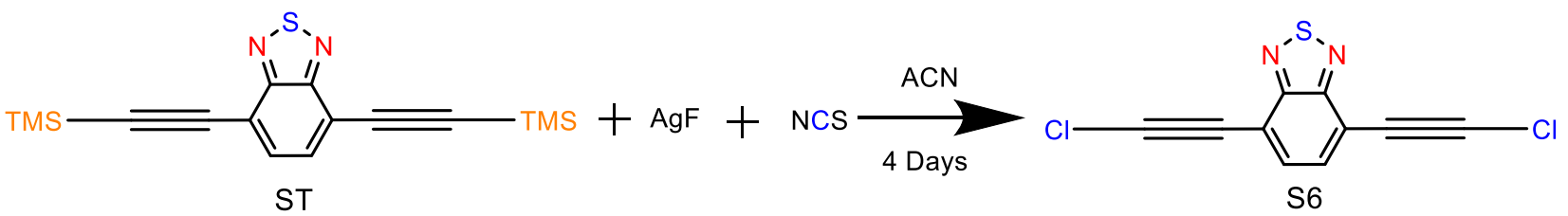

Figure S9. Synthesis of 4,7-bis(chloroethynyl)benzo-1,2,5-thiadiazole (S6)

ST ( $3.50 \mathrm{mmol}, 1.15 \mathrm{~g})$ is dissolved in acetonitrile $(100 \mathrm{ml})$ in a RB flask which is covered in foil, along with AgF (10.5 mmol, $1.33 \mathrm{~g})$ and NCS (10.5 mmol, $1.40 \mathrm{~g})$. The mixture is stirred at RT under $\mathrm{N}_{2}$ for 4 days. The resulting suspension is filtered, rinsed with acetonitrile and solvent evaporated under reduced pressure. The residue is dissolved in $\mathrm{CHCl}_{3}$, washed twice with water and once with $1 \mathrm{M} \mathrm{NaOH}$, dried using $\mathrm{MgSO}_{4}$ and the solvent evaporated under reduced pressure and solid recrystallized from EtOAc to yield a brown product 4,7-bis(chloroethynyl)benzo-1,2,5thiadiazole (S6) in $22.2 \%$ yield. Decomposition: $123.6-131.9^{\circ} \mathrm{C} .{ }^{1} \mathrm{H} \mathrm{NMR}\left(400 \mathrm{MHz}, \mathrm{CDCl}_{3}\right) \delta$ ppm: 7.68 (s, 2H). ${ }^{13} \mathrm{C} \mathrm{NMR}\left(101 \mathrm{MHz}, \mathrm{CDCl}_{3}\right) \delta$ ppm: 154.62, 133.24, 116.70, 65.47, 29.70.

\subsection{Synthesis of 4,7-bis(bromoethynyl)benzo-1,2,5-thiadiazole (S7) ${ }^{11}$}

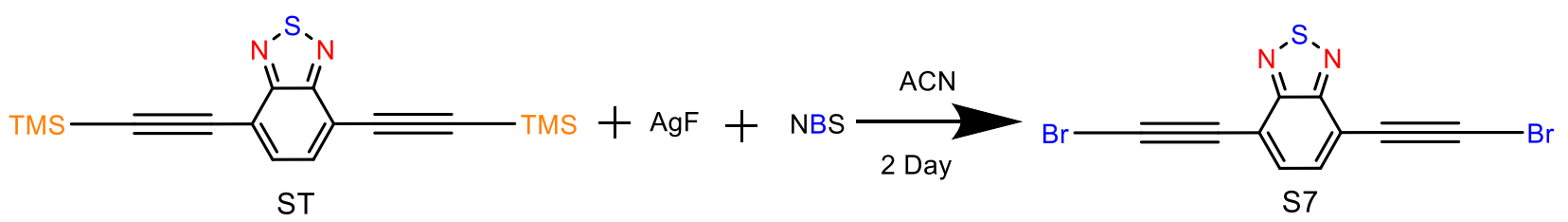

Figure S10. Synthesis of 4,7-bis(bromoethynyl)benzo-1,2,5-thiadiazole (S7) 
ST $(3.50 \mathrm{mmol}, 1.15 \mathrm{~g})$ is dissolved in acetonitrile $(80.0 \mathrm{ml})$ in a $\mathrm{RB}$ flask covered in foil, along with $\mathrm{AgF}(9.10 \mathrm{mmol}, 1.15 \mathrm{~g})$ and $\mathrm{N}$-Bromosuccinimide $(9.10 \mathrm{mmol}, 1.62 \mathrm{~g})$. The mixture is stirred at RT under $\mathrm{N}_{2}$ for 2 days. The resulting mixture is filtered, and the residue washed with additional acetonitrile, and solvent evaporated under reduced pressure. The residue is dissolved in $\mathrm{CHCl}_{3}$, washed twice with water and once with $1 \mathrm{M} \mathrm{NaOH}$, dried using $\mathrm{MgSO}_{4}$ and the solvent evaporated under reduced pressure and solid recrystallized from EtOAc to yield a brown solid product 4,7-bis(bromoethynyl)benzo-1,2,5-thiadiazole (S7) in 38.4\% yield. Decomposition: 153.8-158.6 ${ }^{\circ} \mathrm{C} .{ }^{1} \mathrm{H}$ NMR $\left(400 \mathrm{MHz}, \mathrm{CDCl}_{3}\right) \delta$ ppm: 7.69 (s, 2H). ${ }^{13} \mathrm{C} \mathrm{NMR}\left(101 \mathrm{MHz}, \mathrm{CDCl}_{3}\right) \delta$ ppm: $154.58,133.27,117.24,76.08,59.40$.

\subsection{Synthesis of 4,7-bis(iodoethynyl)benzo-1,2,5-thiadiazole (S8) $)^{11}$}

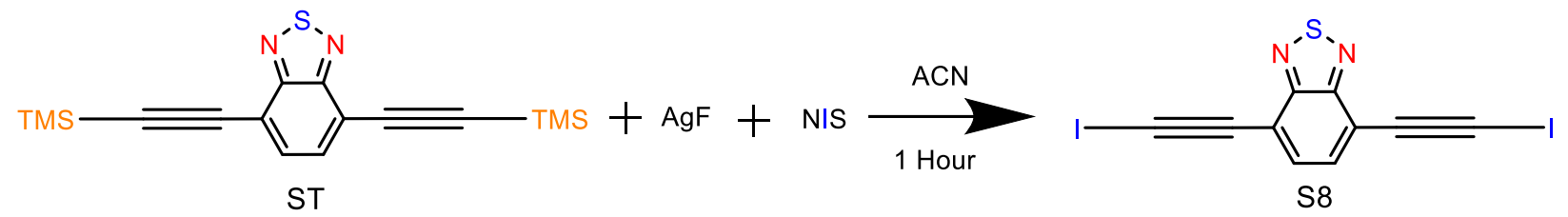

Figure S11. Synthesis of 4,7-bis(iodoethynyl)benzo-1,2,5-thiadiazole (S8)

ST ( $2 \mathrm{mmol}, 0.656 \mathrm{~g})$ is dissolved in acetonitrile $(60 \mathrm{ml})$ in a RB flask covered in foil, along with $\mathrm{AgF}(4.20 \mathrm{mmol}, 0.533 \mathrm{~g})$ and $\mathrm{N}$-Iodosuccinimide $(4.20 \mathrm{mmol}, 0.945 \mathrm{~g})$. The mixture is stirred at $\mathrm{RT}$ under $\mathrm{N}_{2}$ flow for 1 hour. The resulting mixture is filtered and washed with additional acetonitrile, and solvent evaporated under reduced pressure. The residue is dissolved in $\mathrm{CHCl}_{3}$, washed twice with water and once with $1 \mathrm{M} \mathrm{NaOH}$, dried using $\mathrm{MgSO}_{4}$ and the solvent evaporated under reduced pressure and solid recrystallized from EtOAc to yield a brown solid product 4,7bis(iodoethynyl)benzo-1,2,5-thiadiazole (S8) in $35.6 \%$ yield. Decomposition: $177.3-184.0^{\circ} \mathrm{C} .{ }^{1} \mathrm{H}$ NMR (400 MHz, $\left.\mathrm{CDCl}_{3}\right) \delta$ ppm: 7.67 (s, 2H). $\left.{ }^{13} \mathrm{C} \mathrm{NMR} \mathrm{(101} \mathrm{MHz,} \mathrm{CDCl}_{3}\right) \delta$ ppm: 154.81, 133.59, 117.87, 89.96, 17.21.

\subsection{Synthesis of 4,7-dibromobenzo-1,2,5-selenadiazole $(\mathrm{Se} 3)^{8}$}
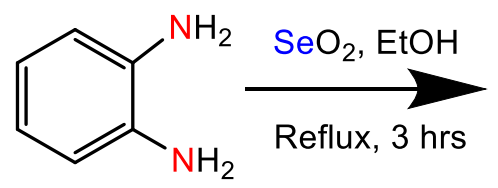<smiles>c1ccc2n[se]nc2c1</smiles>

$\mathrm{Se} 0$

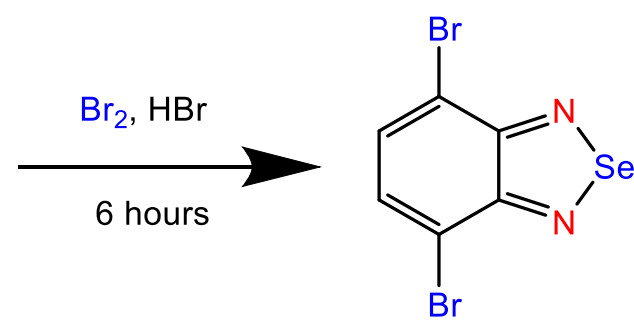

$\mathrm{Se} 3$

Figure S12. Synthesis of 4,7-dibromobenzo-1,2,5-selenadiazole (Se3)

$O$-Phenylenediamine ( $48.5 \mathrm{mmol}, 5.25 \mathrm{~g}$ ) is dissolved in ethanol $(50.0 \mathrm{ml})$, and $\mathrm{SeO}_{2}(53.4 \mathrm{mmol}$, $5.93 \mathrm{~g}$ ) is added. This mixture is refluxed for 3 hours, then cooled and poured into cold water to precipitate the product. The resulting mixture is then filtered under vacuum, and the solid washed with water, dried and recrystallized using EtOAc to yield product benzo-1,2,5-selenadiazole (Se0) in $93.5 \%$ yield. Mp: $74.0-76.2^{\circ} \mathrm{C} .{ }^{1} \mathrm{H}$ NMR $\left(400 \mathrm{MHz}, \mathrm{CDCl}_{3}\right) \delta \mathrm{ppm}: 7.76(\mathrm{~m}, 2 \mathrm{H}), 7.39(\mathrm{~m}, 2 \mathrm{H})$. 
${ }^{13} \mathrm{C}$ NMR $\left(101 \mathrm{MHz}, \mathrm{CDCl}_{3}\right) \delta \mathrm{ppm}: 160.50,129.41,123.45 .{ }^{77} \mathrm{Se}$ NMR $\left(76 \mathrm{MHz}, \mathrm{DMSO}-\mathrm{d}_{6}\right) \delta$ ppm: 1526.18 .

Se0 (20 mmol, $3.66 \mathrm{~g}$ ) and $\mathrm{Ag}_{2} \mathrm{SO}_{4}\left(20 \mathrm{mmol}, 6.24 \mathrm{~g}\right.$ ) are added to conc. $\mathrm{HBr}(150 \mathrm{ml})$. Liquid $\mathrm{Br}_{2}$ $(40 \mathrm{mmol}, 6.40 \mathrm{~g}, 2.00 \mathrm{ml})$ is added dropwise and the mixture is stirred at $120^{\circ} \mathrm{C}$ for 6 hours. After completion based on TLC, the mixture is first filtered, and the residue washed with water. The residue is dried and recrystallized from EtOAc to yield a yellow solid product 4,7-dibromobenzo1,2,5-selenadiazole (Se3) in 56.4\% yield. Mp: $275.7-278.4^{\circ} \mathrm{C} .{ }^{1} \mathrm{H}$ NMR $\left(400 \mathrm{MHz}, \mathrm{CDCl}_{3}\right) \delta \mathrm{ppm}$ : $7.64(\mathrm{~s}, 2 \mathrm{H}) .{ }^{13} \mathrm{C}$ NMR $\left(101 \mathrm{MHz}, \mathrm{CDCl}_{3}\right) \delta \mathrm{ppm}: 156.23,131.83,116.04 .{ }^{77} \mathrm{Se}$ NMR $(76 \mathrm{MHz}$, DMSO-d 6 ) $\delta$ ppm: 1532.40 .

\subsection{Synthesis of 4,7-diiodobenzo-1,2,5-selenadiazole $(\mathrm{Se} 4)^{9}$}

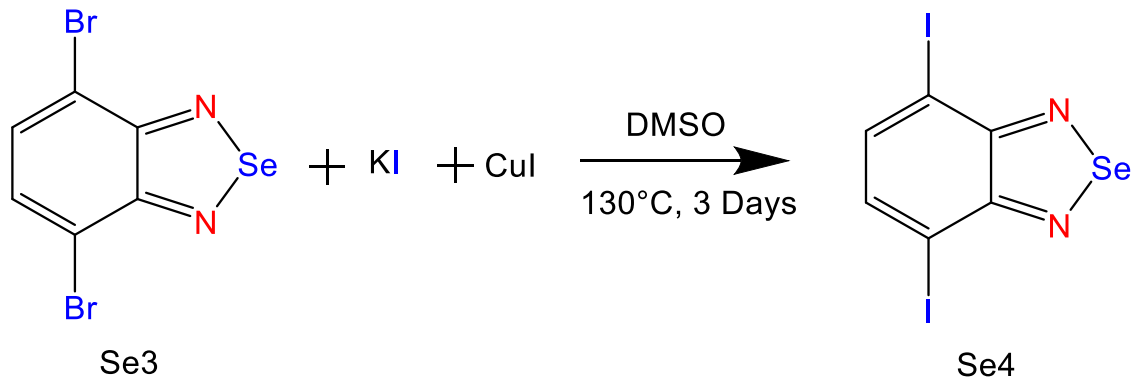

Figure S13. Synthesis of 4,7-diiodobenzo-1,2,5-selenadiazole (Se4)

Se3 (6.00 mmol, $2.05 \mathrm{~g})$ is dissolved in DMSO $(60.0 \mathrm{ml})$, and $\mathrm{CuI}(27.0 \mathrm{mmol}, 5.22 \mathrm{~g})$ is added followed by $\mathrm{KI}(53.0 \mathrm{mmol}, 8.77 \mathrm{~g})$. The mixture is stirred at $130^{\circ} \mathrm{C}$ under $\mathrm{N}_{2}$ for 3 days. After completion, this mixture is poured into $200 \mathrm{ml}$ ice cold water to precipitate a brown solid, which is then filtered under vacuum. This solid is dispersed in $300 \mathrm{ml} \mathrm{NH} 4 \mathrm{OH}$ and stirred for 12 hours at $\mathrm{RT}$, after which a yellow solid is isolated by filtration, dried and recrystallized from EtOAc to yield product 4,7-diiodobenzo-1,2,5-selenadiazole (Se4) in 92.1\% yield along with 4-iodobenzo1,2,5-thiadiazole as a minor side product. Mp: $271.7-274.9^{\circ} \mathrm{C} .{ }^{1} \mathrm{H}$ NMR $\left(400 \mathrm{MHz}, \mathrm{CDCl}_{3}\right) \delta \mathrm{ppm}$ : 7.74 (s, 2H). ${ }^{13} \mathrm{C}$ NMR $\left(101 \mathrm{MHz}, \mathrm{CDCl}_{3}\right) \delta \mathrm{ppm}: 157.00,139.41,92.95 .{ }^{77} \mathrm{Se} \mathrm{NMR}(76 \mathrm{MHz}$, DMSO-d 6 ) $\delta$ ppm: 1511.52 .

\subsection{Synthesis of 3,6-bis((trimethylsilyl)ethynyl)benzene-1,2-diamine (SeT1) $)^{12}$}

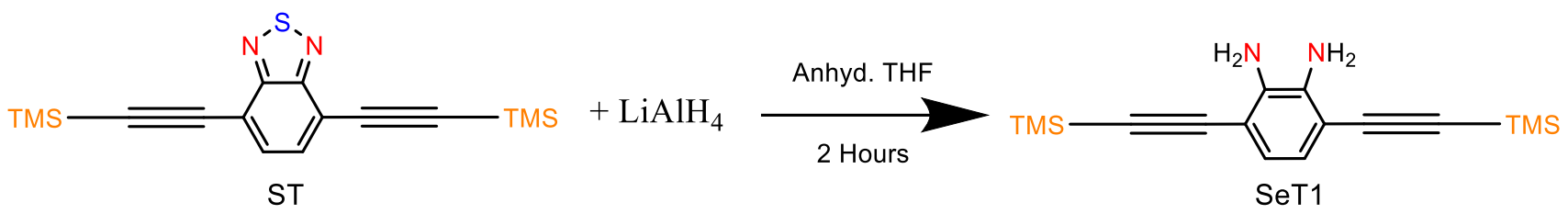

Figure S14. Synthesis of 3,6-bis((trimethylsilyl)ethynyl)benzene-1,2-diamine (SeT1)

ST $(1.5 \mathrm{mmol}, 0.5 \mathrm{~g})$ is dissolved in Anhydrous THF (30 ml), to which $\mathrm{LiAlH}_{4}(5 \mathrm{Eq}, 7.6 \mathrm{mmol}$, $0.29 \mathrm{~g}$ ) is added slowly under ice, and the resulting mixture is stirred at RT for 2 hours. The mixture is cooled once again under ice and sat. $\mathrm{NH}_{4} \mathrm{Cl}$ is added dropwise till fizzing ceases. Water $(50 \mathrm{ml})$ is added to the $\mathrm{RB}$ and the mixture extracted with EtOAc $(3 \mathrm{X} 100 \mathrm{ml})$, washed twice with water, dried with $\mathrm{MgSO}_{4}$ and evaporated under reduced pressure to yield 3,6bis((trimethylsilyl)ethynyl)benzene-1,2-diamine (SeT1) as orange crystalline solid product in 
85.17\% yield. Product being unstable is immediately used for the next reaction. Mp: 142.1143.9 ${ }^{\circ} \mathrm{C} .{ }^{1} \mathrm{H}$ NMR $\left(400 \mathrm{MHz}, \mathrm{CDCl}_{3}\right) \delta$ ppm: 6.78 (s, 2H), 3.94 (br s, 4H), 0.27 (s, 18H).

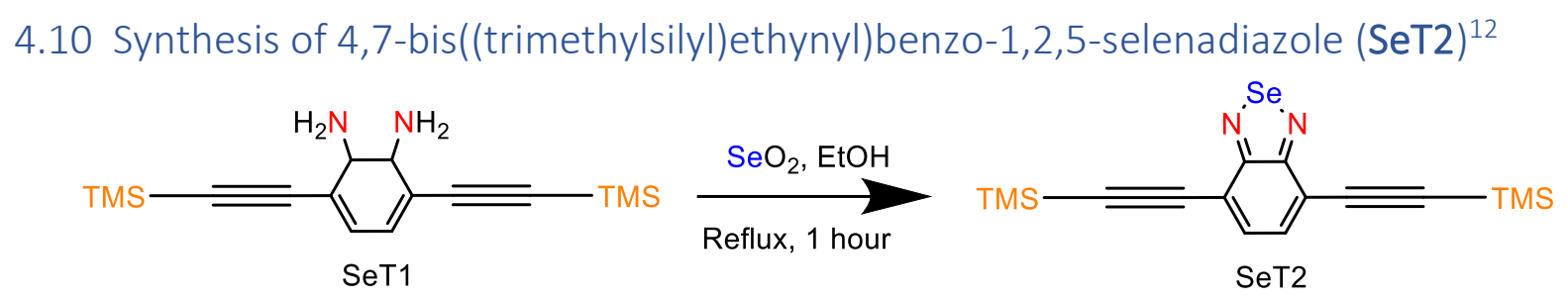

Figure S15. Synthesis of 4,7-bis((trimethylsilyl)ethynyl)benzo-1,2,5-selenadiazole (SeT2)

SeT1 (1.3 mmol, $0.39 \mathrm{~g})$ is dissolved in ethanol $(60 \mathrm{ml}, 15 \mathrm{ml} / 100 \mathrm{mg})$, to which $\mathrm{SeO}_{2}(5 \mathrm{Eq}, 6.5$ $\mathrm{mmol}, 0.72 \mathrm{~g})$ dissolved in warm water $(4 \mathrm{ml}, 1 \mathrm{ml} / 200 \mathrm{mg})$ is added. This mixture is refluxed for 1 hours, and $60 \mathrm{ml}$ cold water is added to the mixture to precipitate out the product, which is then filtered and dried to yield yellow solid product of 4,7-bis((trimethylsilyl)ethynyl)benzo-1,2,5selenadiazole (SeT2) in $90.2 \%$ yield. Mp: $164.9-169.3^{\circ} \mathrm{C} .{ }^{1} \mathrm{H}$ NMR $\left(400 \mathrm{MHz}, \mathrm{CDCl}_{3}\right) \delta \mathrm{ppm}$ : $7.61(\mathrm{~s}, 2 \mathrm{H}), 0.32(\mathrm{~s}, 18 \mathrm{H}) .{ }^{13} \mathrm{C} \mathrm{NMR}\left(101 \mathrm{MHz}, \mathrm{CDCl}_{3}\right) \delta \mathrm{ppm}: 159.12,133.57,119.10,103.49$, $100.67,0.06$.

\subsection{Synthesis of 4,7-bis(chloroethynyl)benzo-1,2,5-selenadiazole (Se6) $)^{11}$}

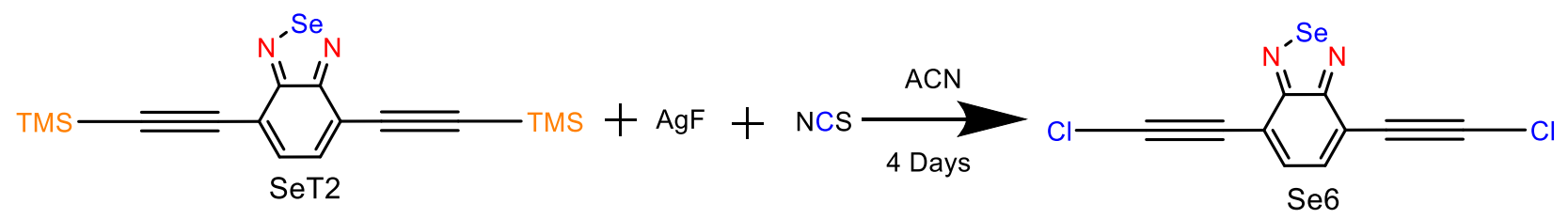

Figure S16. Synthesis of 4,7-bis(chloroethynyl)benzo-1,2,5-selenadiazole (Se6)

SeT2 $(2 \mathrm{mmol}, 0.751 \mathrm{~g})$ is dissolved in acetonitrile $(80.0 \mathrm{ml})$ in a RB flask covered in foil, to which $\mathrm{AgF}(8 \mathrm{mmol}, 1.02 \mathrm{~g})$ and $\mathrm{NCS}(8 \mathrm{mmol}, 1.07 \mathrm{~g})$ is added. The mixture is stirred at RT under $\mathrm{N}_{2}$ for 4 days. The resulting suspension is filtered, rinsed with acetonitrile and the solvent evaporated under reduced pressure. The residue is dissolved in $\mathrm{CHCl}_{3}$, washed twice with water and once with $1 \mathrm{M} \mathrm{NaOH}$, dried using $\mathrm{MgSO}_{4}$ and the solvent evaporated under reduced pressure to yield a brown solid product 4,7-bis(chloroethynyl)benzo-1,2,5-selenadiazole (Se6) in $22.5 \%$ yield. Decomposition: $141.3-152.1{ }^{\circ} \mathrm{C} .{ }^{1} \mathrm{H}$ NMR $\left(400 \mathrm{MHz}, \mathrm{CDCl}_{3}\right) \delta \mathrm{ppm}: 7.60(\mathrm{~s}, 2 \mathrm{H}) .{ }^{13} \mathrm{C}$ NMR $(101$ MHz, DMSO-d 6 ) $\delta$ ppm: $158.34,133.02,117.27,75.47,66.55 .{ }^{77} \mathrm{Se}$ NMR (76 MHz, DMSO-d 6 ) $\delta$ ppm: 1539.23 .

\subsection{Synthesis of 4,7-bis(bromoethynyl)benzo-1,2,5-selenadiazole $(\mathrm{Se} 7)^{11}$}

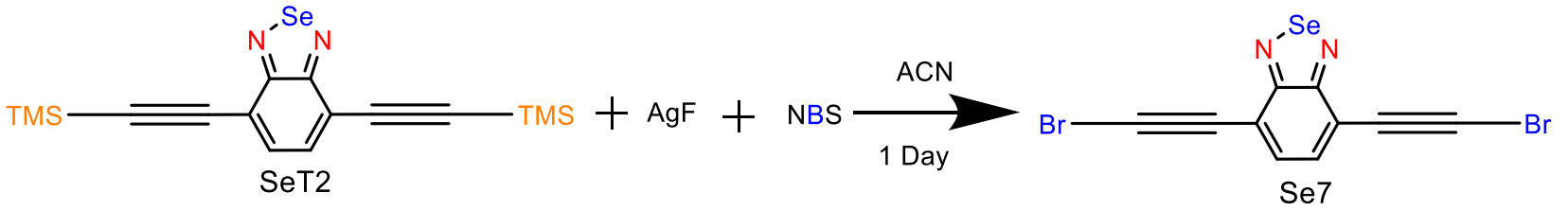

Figure S17. Synthesis of 4,7-bis(bromoethynyl)benzo-1,2,5-selenadiazole (Se7) 
SeT2 $(1.5 \mathrm{mmol}, 0.563 \mathrm{~g})$ is dissolved in acetonitrile $(60.0 \mathrm{ml})$ in a RB flask covered in foil, to which $\mathrm{AgF}$ (3.3 mmol, $0.419 \mathrm{~g}$ ) and NBS (3.3 mmol, $0.587 \mathrm{~g})$ is added. The mixture is stirred at RT under $\mathrm{N}_{2}$ for 1 day. The resulting mixture is filtered, the residue washed with additional acetonitrile and solvent evaporated under reduced pressure. The residue is dissolved in $\mathrm{CHCl}_{3}$, washed twice with water and once with $1 \mathrm{M} \mathrm{NaOH}$, dried using $\mathrm{MgSO}_{4}$ and the solvent evaporated under reduced pressure and solid recrystallized using EtOAc to yield a brown solid product 4,7bis(bromoethynyl)benzo-1,2,5-selenadiazole (Se7) in $23.7 \%$ yield along with 4bromoethynylbenzo-1,2,5-selenadiazole as a minor side product. Decomposition: $160.0-164.9^{\circ} \mathrm{C}$. ${ }^{1} \mathrm{H}$ NMR (400 MHz, DMSO-d 6 ) $\delta$ ppm: 7.68 (s, 2H). ${ }^{13} \mathrm{C}$ NMR (101 MHz, DMSO-d 6 ) $\delta$ ppm: 158.86, 133.56, 118.33, 77.19, 61.22. ${ }^{77}$ Se NMR (76 MHz, DMSO-d 6 ) $\delta$ ppm: 1539.00.

\subsection{Synthesis of 4,7-diethynylbenzo-1,2,5-selenadiazole $(\mathrm{SeT3})^{13}$}

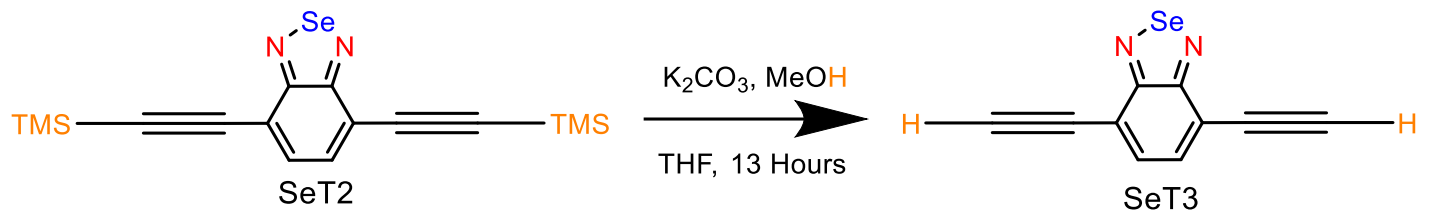

Figure S18. Synthesis of 4,7-diethynylbenzo-1,2,5-selenadiazole (SeT3)

SeT2 $(0.65 \mathrm{mmol}, 0.37 \mathrm{~g})$ is dissolved in a warm mixture of $\mathrm{MeOH}(40 \mathrm{ml})$ and THF (5 ml), to which $\mathrm{K}_{2} \mathrm{CO}_{3}(1 \mathrm{mmol}, 0.14 \mathrm{~g})$ is added and stirred at $\mathrm{RT}$ for 13 hours. The mixture is evaporated under reduced pressure, the residue dissolved in $\mathrm{CHCl}_{3}$ and washed twice with $\mathrm{H}_{2} \mathrm{O}$, dried with $\mathrm{MgSO}_{4}$ and evaporated under reduced pressure to yield a brown solid product 4,7-diethynylbenzo1,2,5-selenadiazole (SeT3) in 69.48\% yield. Product being unstable is immediately used for the next reaction. ${ }^{1} \mathrm{H}$ NMR $\left(400 \mathrm{MHz}, \mathrm{CDCl}_{3}\right) \delta$ ppm: 7.77 (s, 2H), 3.69 (s, 2H).

\subsection{Synthesis of 4,7-bis(iodoethynyl)benzo-1,2,5-selenadiazole (Se8) $)^{14}$}
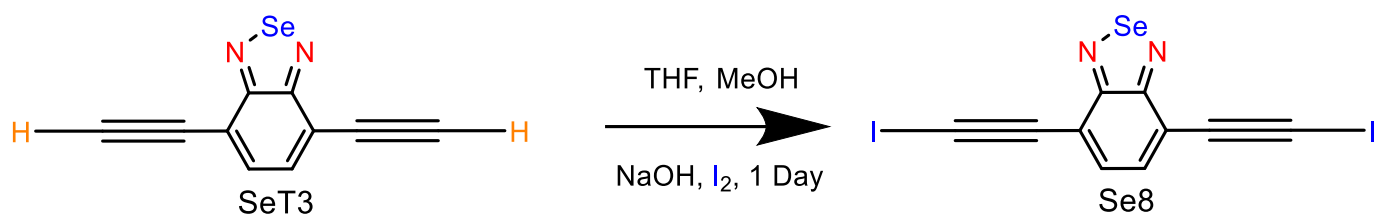

Figure S19. Synthesis of 4,7-bis(iodoethynyl)benzo-1,2,5-selenadiazole (Se8)

SeT3 (1.41 mmol, $0.325 \mathrm{~g})$ is dissolved in THF $(10 \mathrm{ml})$ and $\mathrm{MeOH}(10 \mathrm{ml})$, to which $\mathrm{NaOH}(9$ mmol, $0.360 \mathrm{~g})$ and $\mathrm{I}_{2}(9 \mathrm{mmol}, 2.29 \mathrm{~g})$ are added and stirred at $\mathrm{RT}$ for 1 day. The mixture is evaporated under reduced pressure, the residue dissolved in $\mathrm{CHCl}_{3}$ and washed twice with $\mathrm{H}_{2} \mathrm{O}$ and once with $1 \mathrm{M} \mathrm{NaOH}$, dried with $\mathrm{MgSO}_{4}$ and evaporated under reduced pressure and solid recrystallized from EtOAc to yield an orange solid product 4,7-bis(iodoethynyl)benzo-1,2,5selenadiazole (Se8) in $25.3 \%$ yield. Decomposition: $171.0-182.1^{\circ} \mathrm{C} .{ }^{1} \mathrm{H}$ NMR $(400 \mathrm{MHz}$, DMSO$\left.\mathrm{d}_{6}\right) \delta$ ppm: 7.62 (s, 2H). ${ }^{13} \mathrm{C}$ NMR (101 MHz, DMSO-d 6$) \delta$ ppm: 158.75, 132.82, 118.77, 89.59, 27.29. ${ }^{77} \mathrm{Se}$ NMR $\left(76 \mathrm{MHz}, \mathrm{DMSO}-\mathrm{d}_{6}\right) \delta \mathrm{ppm}: 1536.86$. 
${ }^{1} \mathrm{H}$ NMR (400 MHz, Chloroform- $d$ ) $\delta 7.86(\mathrm{dt}, J=6.8,3.5 \mathrm{~Hz}, 1 \mathrm{H}), 7.43(\mathrm{dt}, J=6.8,3.5 \mathrm{~Hz}, 1 \mathrm{H})$.

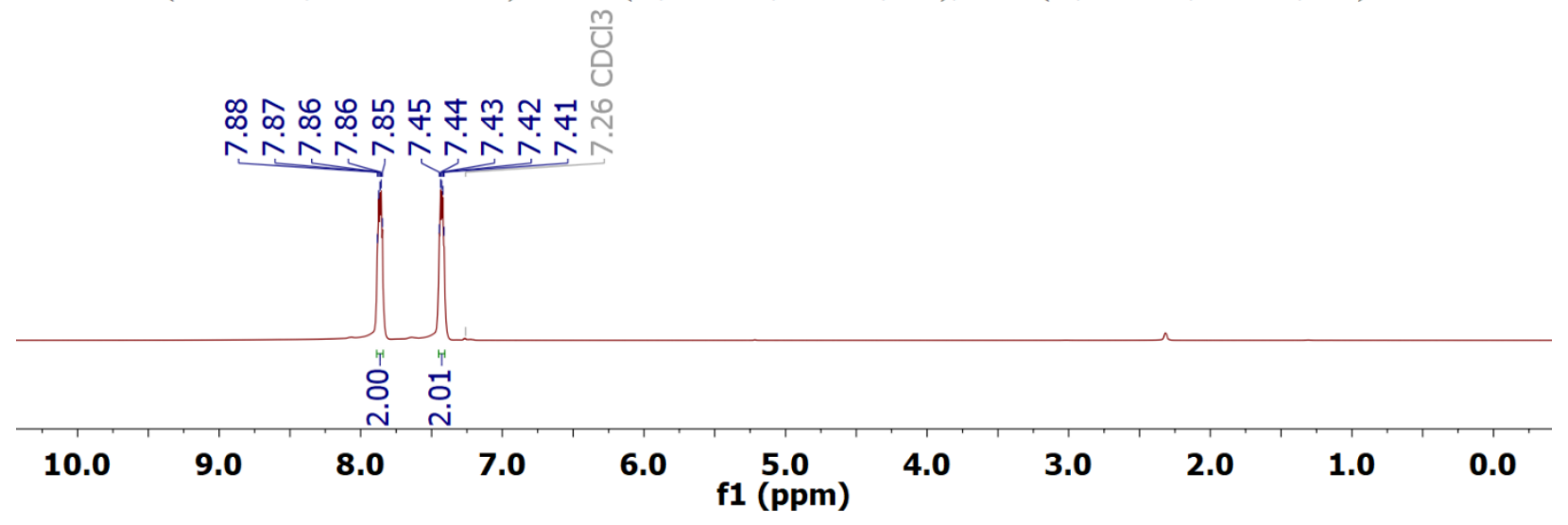

${ }^{13} \mathrm{C}$ NMR (101 MHz, $\left.\mathrm{CDCl}_{3}\right) \delta 154.58,129.08,121.35$.

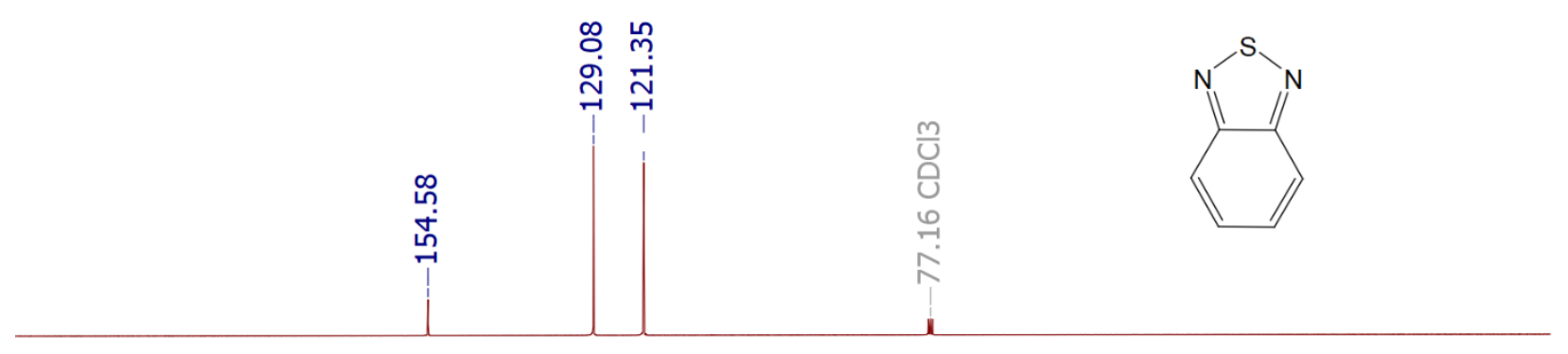

\begin{tabular}{|c|c|c|c|c|c|c|c|c|c|c|c|}
\hline 210 & 190 & 170 & 150 & 130 & $\begin{array}{r}110 \\
\text { f1 }\end{array}$ & $\begin{array}{c}90 \\
\mathrm{~m})\end{array}$ & 70 & 50 & 30 & 10 & -10 \\
\hline
\end{tabular}

Figure S20. ${ }^{1} \mathrm{H}$ (top) and ${ }^{13} \mathrm{C}$ (bottom) NMR spectra of benzo-1,2,5-thiadiazole (S0) 


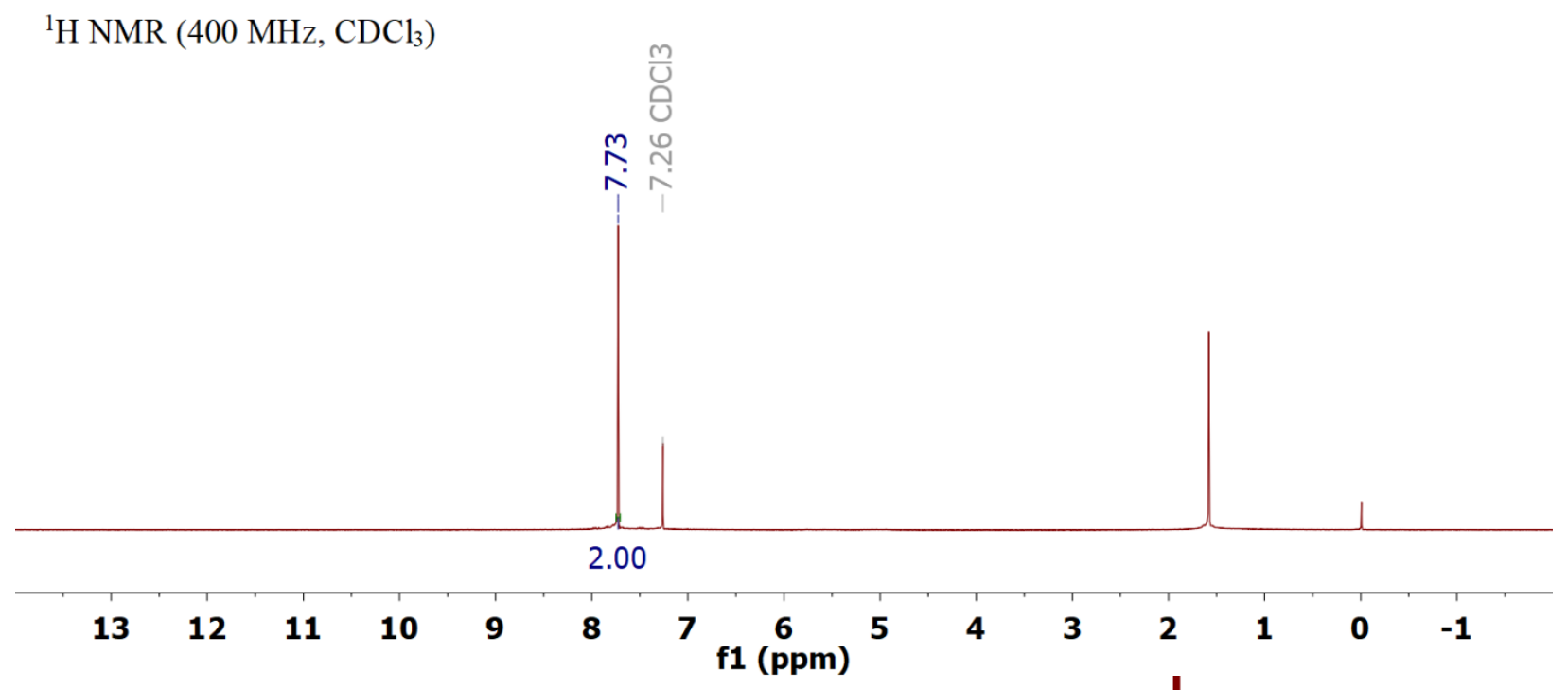

${ }^{13} \mathrm{C}$ NMR (101 MHz, DMSO) $\delta$ 152.32, 132.85, 113.15.

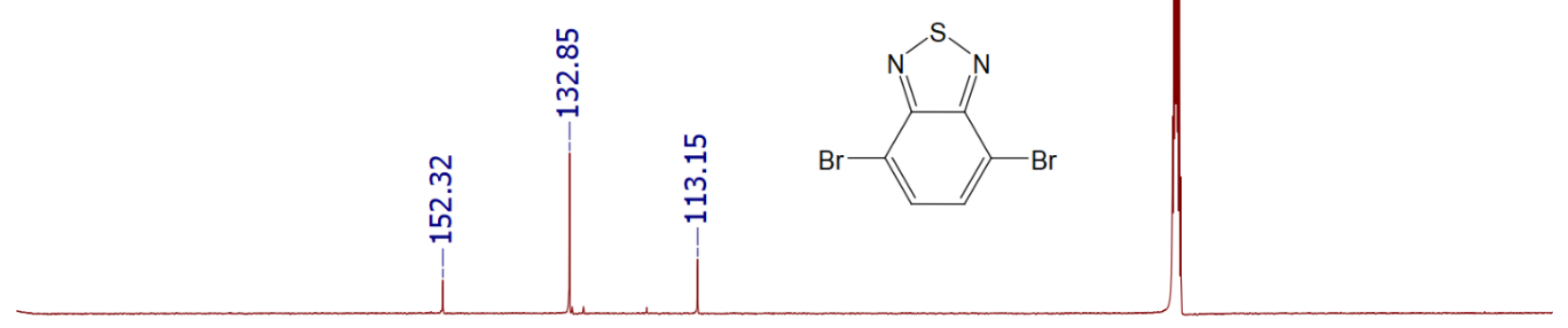

$\begin{array}{llllllllllll}210 & 190 & 170 & 150 & 130 & \begin{array}{c}110 \\ \mathrm{f} 1(\mathrm{ppm})\end{array} & 70 & 50 & 30 & 10 & -10\end{array}$

Figure S21. ${ }^{1} \mathrm{H}$ (top) and ${ }^{13} \mathrm{C}$ (bottom) NMR spectra of 4,7-dibromobenzo-1,2,5-thiadiazole (S3) 
${ }^{1} \mathrm{H}$ NMR (400 MHz, CDCl3) $\delta 7.82$.

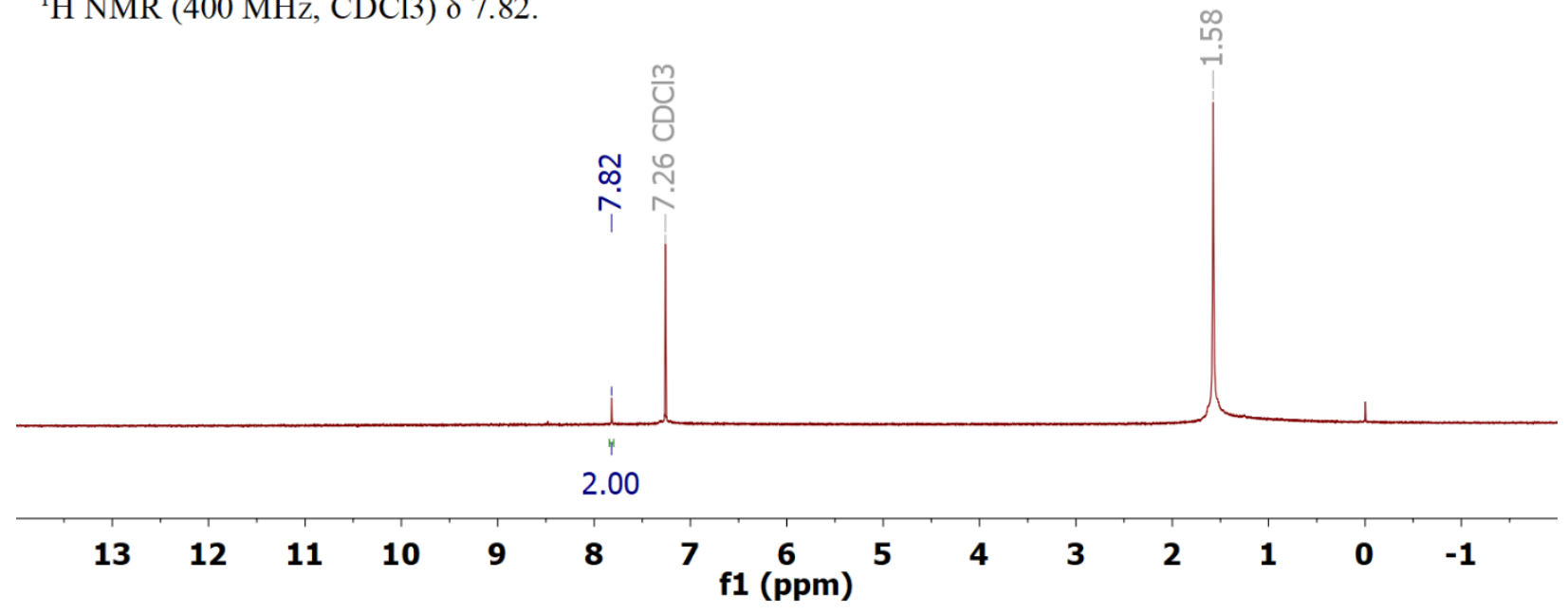

${ }^{13} \mathrm{C} \mathrm{NMR}\left(101 \mathrm{MHz}, \mathrm{CDCl}_{3}\right) \delta 154.00,139.94,87.91$.

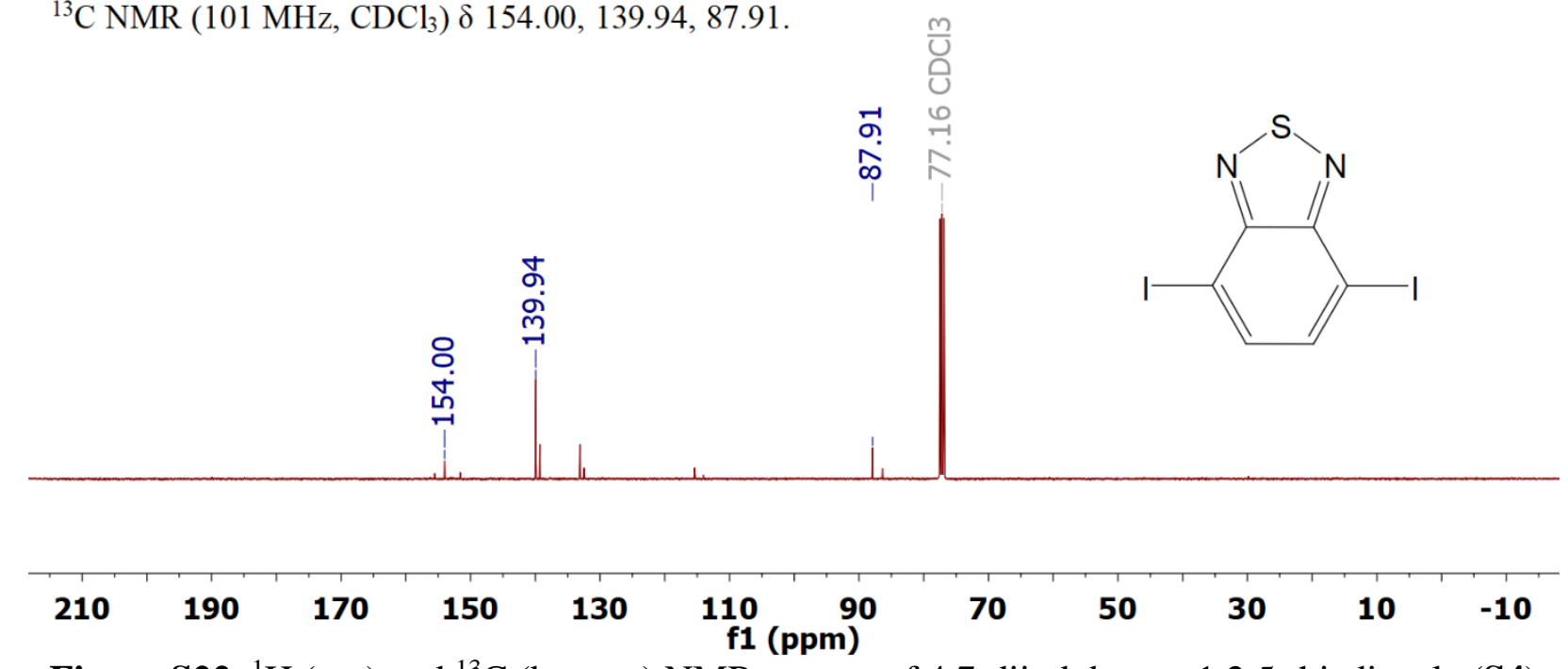

Figure S22. ${ }^{1} \mathrm{H}$ (top) and ${ }^{13} \mathrm{C}$ (bottom) NMR spectra of 4,7-diiodobenzo-1,2,5-thiadiazole (S4) 
${ }^{1} \mathrm{H}$ NMR (400 MHz, $\left.\mathrm{CDCl}_{3}\right) \delta 7.63,0.28$.

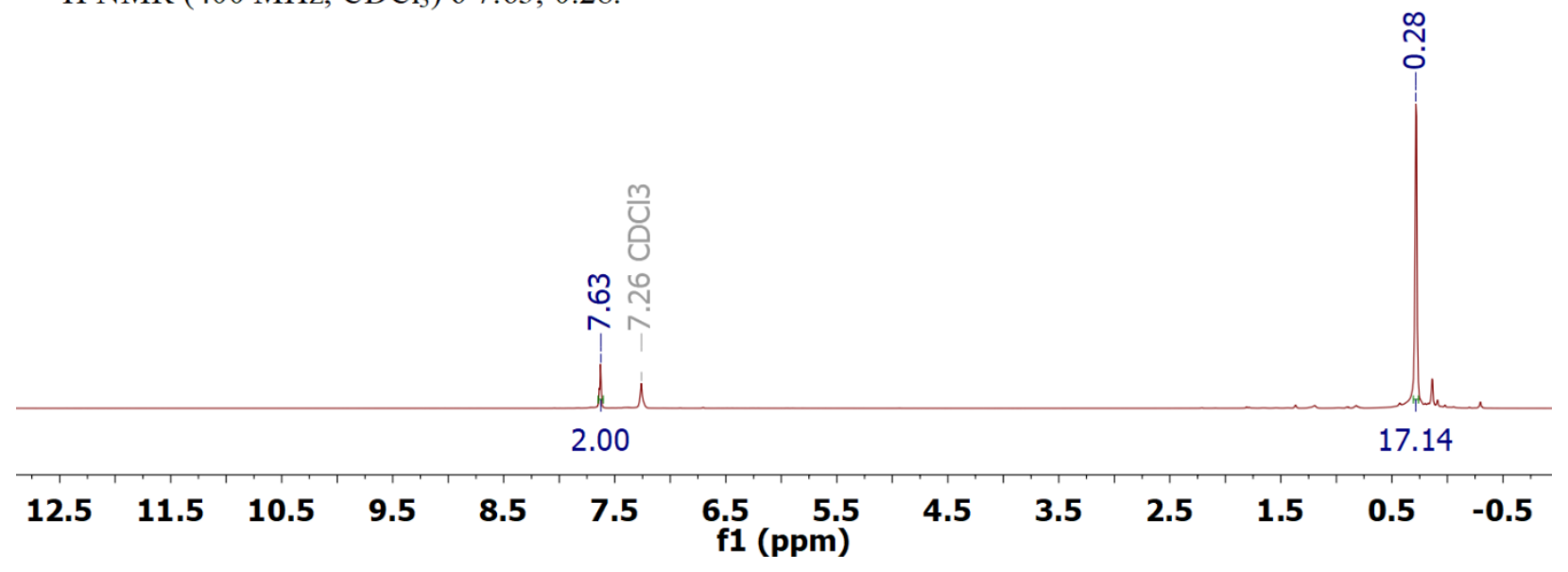

${ }^{13} \mathrm{C}$ NMR (101 MHz, $\left.\mathrm{CDCl}_{3}\right) \delta 154.21,133.11,117.27,103.58,100.09,-0.03$.

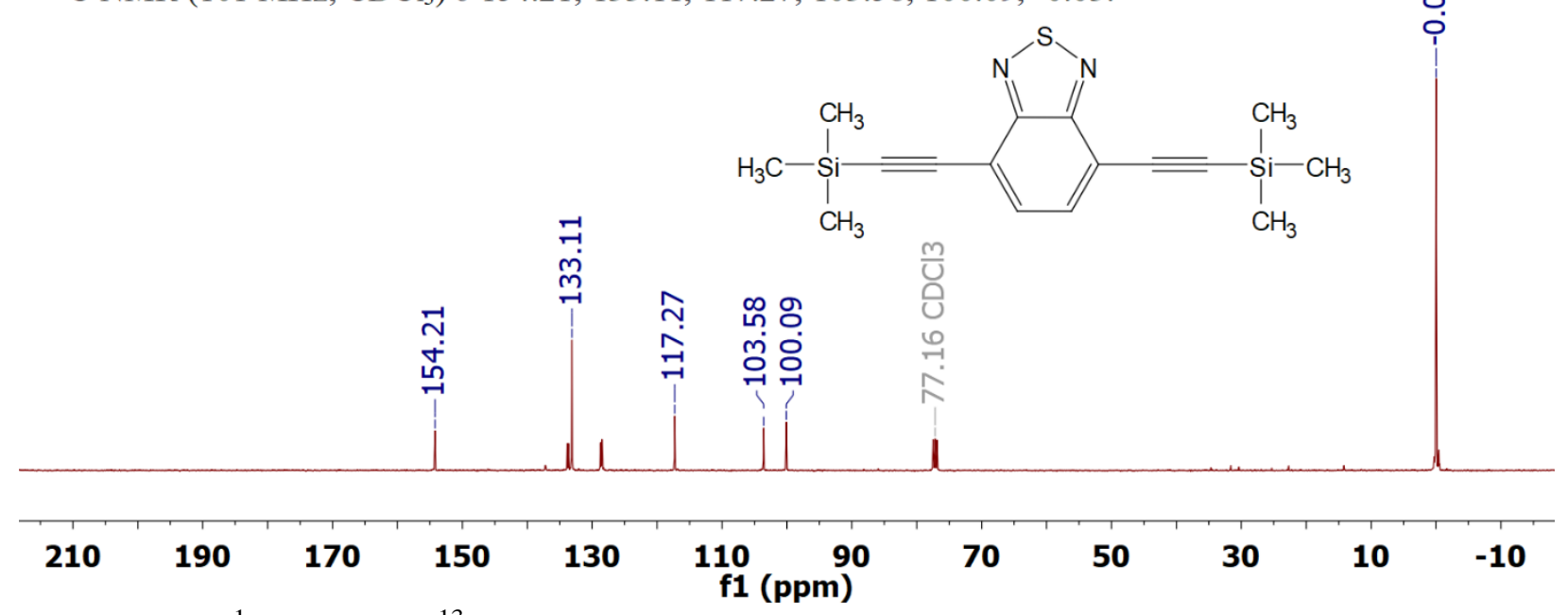

Figure S23. ${ }^{1} \mathrm{H}$ (top) and ${ }^{13} \mathrm{C}$ (bottom) NMR spectrum of 4,7-bis((trimethylsilyl)ethynyl)benzo1,2,5-thiadiazole (ST) 


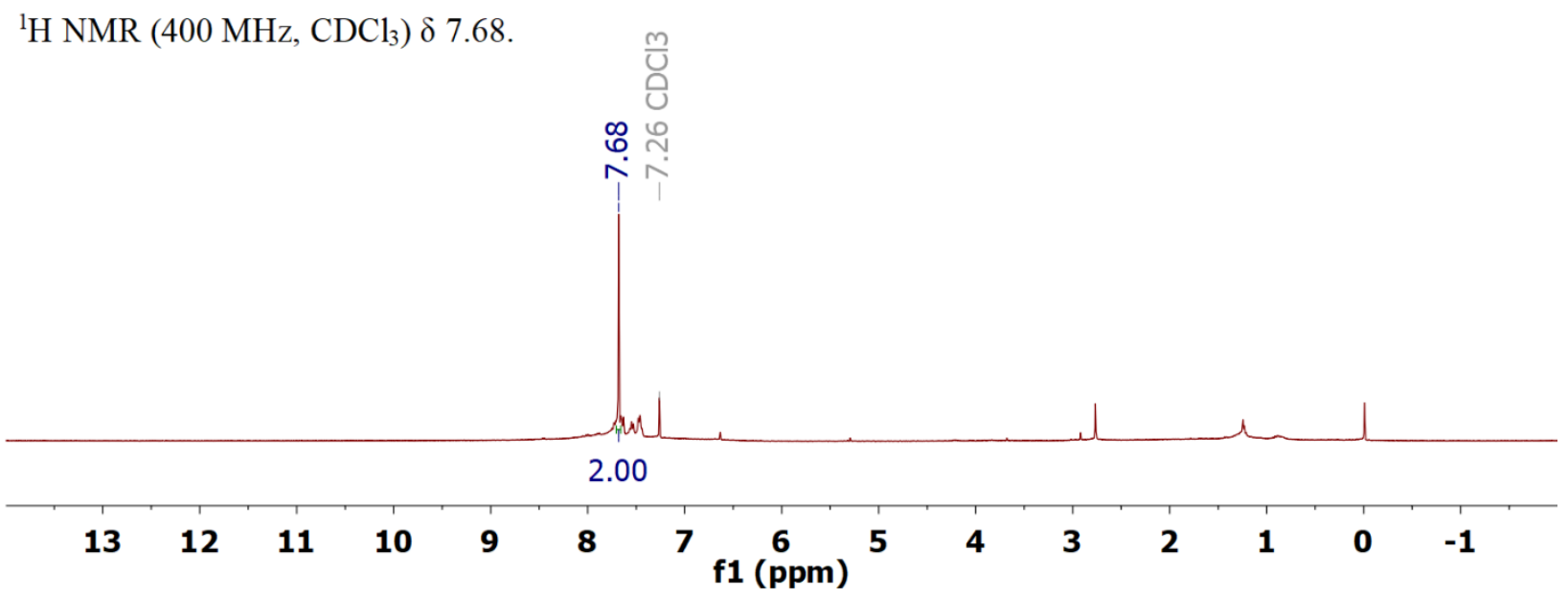

${ }^{13} \mathrm{C}$ NMR (101 MHz, $\left.\mathrm{cdcl}_{3}\right) \delta 154.62,133.24,116.70,65.47,29.70$.

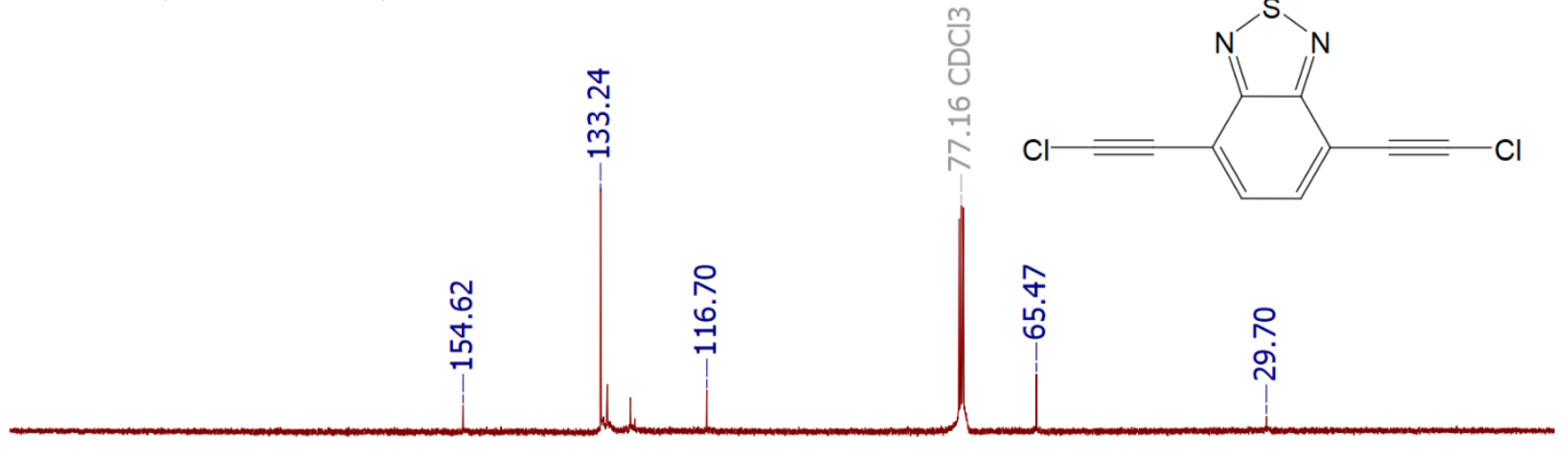

\begin{tabular}{|c|c|c|c|c|c|c|c|c|c|c|c|}
\hline 210 & 190 & 170 & 150 & 130 & $\begin{array}{l}110 \\
\text { f1 (ppm) }\end{array}$ & 90 & 70 & 50 & 30 & 10 & -10 \\
\hline
\end{tabular}

Figure S24. ${ }^{1} \mathrm{H}$ (top) and ${ }^{13} \mathrm{C}$ (bottom) NMR spectrum of 4,7-bis(chloroethynyl)benzo-1,2,5thiadiazole (S6) 
${ }^{1} \mathrm{H} \mathrm{NMR}\left(400 \mathrm{MHz}, \mathrm{CDCl}_{3}\right) \delta 7.69$.

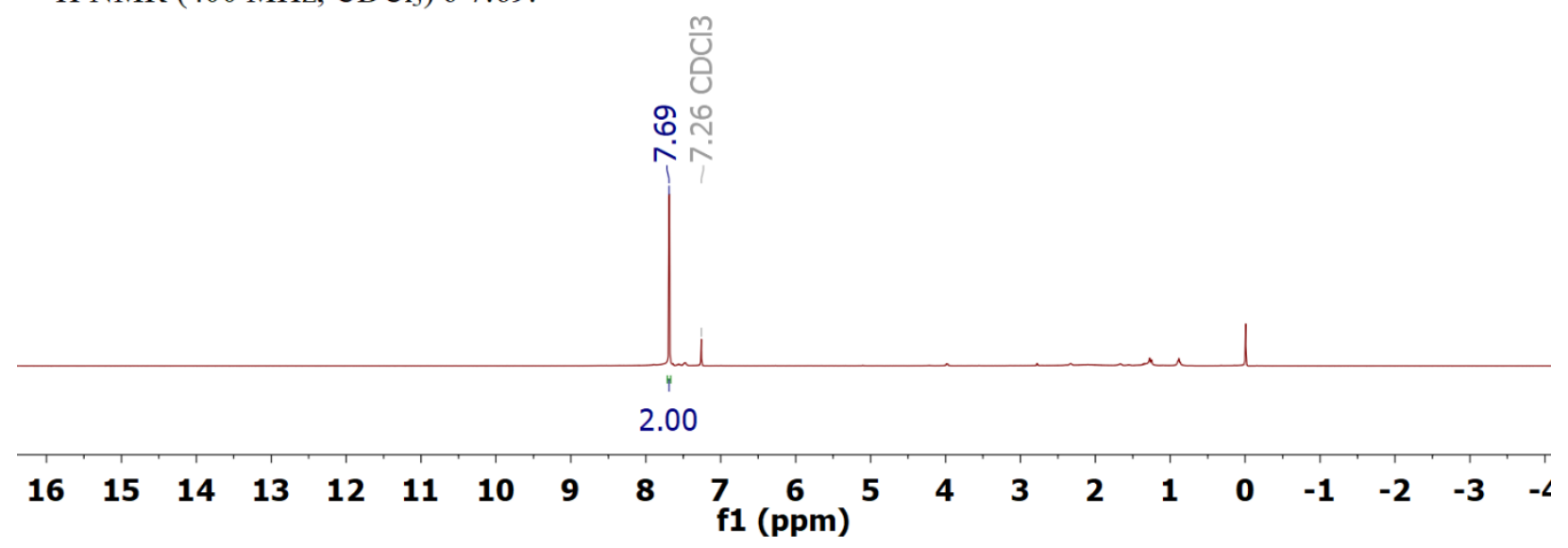

${ }^{13} \mathrm{C}$ NMR $\left(101 \mathrm{MHz}, \mathrm{CDCl}_{3}\right) \delta 154.58,133.27,117.24,76.08,59.40$.

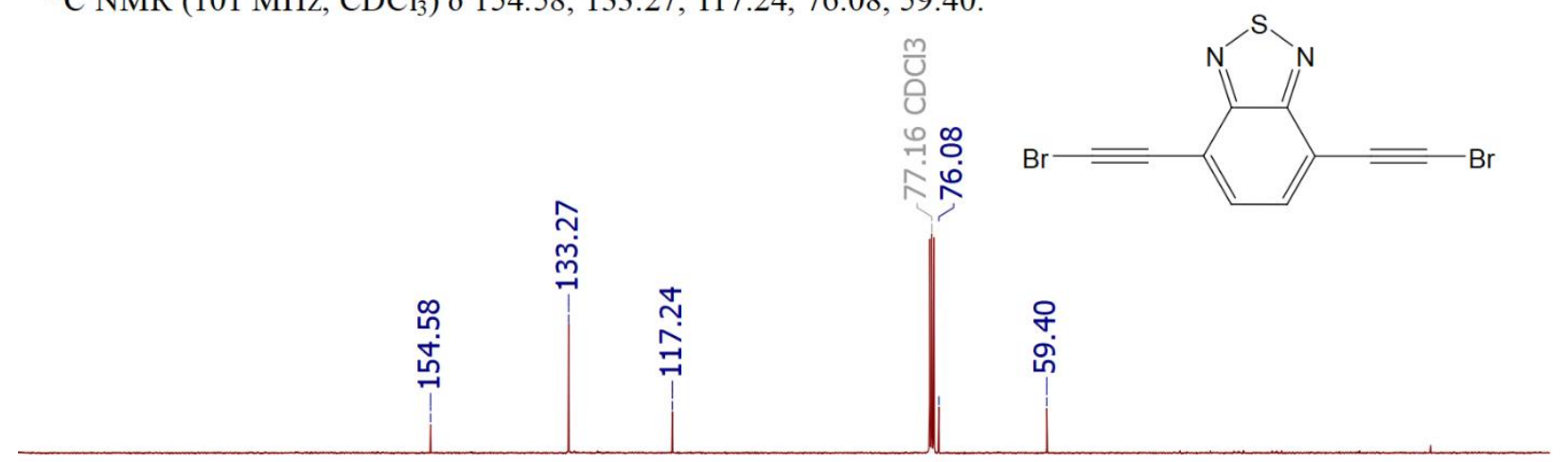

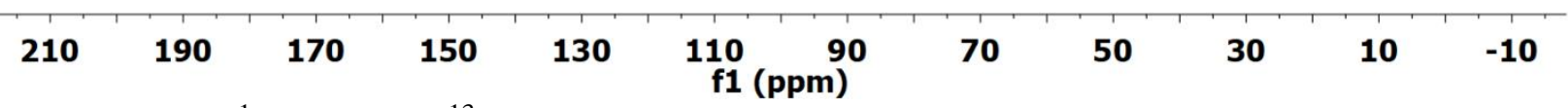

Figure S25. ${ }^{1} \mathrm{H}$ (top) and ${ }^{13} \mathrm{C}$ (bottom) NMR spectrum of 4,7-bis(bromoethynyl)benzo-1,2,5thiadiazole (S7) 
${ }^{1} \mathrm{H} \mathrm{NMR}\left(400 \mathrm{MHz}, \mathrm{CDCl}_{3}\right) \delta 7.67$.

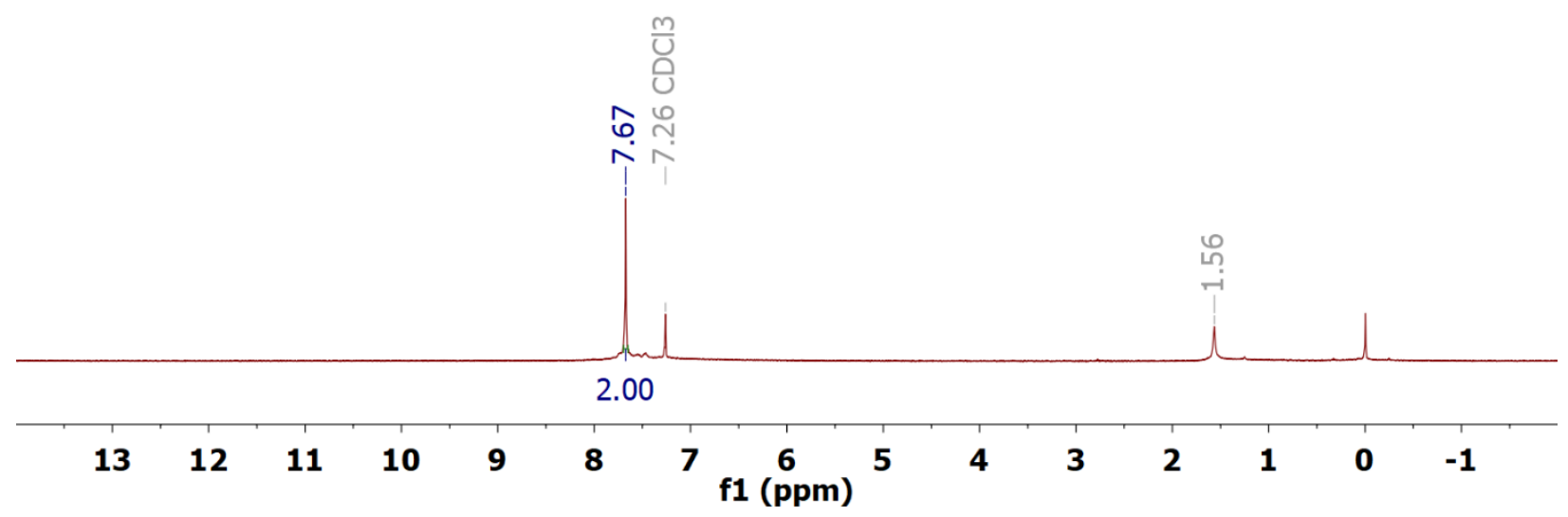

${ }^{13} \mathrm{C}$ NMR (101 MHz, $\left.\mathrm{cdcl}_{3}\right) \delta 154.81,133.59,117.87,89.96,17.21$.
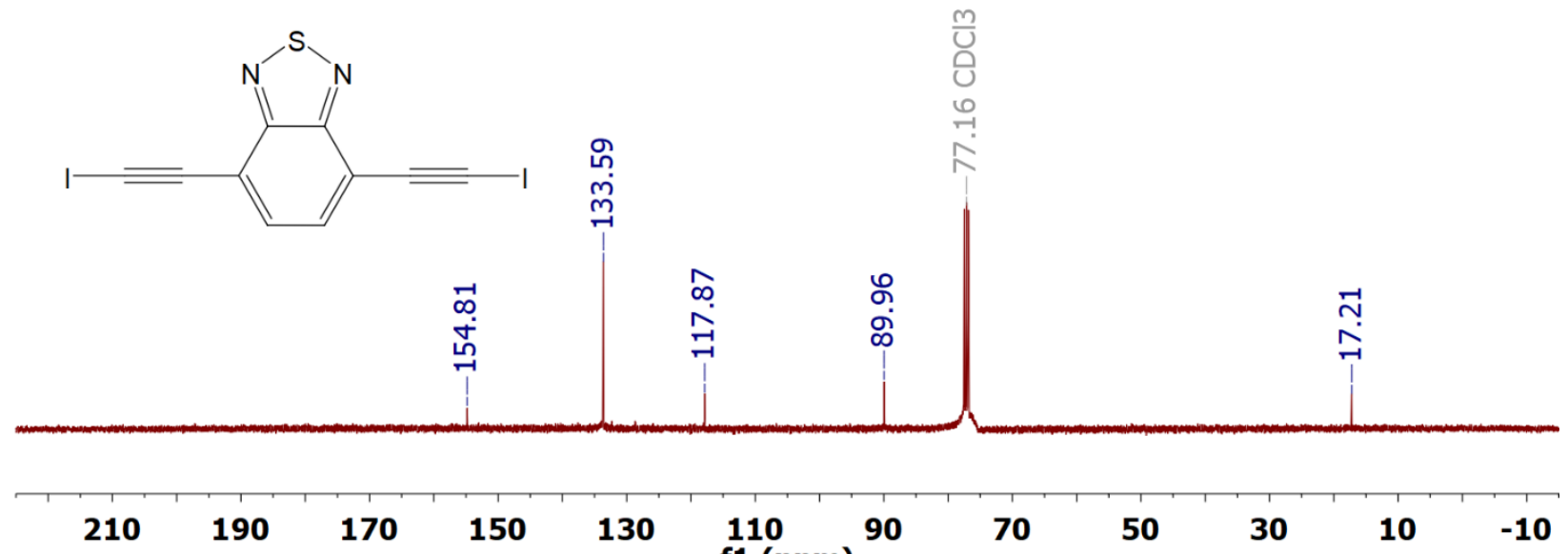

Figure S26. ${ }^{1} \mathrm{H}$ (top) and ${ }^{13} \mathrm{C}$ (bottom) NMR spectrum of 4,7-bis(iodoethynyl)benzo-1,2,5thiadiazole (S8) 
${ }^{1} \mathrm{H} \mathrm{NMR}\left(400 \mathrm{MHz}, \mathrm{CDCl}_{3}\right) \delta 7.76,7.39$.

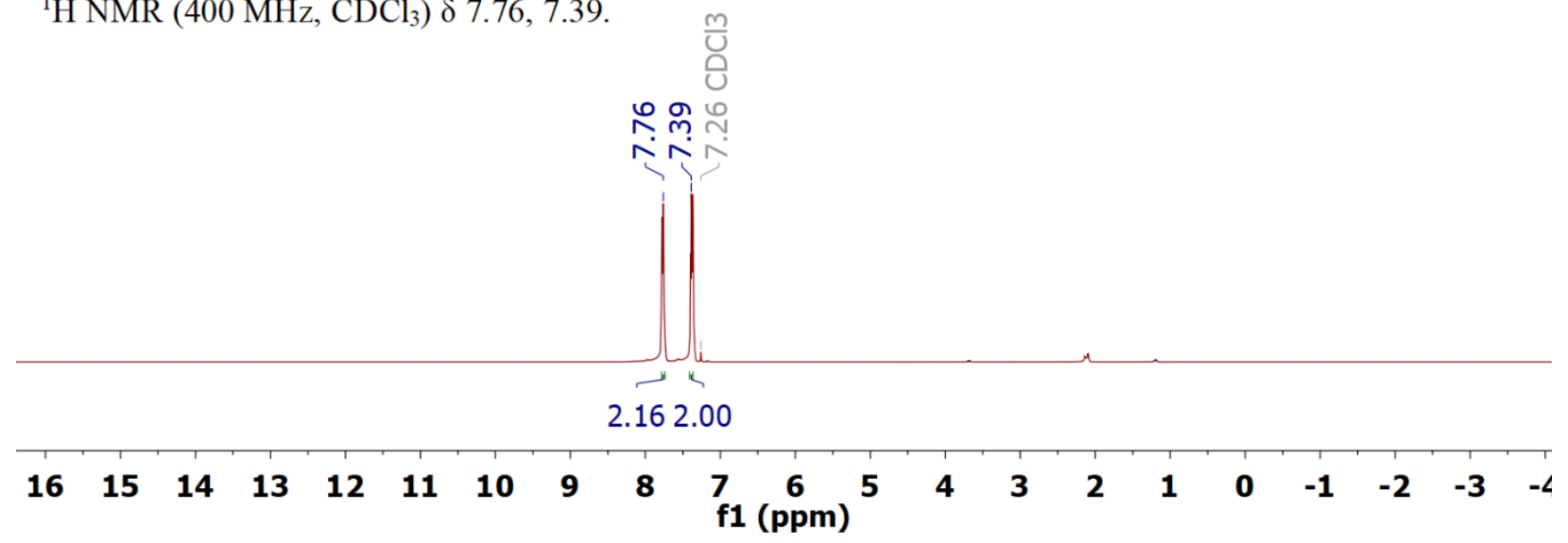

${ }^{77}$ Se NMR (76 MHz, DMSO-d6) $\delta 1526.18$

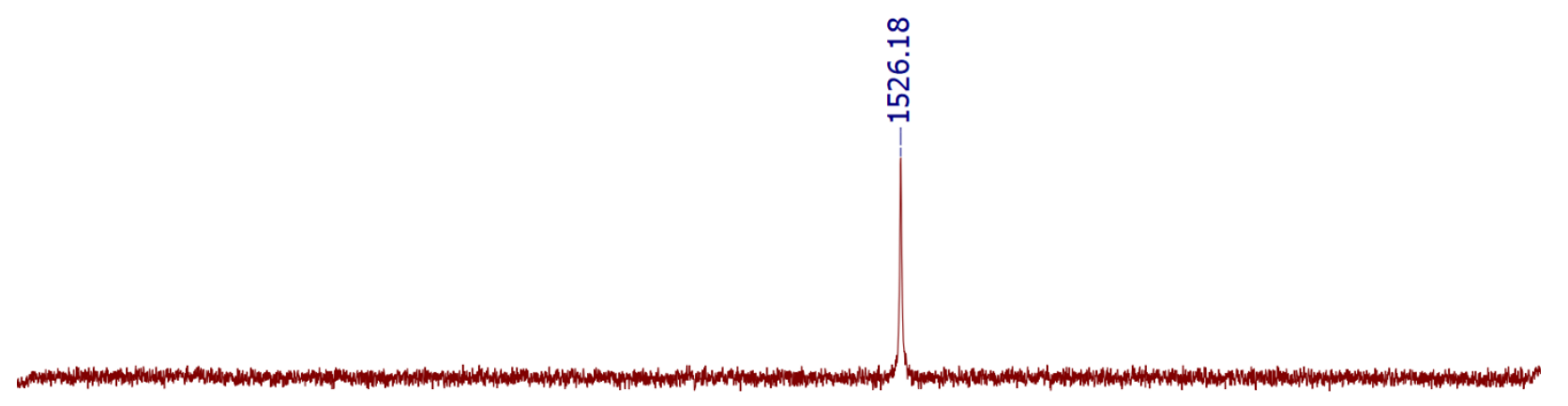

$\begin{array}{lllllllllllllll}1690 & 1670 & 1650 & 1630 & 1610 & 1590 & 1570 & 1550 & 1530 & 1510 & 1490 & 1470 & 1450 & 1430 & 1410\end{array}$

${ }^{13} \mathrm{C}$ NMR (101 MHz, $\left.\mathrm{CDCl}_{3}\right) \delta 160.50,129.41,123.45$.

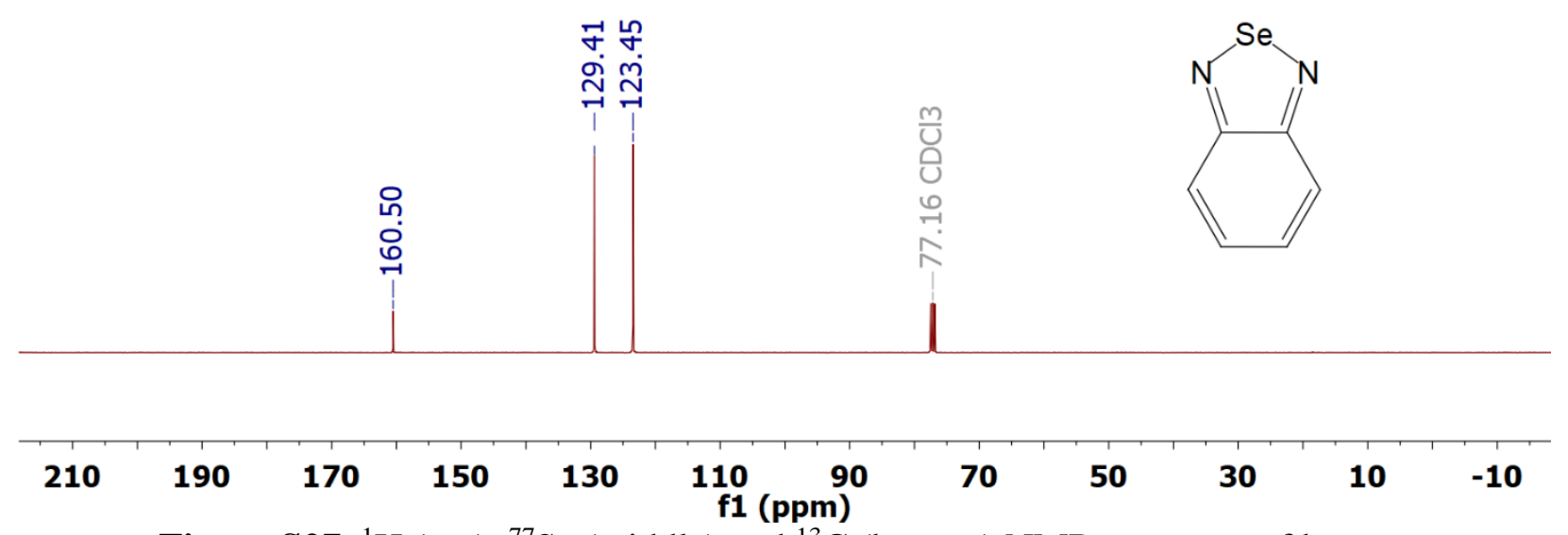

Figure S27. ${ }^{1} \mathrm{H}$ (top), ${ }^{77} \mathrm{Se}$ (middle) and ${ }^{13} \mathrm{C}$ (bottom) NMR spectrum of benzo1,2,5selenadiazole (Se0) 
${ }^{1} \mathrm{H} \mathrm{NMR}\left(400 \mathrm{MHz}, \mathrm{CDCl}_{3}\right) \delta 7.64$.

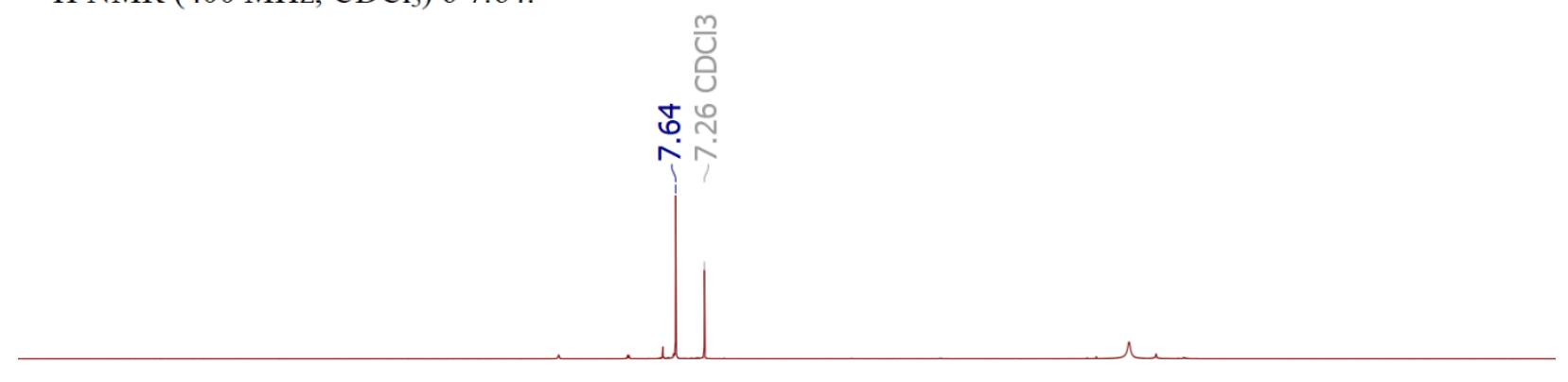

$\begin{array}{lllllllllllllllllllll}16 & 15 & 14 & 13 & 12 & 11 & 10 & 9 & 8 & \underset{\mathrm{f} 1}{(\mathrm{ppm})} \mathbf{6} & 5 & 4 & 3 & 2 & 1 & 0 & -1 & -2 & -3 & -4\end{array}$

${ }^{77} \mathrm{Se}$ NMR (76 MHz, DMSO) $\delta 1532.40$.

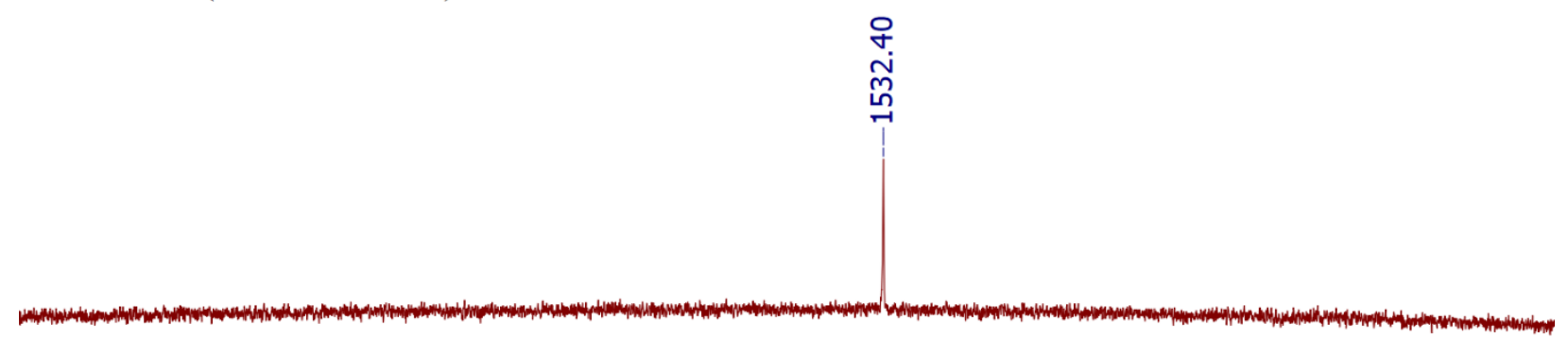

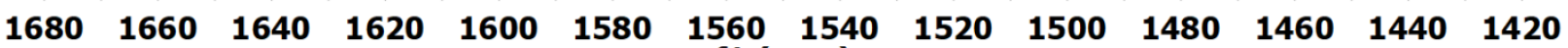
f1 (ppm)

${ }^{13} \mathrm{C}$ NMR (101 MHz, DMSO) $\delta$ 156.23, 131.83, 116.04.

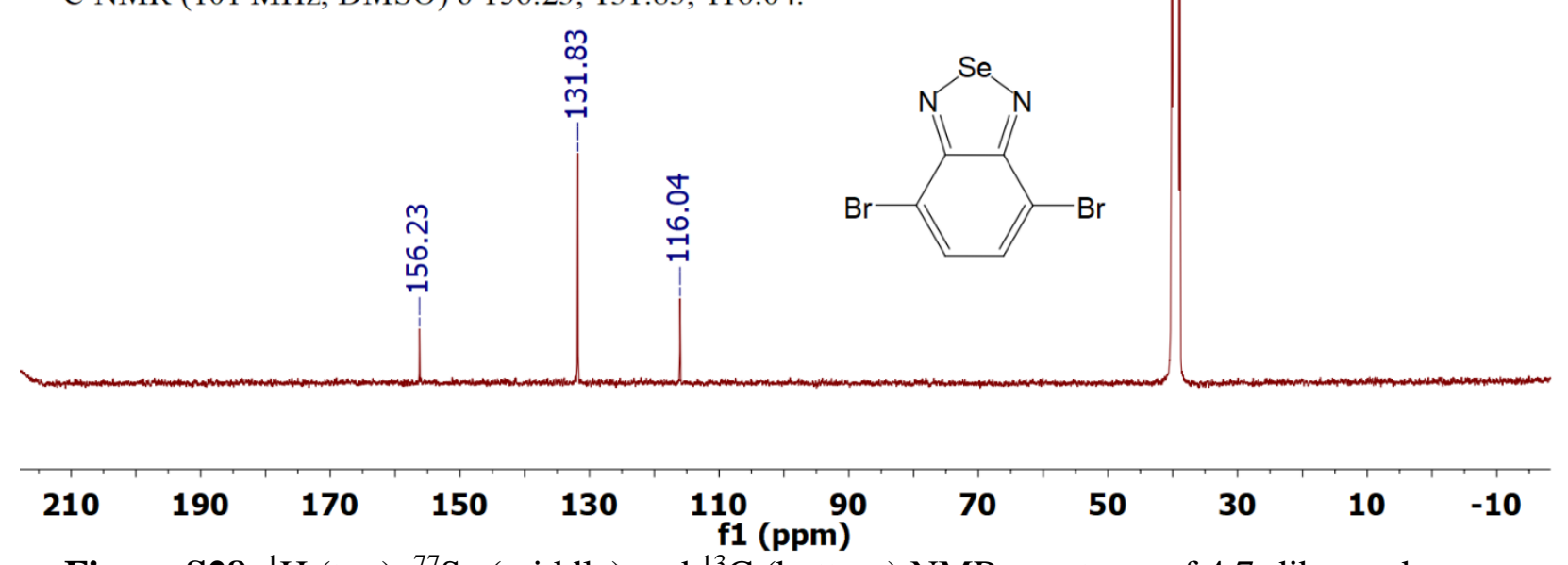

Figure S28. ${ }^{1} \mathrm{H}$ (top), ${ }^{77} \mathrm{Se}$ (middle) and ${ }^{13} \mathrm{C}$ (bottom) NMR spectrum of 4,7-dibromobenzo-

1,2,5-selenadiazole (Se3) 
${ }^{1} \mathrm{H} \mathrm{NMR}\left(400 \mathrm{MHz}, \mathrm{CDCl}_{3}\right) \delta 7.74$

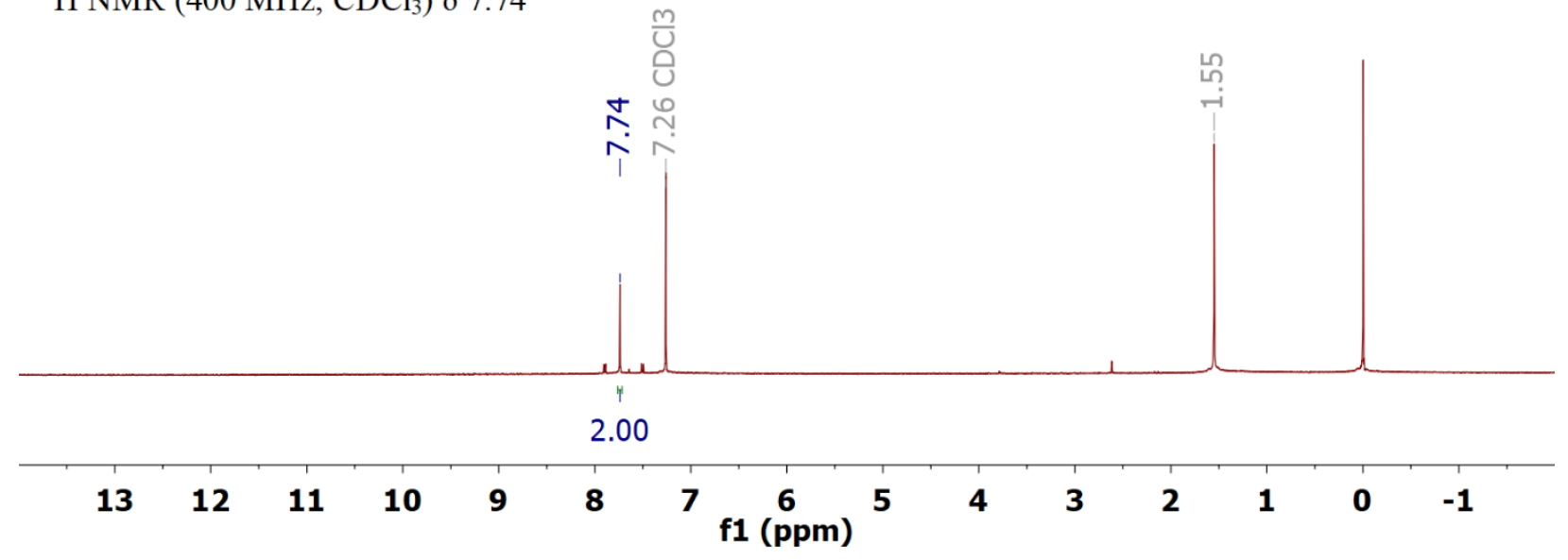

${ }^{77} \mathrm{Se}$ NMR (76 MHz, DMSO-d6) $\delta 1511.52$
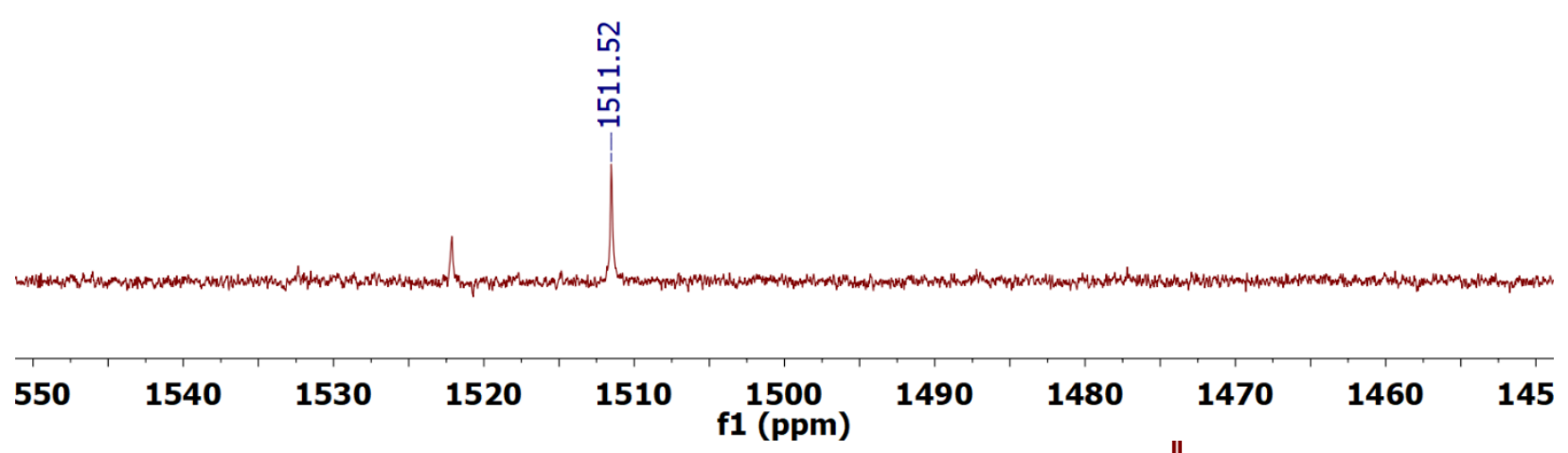

${ }^{13} \mathrm{C}$ NMR (101 MHz, DMSO) $\delta$ 157.00, 139.41, 92.95.

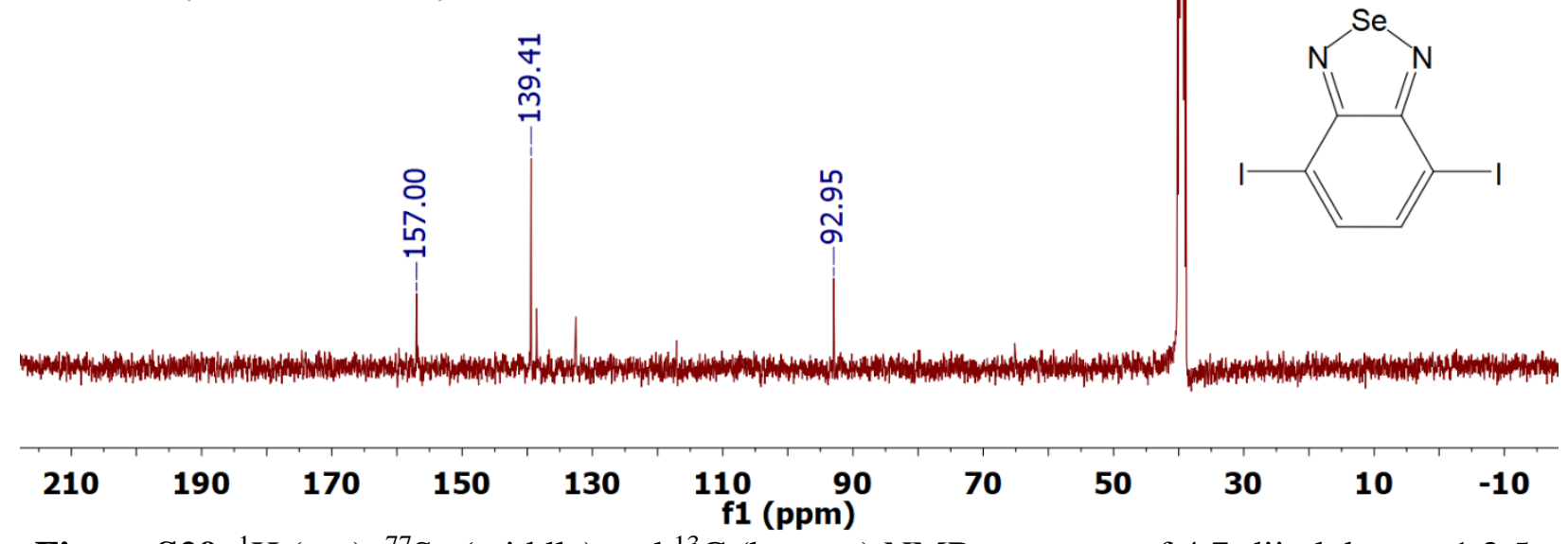

Figure S29. ${ }^{1} \mathrm{H}$ (top), ${ }^{77} \mathrm{Se}$ (middle) and ${ }^{13} \mathrm{C}$ (bottom) NMR spectrum of 4,7-diiodobenzo-1,2,5selenadiazole (Se4) 
${ }^{1} \mathrm{H}$ NMR $\left(400 \mathrm{MHz}, \mathrm{CDCl}_{3}\right) \delta 6.78,3.94,0.27$.

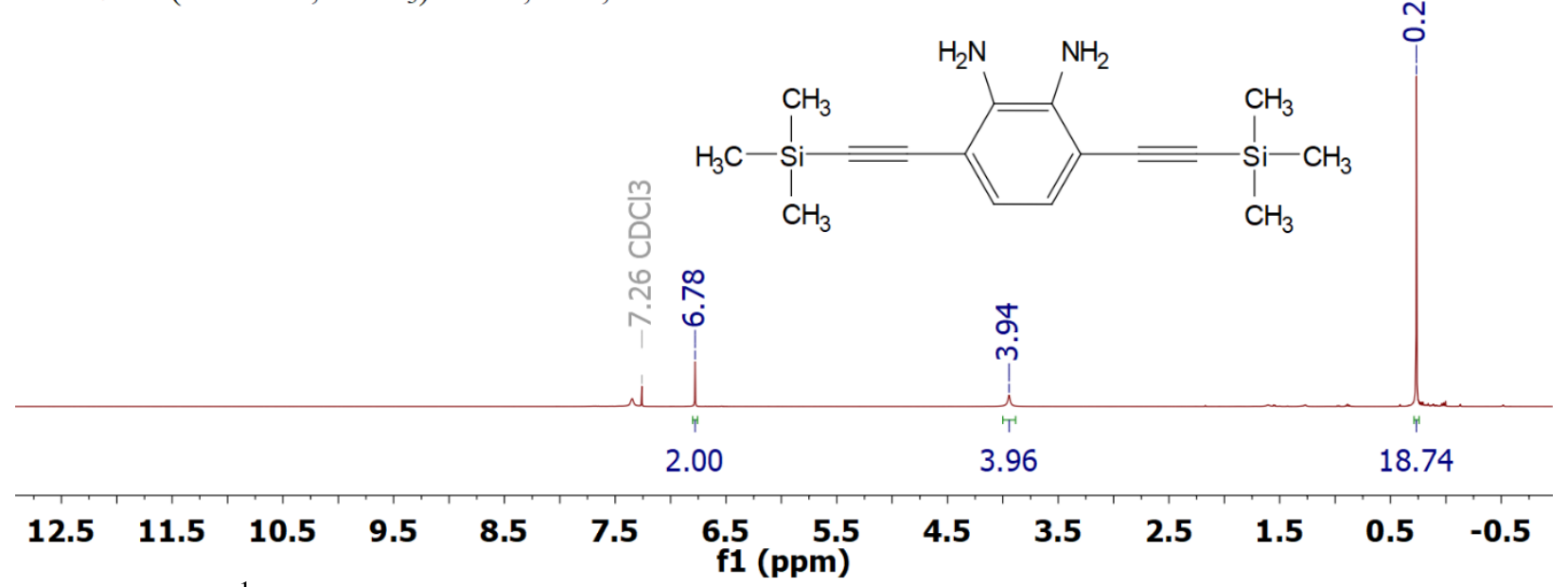

Figure S30. ${ }^{1} \mathrm{H}$ NMR spectrum of 3,6-bis((trimethylsilyl)ethynyl)benzene-1,2-diamine (SeT1)

${ }^{1} \mathrm{H}$ NMR (400 MHz, CDC13) $\delta 7.61,0.32$.
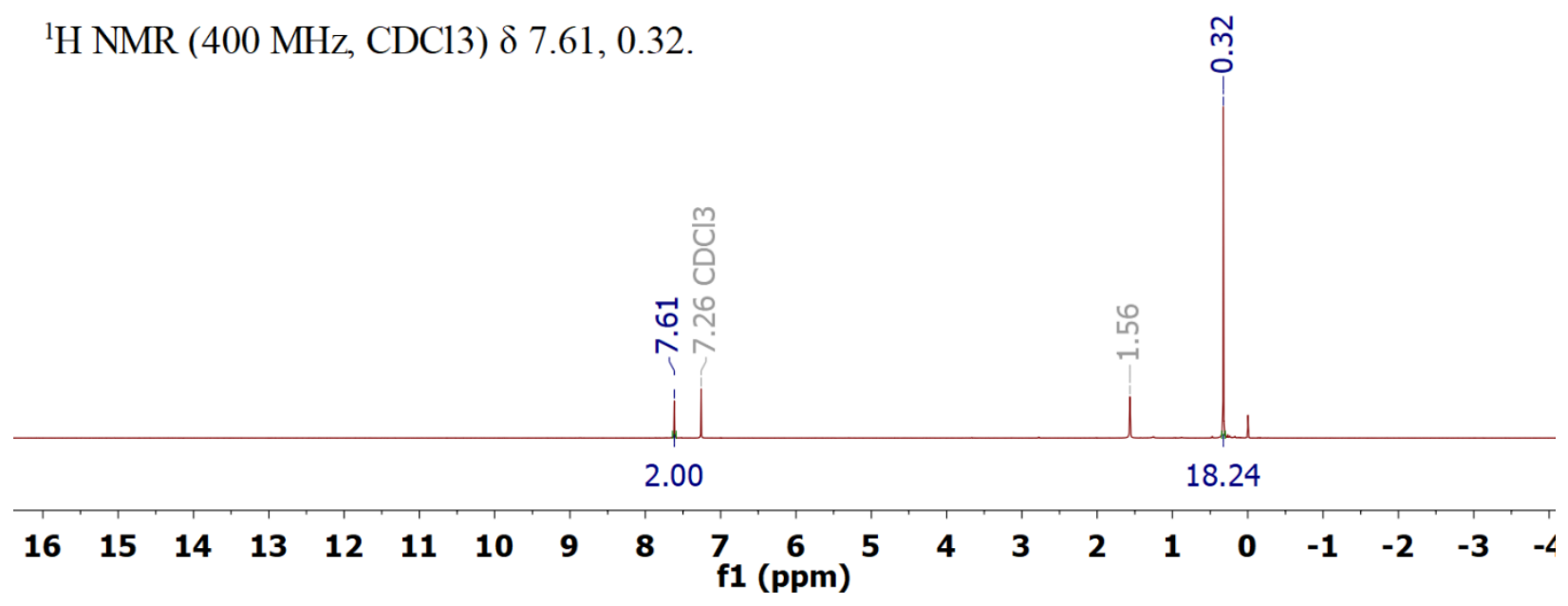

${ }^{13} \mathrm{C} \mathrm{NMR}\left(101 \mathrm{MHz}, \mathrm{CDCl}_{3}\right) \delta 159.12,133.57,119.10,103.49,100.67,0.06$.

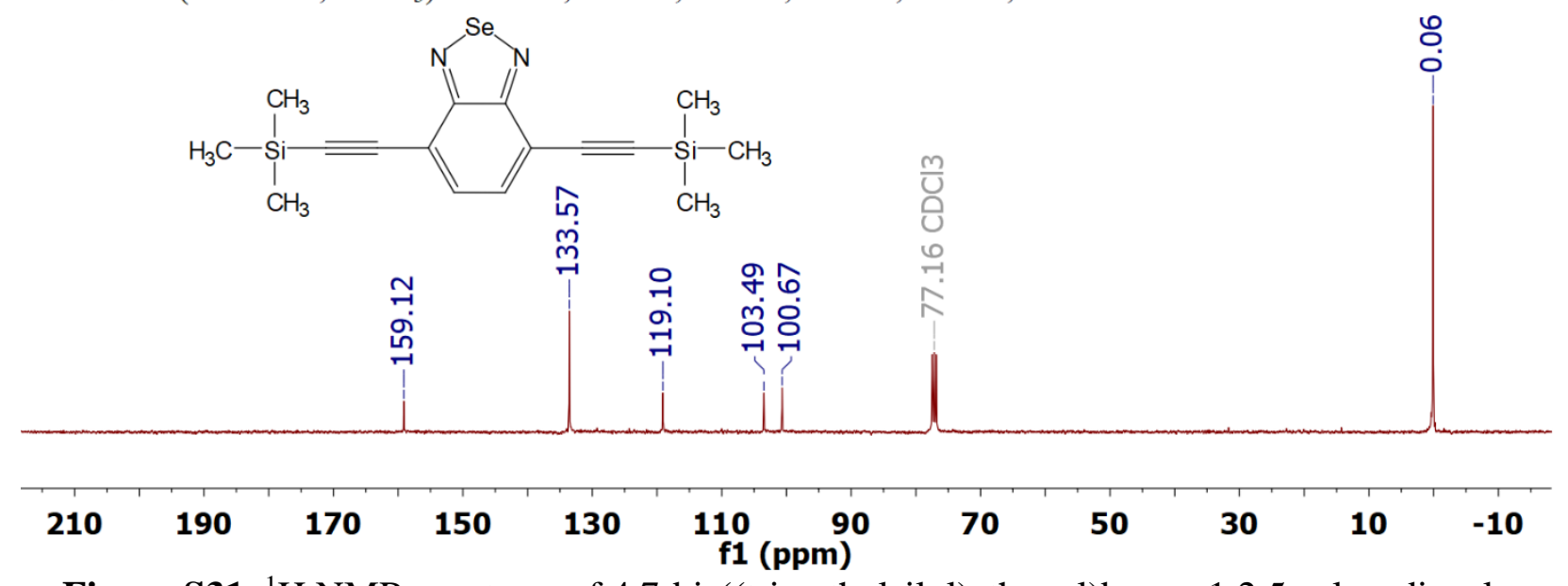

Figure S31. ${ }^{1}$ H NMR spectrum of 4,7-bis((trimethylsilyl)ethynyl)benzo-1,2,5-selenadiazole (SeT2) 
${ }^{1} \mathrm{H}$ NMR (400 MHz, DMSO) $\delta 7.75$.

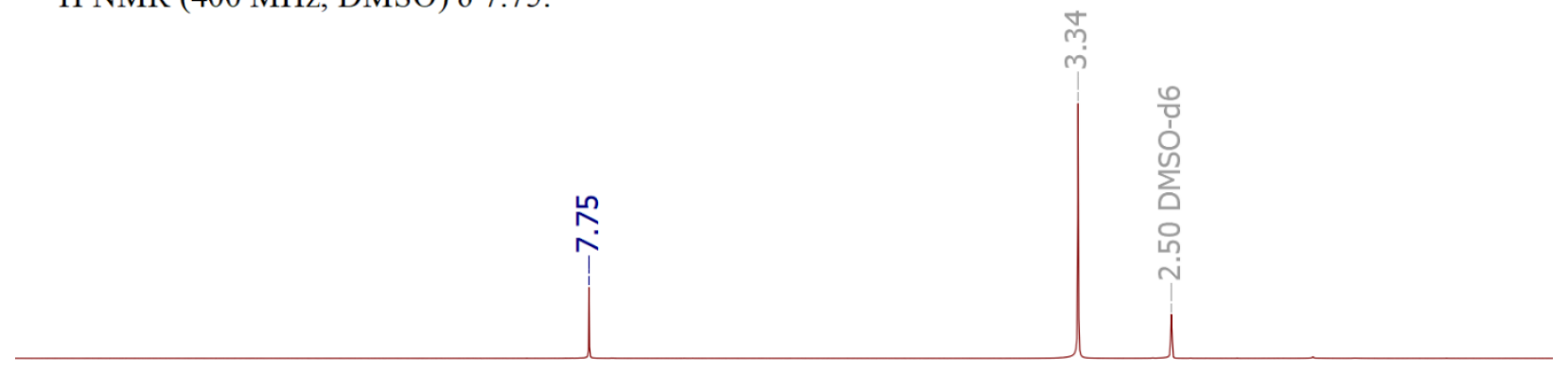

$\begin{array}{llllllllllllll}12.5 & 11.5 & 10.5 & 9.5 & 8.5 & 7.5 & \underset{\mathrm{f} 1(\mathrm{ppm})}{6.5} & 4.5 & 3.5 & 2.5 & 1.5 & 0.5 & -0.5\end{array}$

${ }^{77} \mathrm{Se}$ NMR (76 MHz, DMSO-d6) $\delta 1539.23$

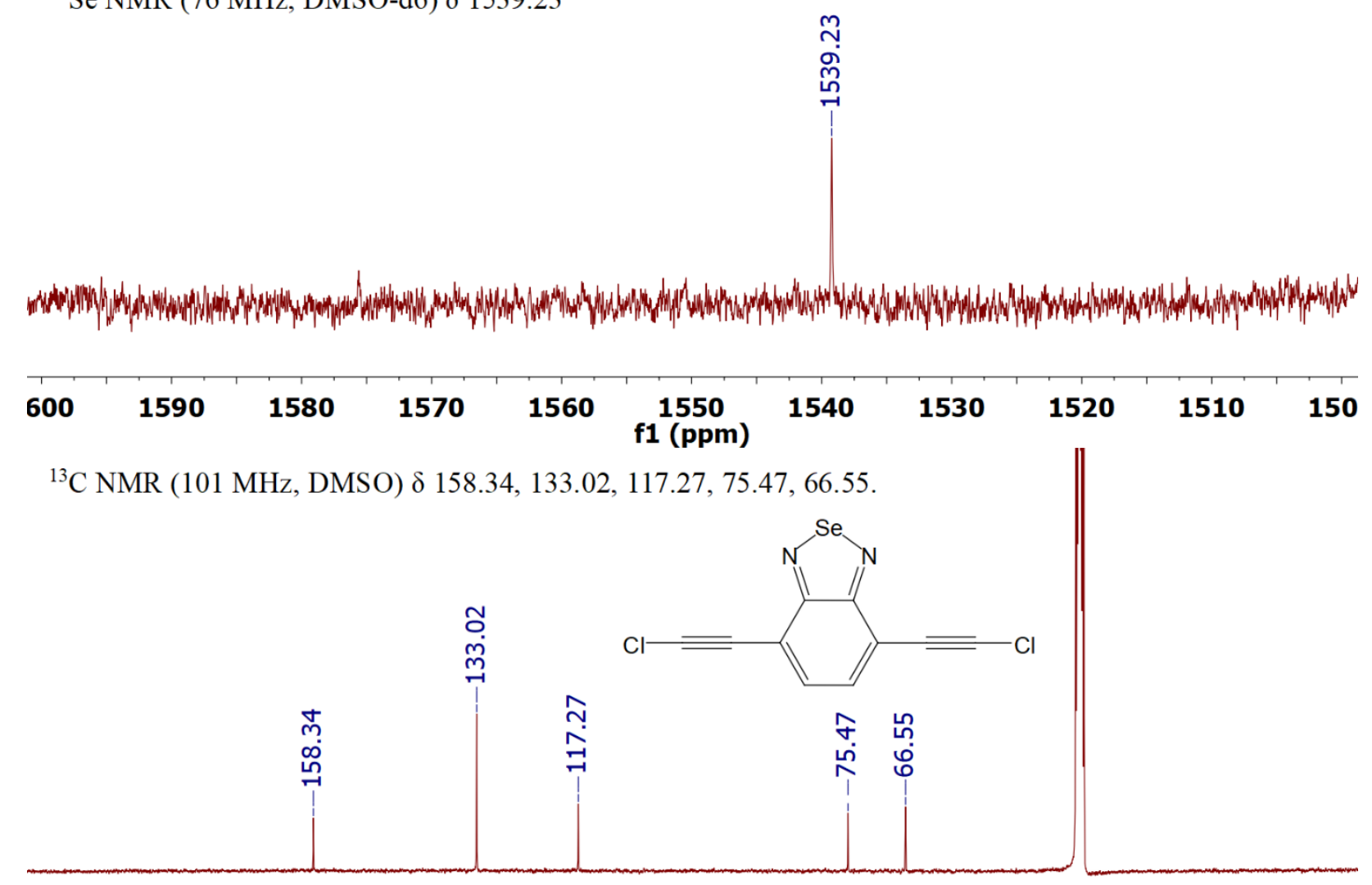

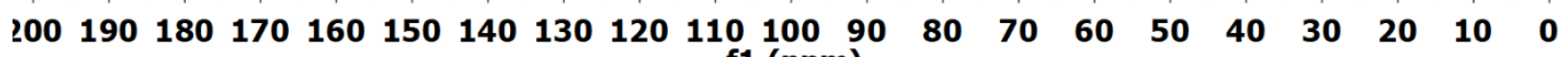
f1 (ppm)

Figure S32. ${ }^{1} \mathrm{H}$ (top), ${ }^{77} \mathrm{Se}$ (middle) and ${ }^{13} \mathrm{C}$ (bottom) NMR spectrum of 4,7bis(chloroethynyl)benzo-1,2,5-selenadiazole (Se6) 
${ }^{1} \mathrm{H}$ NMR (400 MHz, DMSO) $\delta 7.68$.

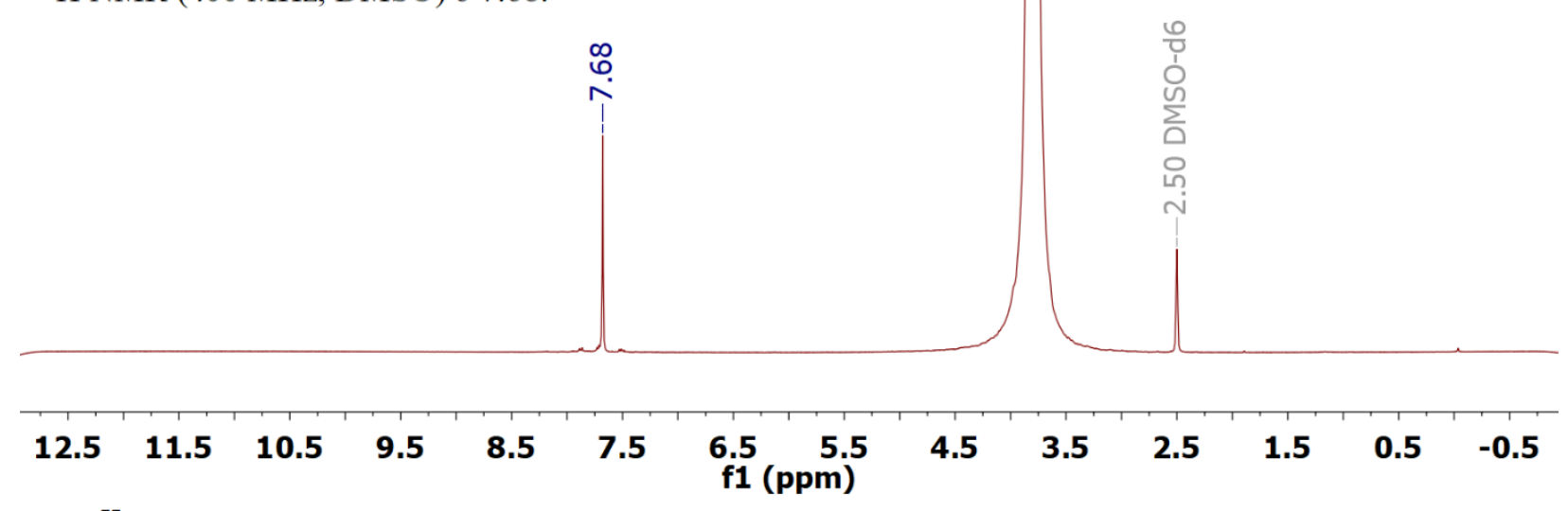

${ }^{77} \mathrm{Se}$ NMR (76 MHz, DMSO-d6)

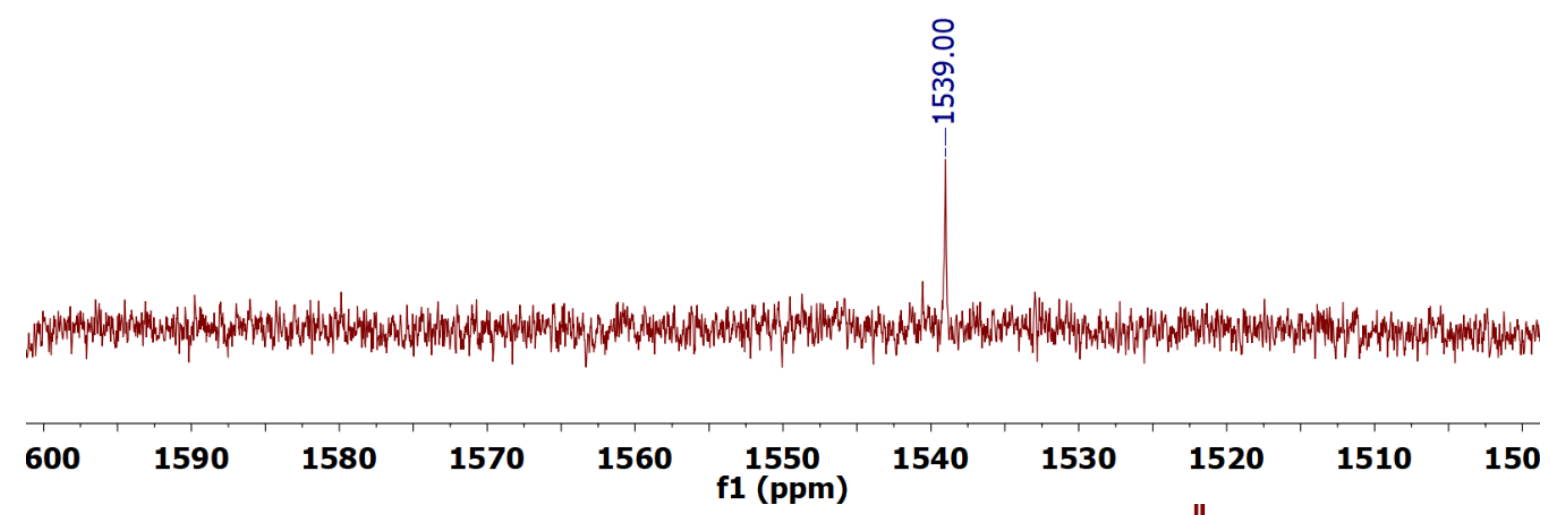

${ }^{13} \mathrm{C}$ NMR (101 MHz, DMSO) $\delta$ 158.86, 133.56, 118.33, 77.19, 61.22.
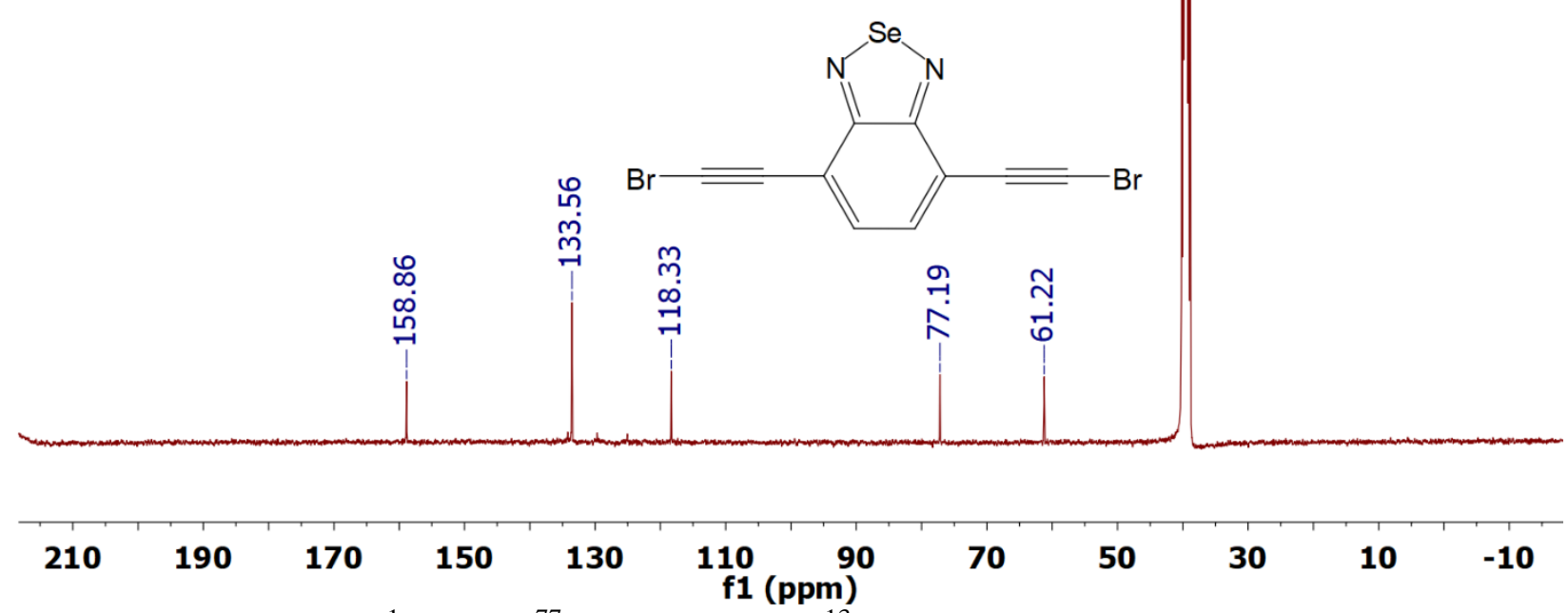

Figure S33. ${ }^{1} \mathrm{H}$ (top), ${ }^{77} \mathrm{Se}$ (middle) and ${ }^{13} \mathrm{C}$ (bottom) NMR spectrum of 4,7bis(bromoethynyl)benzo-1,2,5-selenadiazole (Se7) 


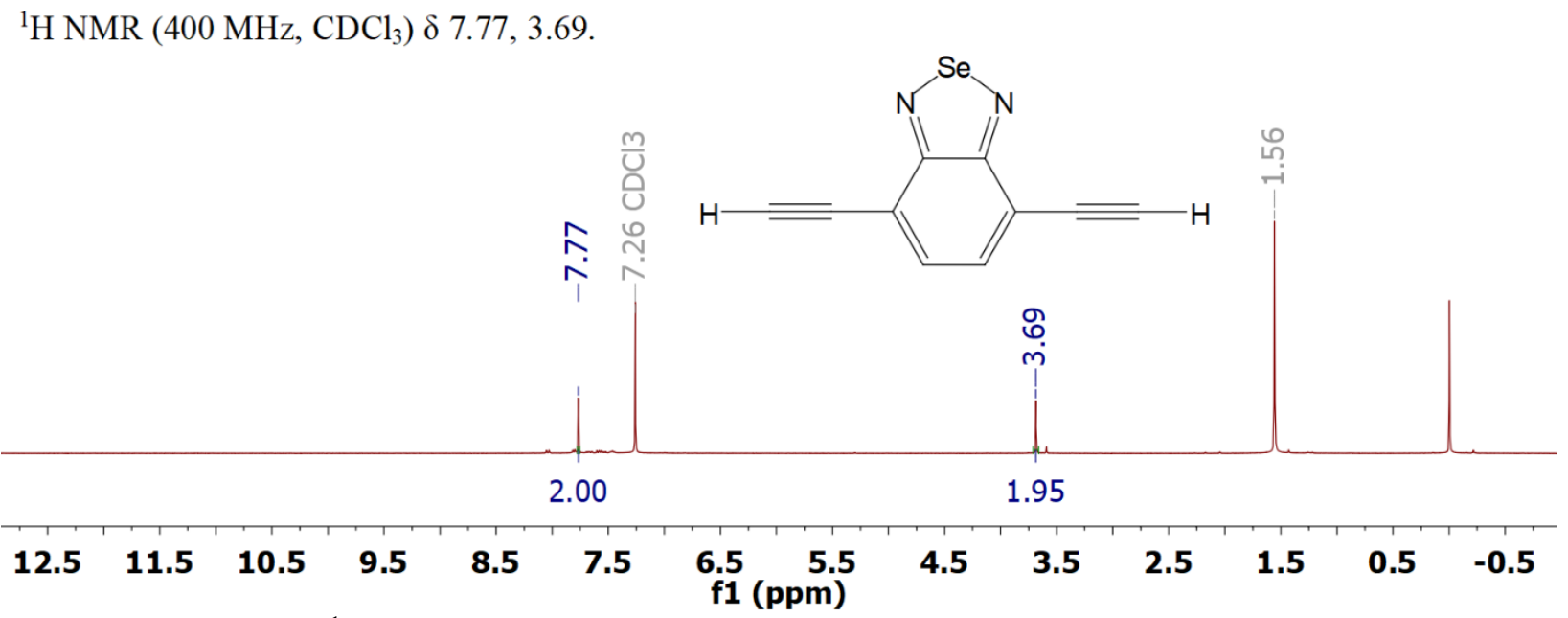

Figure S34. ${ }^{1} \mathrm{H}$ NMR spectrum of 4,7-diethynylbenzo-1,2,5-selenadiazole (SeT3) 
${ }^{1} \mathrm{H}$ NMR (400 MHz, DMSO) $\delta 7.62$.

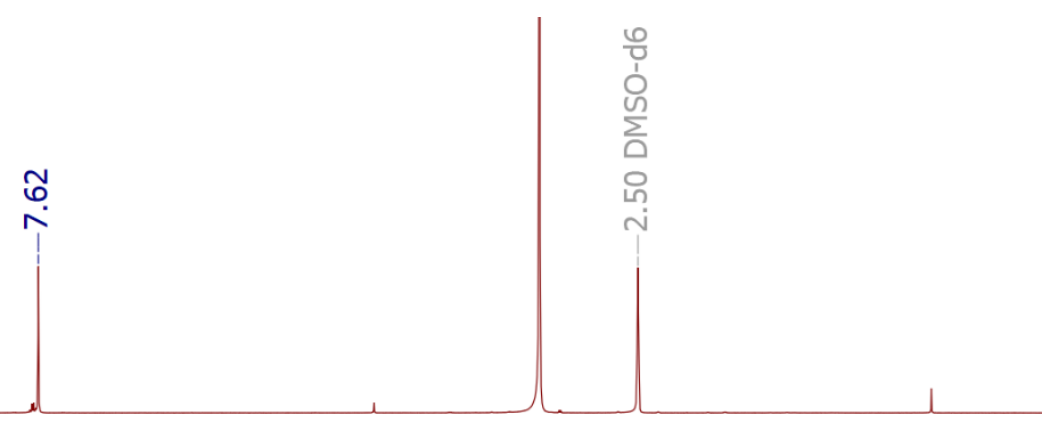

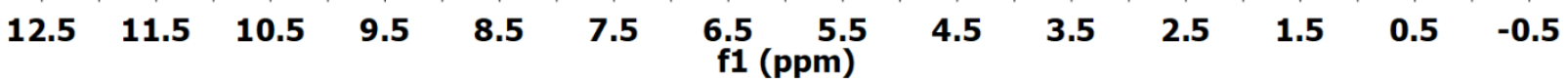

${ }^{77} \mathrm{Se}$ NMR (76 MHz, DMSO) $\delta 1536.86$.

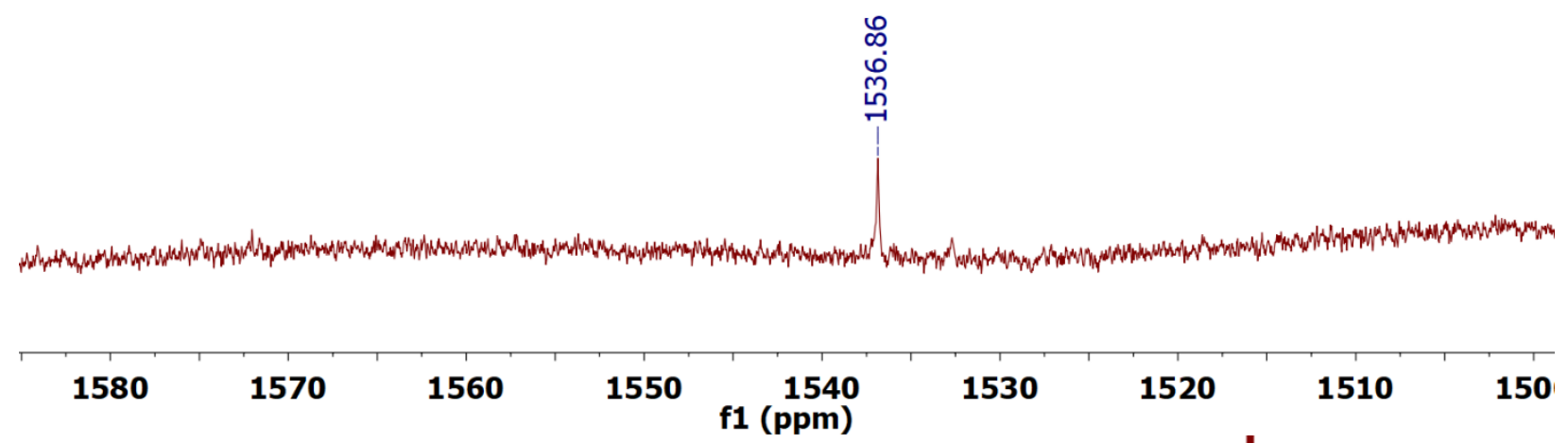

${ }^{13} \mathrm{C}$ NMR (101 MHz, DMSO) $\delta$ 158.75, 132.82, 118.77, 89.59, 27.29.
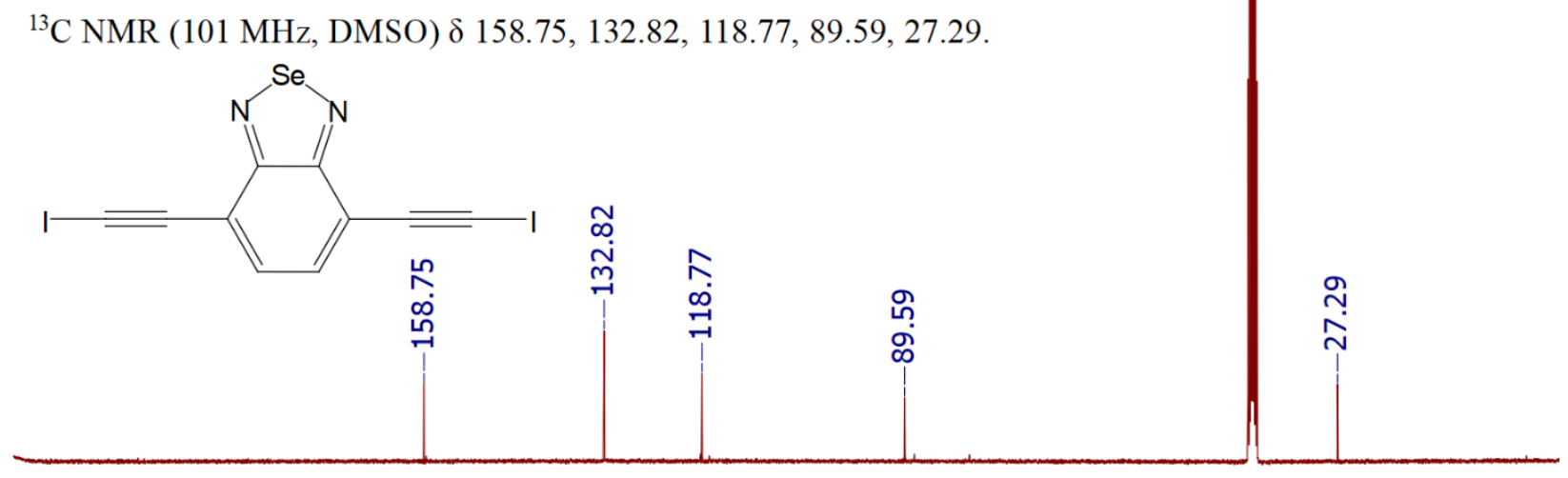

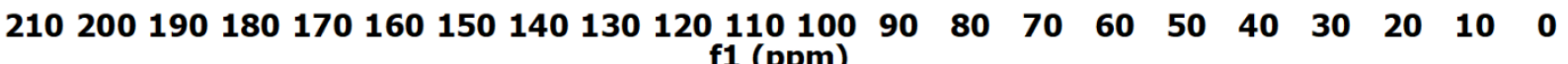

Figure S35. ${ }^{1} \mathrm{H}$ (top), ${ }^{77} \mathrm{Se}$ (middle) and ${ }^{13} \mathrm{C}$ (bottom) NMR spectrum of 4,7bis(iodoethynyl)benzo-1,2,5-selenadiazole (Se8) 


\section{Crystallographic information}

Table S15. Crystallographic information of sulfur targets

\begin{tabular}{|c|c|c|c|c|}
\hline Target code & S6I & S6II & S7 & S8 \\
\hline $\begin{array}{l}\text { CCDC } \\
\text { Number }\end{array}$ & 2089933 & 2089930 & 2089916 & 2089936 \\
\hline $\begin{array}{l}\text { Systematic } \\
\text { name }\end{array}$ & $\begin{array}{c}4,7- \\
\text { bis(chloroethynyl)be } \\
\text { nzo-1,2,5-thiadiazole }\end{array}$ & $\begin{array}{c}4,7- \\
\text { bis(chloroethynyl)be } \\
\text { nzo-1,2,5-thiadiazole }\end{array}$ & $\begin{array}{c}4,7- \\
\text { bis(bromoethynyl)be } \\
\text { nzo-1,2,5-thiadiazole }\end{array}$ & $\begin{array}{c}4,7- \\
\text { bis(iodoethynyl)benz } \\
\text { o-1,2,5-thiadiazole }\end{array}$ \\
\hline $\begin{array}{c}\text { Formula } \\
\text { moiety }\end{array}$ & $\mathrm{C}_{10} \mathrm{H}_{2} \mathrm{Cl}_{2} \mathrm{~N}_{2} \mathrm{~S}$ & $\mathrm{C}_{10} \mathrm{H}_{2} \mathrm{Cl}_{2} \mathrm{~N}_{2} \mathrm{~S}$ & $\mathrm{C}_{10} \mathrm{H}_{2} \mathrm{Br}_{2} \mathrm{~N}_{2} \mathrm{~S}$ & $\mathrm{C}_{10} \mathrm{H}_{2} \mathrm{I}_{2} \mathrm{~N}_{2} \mathrm{~S}$ \\
\hline $\begin{array}{c}\text { Empirical } \\
\text { formula }\end{array}$ & $\mathrm{C}_{10} \mathrm{H}_{2} \mathrm{Cl}_{2} \mathrm{~N}_{2} \mathrm{~S}$ & $\mathrm{C}_{10} \mathrm{H}_{2} \mathrm{Cl}_{2} \mathrm{~N}_{2} \mathrm{~S}$ & $\mathrm{C}_{10} \mathrm{H}_{2} \mathrm{Br}_{2} \mathrm{~N}_{2} \mathrm{~S}$ & $\mathrm{C}_{10} \mathrm{H}_{2} \mathrm{I}_{2} \mathrm{~N}_{2} \mathrm{~S}$ \\
\hline $\begin{array}{c}\text { Molecular } \\
\text { weight }\end{array}$ & 253.10 & 253.10 & 339.38 & 436.00 \\
\hline $\begin{array}{l}\text { Solvent used } \\
\text { for } \\
\text { crystallization }\end{array}$ & THF & THF & THF & THF \\
\hline Color, Habit & Light yellow, Needle & Orange, Needle & Brown, Needle & Orange, Block \\
\hline Crystal system & Monoclinic & Monoclinic & Monoclinic & Monoclinic \\
\hline Space group, $Z$ & $\mathrm{P} 2{ }_{1} / \mathrm{c}, 4$ & $\mathrm{P} 2_{1} / \mathrm{c}, 4$ & $\mathrm{P} 2_{1}, 6$ & $\mathrm{P} 2{ }_{1} / \mathrm{c}, 4$ \\
\hline$a, \AA$ & $13.0257(4)$ & $7.1029(3)$ & $3.87780(10)$ & $7.81350(10)$ \\
\hline$b, \AA$ & $3.81240(10)$ & $19.5481(9)$ & $20.4039(4)$ & $7.86850(10)$ \\
\hline$c, \AA$ & $20.9189(7)$ & $7.4374(3)$ & $19.8682(4)$ & $18.4211(2)$ \\
\hline$\alpha,^{\circ}$ & 90 & 90 & 90 & 90 \\
\hline$\beta,^{\circ}$ & $104.090(3)$ & $101.812(4)$ & $91.071(2)$ & $98.9460(10)$ \\
\hline$\gamma^{\circ}{ }^{o}$ & 90 & 90 & 90 & 90 \\
\hline Volume, $\AA^{3}$ & $1007.56(5)$ & $1010.80(8)$ & $1571.74(6)$ & $1118.76(2)$ \\
\hline Density, $\mathrm{g} / \mathrm{cm}^{3}$ & 1.668 & 1.663 & 2.151 & 2.589 \\
\hline$T,{ }^{\circ} \mathrm{K}$ & $150.00(10)$ & 296.(2) & $150.00(10)$ & 200.(2) \\
\hline $\begin{array}{c}\text { Crystal size, } \\
\text { min x mid x } \\
\max \end{array}$ & $\begin{array}{c}0.154 \mathrm{X} 0.295 \mathrm{X} \\
0.518\end{array}$ & $\begin{array}{c}0.010 \times 0.015 \times \\
0.150\end{array}$ & $0.015 \times 0.02 \times 0.09$ & $\begin{array}{c}0.035 \times 0.035 \times \\
0.040\end{array}$ \\
\hline $\begin{array}{c}\text { X-ray } \\
\text { wavelength, } \AA\end{array}$ & 1.54184 & 1.54178 & 1.54184 & 1.54178 \\
\hline$\mu, \mathrm{mm}^{-1}$ & 7.422 & 7.399 & 11.302 & 45.628 \\
\hline $\begin{array}{c}\text { Trans min / } \\
\max \end{array}$ & $0.75634 / 1.00000$ & $0.40 / 0.93$ & $0.61659 / 1.00000$ & $0.26 / 0.30$ \\
\hline$\theta_{\min },{ }^{\mathbf{o}}$ & 3.498 & 4.52 & 3.105 & 5.73 \\
\hline$\theta_{\max },{ }^{\mathbf{o}}$ & 77.048 & 70.36 & 67.073 & 70.43 \\
\hline \multicolumn{5}{|l|}{ Reflections } \\
\hline collected & 6925 & 9430 & 43332 & 9309 \\
\hline independent & 2095 & 1868 & 5393 & 2099 \\
\hline observed & 1906 & 1463 & 5110 & 1982 \\
\hline $\mathrm{R}_{\mathrm{int}}$ & 0.0242 & 0.0614 & 0.0485 & 0.0372 \\
\hline $\begin{array}{l}\text { Threshold } \\
\text { expression }\end{array}$ & $>2 \sigma(I)$ & $>2 \sigma(I)$ & $>2 \sigma(I)$ & $>2 \sigma(I)$ \\
\hline $\begin{array}{c}\text { No. } \\
\text { parameters }\end{array}$ & 136 & 136 & 691 & 136 \\
\hline No. restraints & 0 & 0 & 817 & 0 \\
\hline $\mathrm{R}_{1}$ (observed) & 0.0455 & 0.0587 & 0.0591 & 0.0249 \\
\hline
\end{tabular}




\begin{tabular}{|c|c|c|c|c|}
\hline $\begin{array}{c}w \mathrm{R}_{2} \text { (all) } \\
\begin{array}{c}\text { Goodness of } \\
\text { fit (all) }\end{array}\end{array}$ & 0.1355 & 0.1568 & 0.1685 & 0.0625 \\
\hline $\begin{array}{c}\rho_{\text {max }}, \rho_{\min }, \mathrm{e} \\
\AA^{-3}\end{array}$ & $0.508,-0.547$ & $0.769,-0.326$ & $1.320,-1.145$ & 1.064 \\
\hline $\begin{array}{c}\text { Completeness } \\
\text { to } 2 \theta \text { limit }\end{array}$ & 0.985 & 0.967 & 0.987 & 0.976 \\
\hline
\end{tabular}

Table S16. Crystallographic information of selenium targets

\begin{tabular}{|c|c|c|c|c|}
\hline Target code & Se3 & Se4 & Se6 & Se7 \\
\hline $\begin{array}{l}\text { CCDC } \\
\text { Number }\end{array}$ & 2089920 & 2089921 & 2089922 & 2089924 \\
\hline $\begin{array}{l}\text { Systematic } \\
\text { name }\end{array}$ & $\begin{array}{l}\text { 4,7-dibromobenzo- } \\
\text { 1,2,5-selenadiazole }\end{array}$ & $\begin{array}{l}\text { 4,7-diiodobenzo- } \\
\text { 1,2,5-selenadiazole }\end{array}$ & $\begin{array}{c}4,7- \\
\text { bis(chloroethynyl)ben } \\
\text { zo- } 1,2,5- \\
\text { selenadiazole } \\
\end{array}$ & $\begin{array}{c}4,7- \\
\text { bis(bromoethynyl)be } \\
\text { nzo-1,2,5- } \\
\text { selenadiazole } \\
\end{array}$ \\
\hline $\begin{array}{l}\text { Formula } \\
\text { moiety }\end{array}$ & $\mathrm{C}_{6} \mathrm{H}_{2} \mathrm{Br}_{2} \mathrm{~N}_{2} \mathrm{Se}$ & $\mathrm{C}_{6} \mathrm{H}_{2} \mathrm{I}_{2} \mathrm{~N}_{2} \mathrm{Se}$ & $\mathrm{C}_{10} \mathrm{H}_{2} \mathrm{Cl}_{2} \mathrm{~N}_{2} \mathrm{Se}$ & $\mathrm{C}_{10} \mathrm{H}_{2} \mathrm{Br}_{2} \mathrm{~N}_{2} \mathrm{Se}$ \\
\hline $\begin{array}{l}\text { Empirical } \\
\text { formula }\end{array}$ & $\mathrm{C}_{6} \mathrm{H}_{2} \mathrm{Br}_{2} \mathrm{~N}_{2} \mathrm{Se}$ & $\mathrm{C}_{6} \mathrm{H}_{2} \mathrm{I}_{2} \mathrm{~N}_{2} \mathrm{Se}$ & $\mathrm{C}_{10} \mathrm{H}_{2} \mathrm{Cl}_{2} \mathrm{~N}_{2} \mathrm{Se}$ & $\mathrm{C}_{10} \mathrm{H}_{2} \mathrm{Br}_{2} \mathrm{~N}_{2} \mathrm{Se}$ \\
\hline $\begin{array}{l}\text { Molecular } \\
\text { weight }\end{array}$ & 340.88 & 434.86 & 300.00 & 388.92 \\
\hline $\begin{array}{l}\text { Solvent used } \\
\text { for } \\
\text { crystallization }\end{array}$ & Dioxane & Dioxane & Dioxane & Chloroform \\
\hline Color, Habit & $\begin{array}{c}\text { Yellow, } \\
\text { Parallelopiped }\end{array}$ & Yellow, Needle & Orange, Plate & Yellow, Needle \\
\hline $\begin{array}{l}\text { Crystal } \\
\text { system }\end{array}$ & Monoclinic & Monoclinic & Monoclinic & Monoclinic \\
\hline $\begin{array}{c}\text { Space group, } \\
Z\end{array}$ & $\mathrm{P} 2{ }_{1} / \mathrm{n}, 4$ & $\mathrm{P} 2_{1} / \mathrm{c}, 4$ & $\mathrm{P} 2_{1} / \mathrm{c}, 4$ & $\mathrm{P} 2{ }_{1} / \mathrm{c}, 4$ \\
\hline$a, \AA$ & $3.9406(2)$ & $4.2684(3)$ & $7.0654(18)$ & $7.2044(5)$ \\
\hline$b, \AA$ & $18.3200(8)$ & $18.1702(11)$ & $19.592(5)$ & 19.8658(13) \\
\hline$c, \AA$ & $11.1353(5)$ & $11.1483(7)$ & $7.4952(19)$ & $7.6339(5)$ \\
\hline$\alpha,{ }^{\circ}$ & 90 & 90 & 90 & 90 \\
\hline$\beta,^{\circ}$ & $94.838(2)$ & $91.013(3)$ & $104.045(8)$ & $105.281(4)$ \\
\hline$\gamma,{ }^{\circ}$ & 90 & 90 & 90 & 90 \\
\hline Volume, $\AA^{3}$ & $801.01(6)$ & $864.50(10)$ & $1006.5(4)$ & 1053.94(12) \\
\hline $\begin{array}{c}\text { Density, } \\
\mathrm{g} / \mathrm{cm}^{3}\end{array}$ & 2.827 & 3.341 & 1.980 & 2.451 \\
\hline$T,{ }^{\circ} \mathrm{K}$ & 296.(2) & $296 .(2)$ & 200.(2) & 199.99 \\
\hline $\begin{array}{l}\text { Crystal size, } \\
\min x \operatorname{mid} x \\
\max \end{array}$ & $\begin{array}{c}0.020 \times 0.065 \mathrm{X} \\
0.125\end{array}$ & $\begin{array}{c}0.082 \times 0.202 \mathrm{X} \\
0.406\end{array}$ & $\begin{array}{c}0.030 \times 0.216 \mathrm{X} \\
0.225\end{array}$ & $0.015 \times 0.1 \times 0.145$ \\
\hline $\begin{array}{c}\text { X-ray } \\
\text { wavelength, } \AA\end{array}$ & 1.54178 & 0.71073 & 1.54178 & 1.54178 \\
\hline$\mu, \mathrm{mm}^{-1}$ & 17.471 & 11.419 & 9.628 & 13.415 \\
\hline $\begin{array}{c}\text { Trans min / } \\
\max \end{array}$ & $0.22 / 0.72$ & $0.09 / 0.45$ & $0.22 / 0.76$ & $0.4969 / 0.7531$ \\
\hline$\theta_{\min },^{\circ}$ & 4.66 & 2.14 & 4.51 & 4.451 \\
\hline$\theta_{\max },{ }^{\mathbf{}}$ & 70.11 & 25.89 & 68.12 & 68.385 \\
\hline
\end{tabular}




\begin{tabular}{|c|c|c|c|c|}
\hline Reflections & & & & \\
\hline collected & 7424 & 20544 & 4967 & 8662 \\
\hline independent & 1500 & 1683 & 1737 & 1884 \\
\hline observed & 1479 & 1504 & 1650 & 1498 \\
\hline $\mathrm{R}_{\text {int }}$ & 0.0453 & 0.0562 & 0.0514 & 0.0853 \\
\hline $\begin{array}{c}\text { Threshold } \\
\text { expression }\end{array}$ & $>2 \sigma(I)$ & $>2 \sigma(I)$ & $>2 \sigma(I)$ & $2 \sigma(I)$ \\
\hline $\begin{array}{c}\text { No. } \\
\text { parameters }\end{array}$ & 100 & 100 & 136 & 136 \\
\hline No. restraints & 0 & 0 & 0 & 0 \\
\hline $\mathrm{R}_{1}$ (observed) & 0.0443 & 0.0253 & 0.0540 & 0.0574 \\
\hline$w \mathrm{R}_{2}$ (all) & 0.1228 & 0.0659 & 0.1483 & 1.091 \\
\hline $\begin{array}{c}\text { Goodness of } \\
\text { fit (all) }\end{array}$ & 1.187 & 1.088 & 1.084 & $1.381,-0.994$ \\
\hline $\begin{array}{c}\rho_{\text {max }}, \rho_{\text {min }}, \mathrm{e} \\
\AA^{-3}\end{array}$ & $1.165,-1.066$ & $0.564,-1.213$ & $0.973,-1.386$ & 0.970 \\
\hline $\begin{array}{c}\text { Completeness } \\
\text { to } 2 \theta \text { limit }\end{array}$ & 0.985 & 0.999 & 0.949 & \\
\hline
\end{tabular}


7 RIMP2/Def2-TZVP optimized dimer xyz coordinates

\subsection{4,7-difluorobenzo-1,2,5-thiadiazole (S1)}

26

SF-dimer-nonactivated-ChB (S1) E(RIMP2/Def2-TZVP)= -1871.6726332549 hartree N 3.03201 .57030 .0000

$\mathrm{N}-3.0320-1.57030 .0000$

N $1.4240-0.36180 .0000$

$\mathrm{N}-1.42400 .36180 .0000$

C 3.64770 .35690 .0000

C $-3.6477-0.35690 .0000$

C $2.7306-0.74280 .0000$

C - 2.73060 .74280 .0000

S 1.44911 .25670 .0000

S - $1.4491-1.25670 .0000$

C 5.03150 .10410 .0000

C $-5.0315-0.10410 .0000$

C $3.2221-2.05970 .0000$

C -3.2221 2.05970 .0000

C $5.4832-1.19250 .0000$

C -5.48321 .19250 .0000$

C $4.5772-2.27780 .0000$

C - 4.57722 .27780 .0000

F 5.88661 .13000 .0000

F -5.8866 - 1.13000 .0000

F 2.3582 -3.0805 0.0000

F -2.3582 3.08050 .0000

H $6.5511-1.37390 .0000$

$\mathrm{H}-6.55111 .37390 .0000$

H 4.9453 -3.2965 0.0000

H -4.9453 3.2965 0.0000

26

SF-dimer-nonactivated-XB (S1) E(RIMP2/Def2-TZVP) $=-1871.6648248653$ hartree

$\mathrm{N} 2.08073 .60660 .0000$

$\mathrm{N}-2.0807-3.60660 .0000$

$\mathrm{N} 0.89761 .37910 .0000$

$\mathrm{N}-0.8976-1.37910 .0000$

C 2.92862 .54000 .0000

C $-2.9286-2.54000 .0000$

C 2.25491 .27390 .0000

C $-2.2549-1.27390 .0000$

S 0.60122 .96180 .0000

S $-0.6012-2.96180 .0000$ 


$$
\begin{aligned}
& \text { C } 4.33442 .57900 .0000 \\
& \text { C - } 4.3344-2.57900 .0000 \\
& \text { C } 3.01090 .08750 .0000 \\
& \text { C -3.0109-0.0875 } 0.0000 \\
& \text { C } 5.04521 .40450 .0000 \\
& \text { C }-5.0452-1.40450 .0000 \\
& \text { C } 4.38190 .15650 .0000 \\
& \text { C -4.3819 -0.15650.0000 } \\
& \text { F 4.95893.75970.0000 } \\
& \text { F -4.9589 -3.7597 } 0.0000 \\
& \text { F } 2.3853-1.09500 .0000 \\
& \text { F-2.3853 } 1.09500 .0000 \\
& \text { H } 6.12761 .44730 .0000 \\
& \text { H -6.1276 - } 1.44730 .0000 \\
& \text { H } 4.9523-0.76440 .0000 \\
& \mathrm{H}-4.95230 .76440 .0000
\end{aligned}
$$

\subsection{4,7-dichlorobenzo-1,2,5-thiadiazole (S2)}

26

SCl-dimer-nonactivated-ChB (S2) E(RIMP2/Def2-TZVP) $=-3311.5865949694$ hartree N 3.01761 .57490 .0000

$\mathrm{N}-3.0176-1.57490 .0000$

$\mathrm{N} 1.4097-0.35650 .0000$

$\mathrm{N}-1.40970 .35650 .0000$

C 3.63460 .36200 .0000

C $-3.6346-0.36200 .0000$

C $2.7156-0.73900 .0000$

C -2.71560 .73900 .0000$

S 1.43421 .26220 .0000

$\mathrm{S}-1.4342-1.26220 .0000$

C 5.02220 .12260 .0000

C $-5.0222-0.12260 .0000$

C $3.1924-2.06270 .0000$

C -3.19242.06270.0000

C $5.4618-1.18780 .0000$

C -5.46181 .18780 .0000$

C $4.5584-2.26890 .0000$

C -4.5584 2.26890 .0000

$\mathrm{Cl} 6.12151 .43860 .0000$

Cl -6.1215 -1.4386 0.0000

Cl 2.0812 -3.3714 0.0000

$\mathrm{Cl}-2.08123 .37140 .0000$

H $6.5277-1.38400 .0000$

$\mathrm{H}-6.52771 .38400 .0000$

H $4.9389-3.28370 .0000$ 
H -4.9389 3.28370 .0000

26

SCl-dimer-nonactivated-XB (S2) E(RIMP2/Def2-TZVP)= -3311.5801975907 hartree

N 2.74854 .27750 .0000

$\mathrm{N}-2.7485-4.27750 .0000$

$\mathrm{N} 1.07832 .38900 .0000$

$\mathrm{N}-1.0783-2.38900 .0000$

C 3.32513 .04240 .0000

C $-3.3251-3.04240 .0000$

C 2.37521 .96600 .0000

C - $2.3752-1.96600 .0000$

S 1.16153 .99910 .0000

S - $1.1615-3.99910 .0000$

C 4.70592 .76770 .0000

C - $4.7059-2.76770 .0000$

C 2.81560 .62770 .0000

C $-2.8156-0.62770 .0000$

C 5.11051 .44660 .0000

C -5.1105 -1.4466 0.0000

C 4.17780 .39140 .0000

C $-4.1778-0.39140 .0000$

Cl 5.83924 .05520 .0000

$\mathrm{Cl}-5.8392-4.05520 .0000$

Cl $1.6702-0.64530 .0000$

$\mathrm{Cl}-1.67020 .64530 .0000$

H 6.17091 .22230 .0000

H $-6.1709-1.22230 .0000$

H $4.5315-0.63310 .0000$

H -4.53150 .63310 .0000$

7.3 4,7-dibromobenzo-1,2,5-thiadiazole (S3)

26

SBr-dimer-nonactivated-ChB (S3) E(RIMP2/Def2-TZVP)= -11763.1099574818 hartree

N 3.01661 .57160 .0000

$\mathrm{N}-3.0166-1.57160 .0000$

$\mathrm{N} 1.4112-0.36220 .0000$

$\mathrm{N}-1.41120 .36220 .0000$

C 3.63640 .36010 .0000

C $-3.6364-0.36010 .0000$

C $2.7174-0.74420 .0000$

C -2.71740 .74420 .0000$

S 1.43351 .25680 .0000

$\mathrm{S}-1.4335-1.25680 .0000$

C 5.02320 .12190 .0000 


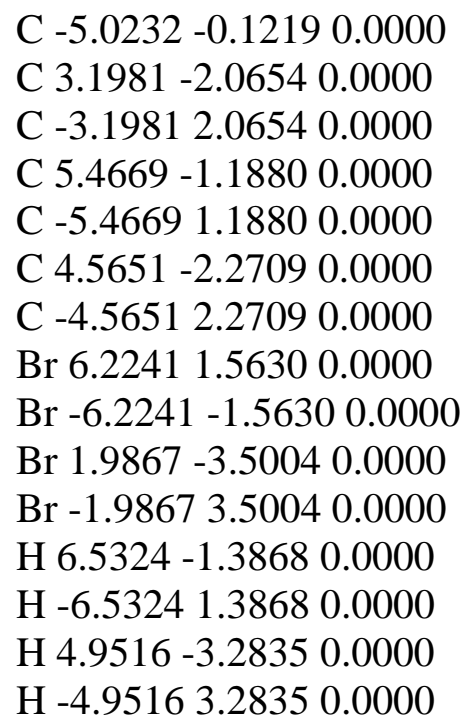

26

SBr-dimer-nonactivated-XB (S3) E(RIMP2/Def2-TZVP)= -11763.1041263003 hartree N 2.82634.3054 0.0000

$\mathrm{N}-2.8263-4.30540 .0000$

$\mathrm{N} 1.18422 .39240 .0000$

$\mathrm{N}-1.1842-2.39240 .0000$

C 3.42213 .07930 .0000

C $-3.4221-3.07930 .0000$

C 2.48751 .98680 .0000

C - $2.4875-1.98680 .0000$

S 1.24374 .00410 .0000

S - $1.2437-4.00410 .0000$

C 4.80592 .82510 .0000

C $-4.8059-2.82510 .0000$

C 2.94990 .65670 .0000

C $-2.9499-0.65670 .0000$

C 5.23281 .51000 .0000

C $-5.2328-1.51000 .0000$

C 4.31620 .44030 .0000

C -4.3162 -0.44030.0000

Br 6.0245 4.25180.0000

$\mathrm{Br}-6.0245-4.25180 .0000$

Br $1.7144-0.75310 .0000$

Br - 1.71440 .75310 .0000

H 6.29581 .29790 .0000

H -6.2958 -1.2979 0.0000

H $4.6899-0.57720 .0000$

H -4.6899 0.57720 .0000 


\subsection{4,7-diiodobenzo-1,2,5-thiadiazole (S4)}

26

SI-dimer-nonactivated-ChB (S4) E(RIMP2/Def2-TZVP)= -2659.9966515151 hartree

$\mathrm{N} 3.02241 .55450 .0000$

$\mathrm{N}-3.0224-1.55450 .0000$

N $1.4252-0.38530 .0000$

$\mathrm{N}-1.42520 .38530 .0000$

C 3.64910 .34580 .0000

C $-3.6491-0.34580 .0000$

C $2.7339-0.76430 .0000$

C -2.73390.76430.0000

S 1.44091 .23380 .0000

S $-1.4409-1.23380 .0000$

C 5.03800 .12120 .0000

C $-5.0380-0.12120 .0000$

C $3.2188-2.08430 .0000$

C -3.2188 2.08430.0000

C $5.4866-1.18980 .0000$

C -5.48661 .18980 .0000$

C $4.5907-2.27720 .0000$

C -4.5907 2.27720.0000

I 6.35651 .72610 .0000

I -6.3565 - 1.72610 .0000

I $1.8927-3.68500 .0000$

I - 1.89273 .68500 .0000

H $6.5522-1.39020 .0000$

H -6.5522 1.39020 .0000

H $4.9901-3.28520 .0000$

H -4.99013.28520.0000

26

SI-dimer-nonactivated-XB (S4) E(RIMP2/Def2-TZVP)= -2659.9909479417 hartree

N 2.94924 .34590 .0000

$\mathrm{N}-2.9492-4.34590 .0000$

$\mathrm{N} 1.34322 .40360 .0000$

$\mathrm{N}-1.3432-2.40360 .0000$

C 3.56963 .13120 .0000

C $-3.5696-3.13120 .0000$

C 2.65482 .01930 .0000

C - $2.6548-2.01930 .0000$

S 1.37284 .01670 .0000

S - $1.3728-4.01670 .0000$

C 4.95892 .90960 .0000

C $-4.9589-2.90960 .0000$

C 3.13890 .69690 .0000 
C $-3.1389-0.69690 .0000$

C 5.40811 .59920 .0000

C $-5.4081-1.59920 .0000$

C 4.51260 .51200 .0000

C $-4.5126-0.51200 .0000$

I 6.27614 .51590 .0000

I $-6.2761-4.51590 .0000$

I $1.7973-0.88830 .0000$

I - 1.79730 .88830 .0000

H 6.47401 .39990 .0000

$\mathrm{H}-6.4740-1.39990 .0000$

H $4.9137-0.49540 .0000$

H -4.9137 0.49540 .0000

\subsection{4,7-difluorobenzo-1,2,5-selenadiazole (Se1)}

26

SeF-dimer-nonactivated-ChB (Se1) E(RIMP2/Def2-TZVP) $=-5876.2216996346$ hartree N 3.07511 .63960 .0000

$\mathrm{N}-3.0751-1.63960 .0000$

$\mathrm{N} 1.3613-0.37150 .0000$

$\mathrm{N}-1.36130 .37150 .0000$

C 3.61210 .39110 .0000

C $-3.6121-0.39110 .0000$

C $2.6804-0.70110 .0000$

C - 2.68040 .70110 .0000

Se 1.31801 .40790 .0000

Se $-1.3180-1.40790 .0000$

C 4.99380 .10650 .0000

C $-4.9938-0.10650 .0000$

C $3.1645-2.02360 .0000$

C -3.16452 .02360 .0000$

C $5.4328-1.19370 .0000$

C -5.4328 1.19370 .0000

C $4.5141-2.26770 .0000$

C - 4.51412 .26770 .0000

F 5.86441 .12040 .0000

F -5.8644 -1.1204 0.0000

F 2.2822 -3.0318 0.0000

F -2.2822 3.03180 .0000

H $6.4990-1.38540 .0000$

H -6.4990 1.38540 .0000

H 4.8651 -3.2924 0.0000

H -4.8651 3.2924 0.0000 


\subsection{4,7-dichlorobenzo-1,2,5-selenadiazole (Se2)}

26

SeCl-dimer-nonactivated-ChB (Se2) E(RIMP2/Def2-TZVP)= -7316.1359690168 hartree N 3.06781 .63390 .0000

$\mathrm{N}-3.0678-1.63390 .0000$

N $1.3592-0.38000 .0000$

$\mathrm{N}-1.35920 .38000 .0000$

C 3.61040 .38720 .0000

C -3.6104 -0.38720.0000

C $2.6793-0.70970 .0000$

C -2.67930.70970.0000

Se 1.31181 .39880 .0000

$\mathrm{Se}-1.3118-1.39880 .0000$

C 4.99720 .12100 .0000

C -4.9972 -0.1210 0.0000

C $3.1564-2.03620 .0000$

C -3.15642.03620.0000

C $5.4300-1.19120 .0000$

C -5.43001 .19120 .0000$

C $4.5185-2.26310 .0000$

C -4.51852.26310.0000

Cl 6.11321 .42440 .0000

$\mathrm{Cl}-6.1132-1.42440 .0000$

Cl 2.0358 -3.3407 0.0000

$\mathrm{Cl}-2.03583 .34070 .0000$

H 6.4949 -1.3931 0.0000

H -6.4949 1.39310 .0000

H $4.8853-3.28290 .0000$

H -4.8853 3.28290 .0000

26

SeCl-dimer-nonactivated-XB (Se2) E(RIMP2/Def2-TZVP) = -7316.1218979016 hartree N 2.84394 .33340 .0000

$\mathrm{N}-2.8439-4.33340 .0000$

$\mathrm{N} 1.06542 .35550 .0000$

$\mathrm{N}-1.0654-2.35550 .0000$

C 3.34213 .06500 .0000

C $-3.3421-3.06500 .0000$

C 2.38021 .99290 .0000

C -2.3802 -1.99290.0000

Se 1.08644 .12590 .0000

$\mathrm{Se}-1.0864$-4.1259 0.0000

C 4.72202 .76590 .0000

C $-4.7220-2.76590 .0000$

C 2.82250 .65110 .0000 
C $-2.8225-0.65110 .0000$

C 5.12111 .44390 .0000

C -5.1211 -1.44390.0000

C 4.18080 .39760 .0000

C $-4.1808-0.39760 .0000$

Cl 5.87034 .04160 .0000

$\mathrm{Cl}-5.8703-4.04160 .0000$

Cl $1.6675-0.61500 .0000$

$\mathrm{Cl}-1.66750 .61500 .0000$

H 6.18051 .21490 .0000

H $-6.1805-1.21490 .0000$

H $4.5223-0.63100 .0000$

H -4.52230.6310 0.0000

\subsection{4,7-dibromobenzo-1,2,5-selenadiazole (Se3)}

26

SeBr-dimer-nonactivated-ChB (Se3) E(RIMP2/Def2-TZVP) $=-15767.6593996104$ hartree N 3.07631 .62490 .0000

$\mathrm{N}-3.0763-1.62490 .0000$

N $1.3708-0.39290 .0000$

$\mathrm{N}-1.37080 .39290 .0000$

C 3.62270 .37950 .0000

C $-3.6227-0.37950 .0000$

C $2.6923-0.72160 .0000$

C -2.69230.72160.0000

Se 1.32131 .38610 .0000

Se $-1.3213-1.38610 .0000$

C 5.00890 .11710 .0000

C -5.0089 -0.1171 0.0000

C $3.1767-2.04440 .0000$

C -3.1767 2.04440 .0000

C $5.4486-1.19380 .0000$

C -5.4486 1.19380 .0000

C $4.5405-2.26830 .0000$

C -4.5405 2.26830.0000

Br 6.22591 .54630 .0000

Br -6.2259 - 1.54630 .0000

Br 1.9625 -3.4809 0.0000

Br - 1.96253 .48090 .0000

H $6.5135-1.39640 .0000$

H -6.5135 1.39640 .0000

H $4.9145-3.28560 .0000$

H -4.9145 3.2856 0.0000 
SeBr-dimer-nonactivated-XB (Se3) E(RIMP2/Def2-TZVP) $=-15767.6460438493$ hartree N 2.91884 .36200 .0000

$\mathrm{N}-2.9188-4.36200 .0000$

$\mathrm{N} 1.16972 .35820 .0000$

$\mathrm{N}-1.1697-2.35820 .0000$

C 3.43713 .10110 .0000

C $-3.4371-3.10110 .0000$

C 2.49042 .01260 .0000

C $-2.4904-2.01260 .0000$

Se 1.16504 .12900 .0000

Se $-1.1650-4.12900 .0000$

C 4.82002 .82230 .0000

C $-4.8200-2.82230 .0000$

C 2.95490 .67950 .0000

C $-2.9549-0.67950 .0000$

C 5.24191 .50610 .0000

C $-5.2419-1.50610 .0000$

C 4.31770 .44550 .0000

C $-4.3177-0.44550 .0000$

Br 6.0564 4.2356 0.0000

Br -6.0564 -4.2356 0.0000

Br $1.7092-0.72350 .0000$

$\mathrm{Br}-1.70920 .72350 .0000$

H 6.30401 .28960 .0000

$\mathrm{H}-6.3040-1.28960 .0000$

H $4.6791-0.57650 .0000$

H -4.67910.57650.0000

\subsection{4,7-diiodobenzo-1,2,5-selenadiazole (Se4)}

26

SeI-dimer-nonactivated-ChB (Se4) E(RIMP2/Def2-TZVP) $=-6664.5456564155$ hartree N 3.09441 .60440 .0000

$\mathrm{N}-3.0944-1.60440 .0000$

N $1.3965-0.42090 .0000$

$\mathrm{N}-1.39650 .42090 .0000$

C 3.64780 .36110 .0000

C $-3.6478-0.36110 .0000$

C $2.7210-0.74630 .0000$

C -2.72100 .74630 .0000$

Se 1.34131 .35820 .0000

Se $-1.3413-1.35820 .0000$

C 5.03620 .11350 .0000

C -5.0362 -0.11350.0000

C $3.2117-2.06690 .0000$

C -3.2117 2.06690 .0000 
C $5.4822-1.19800 .0000$

C -5.48221 .19800 .0000$

C $4.5809-2.27720 .0000$

C -4.58092 .27720 .0000$

I 6.37131 .70660 .0000

I -6.3713 -1.7066 0.0000

I $1.8890-3.67400 .0000$

I - 1.88903 .67400 .0000

H $6.5472-1.40160 .0000$

H -6.5472 1.40160 .0000

H $4.9690-3.28960 .0000$

H -4.9690 3.28960 .0000

26

SeI-dimer-nonactivated-XB (Se4) E(RIMP2/Def2-TZVP) $=-6664.5328596384$ hartree

N 3.04224 .40530 .0000

$\mathrm{N}-3.0422-4.40530 .0000$

N 1.33062 .37090 .0000

$\mathrm{N}-1.3306-2.37090 .0000$

C 3.58563 .15400 .0000

C $-3.5856-3.15400 .0000$

C 2.65852 .04630 .0000

C $-2.6585-2.04630 .0000$

Se 1.29364 .14190 .0000

Se $-1.2936-4.14190 .0000$

C 4.97432 .90750 .0000

C $-4.9743-2.90750 .0000$

C 3.14520 .72110 .0000

C $-3.1452-0.72110 .0000$

C 5.41891 .59600 .0000

C $-5.4189-1.59600 .0000$

C 4.51570 .51790 .0000

C $-4.5157-0.51790 .0000$

I 6.31204 .49900 .0000

I $-6.3120-4.49900 .0000$

I $1.7926-0.85700 .0000$

I -1.79260 .85700 .0000$

H 6.48391 .39230 .0000

H -6.4839 - 1.39230 .0000

H $4.9041-0.49440 .0000$

H -4.9041 0.49440 .0000

\subsection{4,7-difluorobenzo-1,2,5-telluradiazole (Te1)}

26

TeF-dimer-nonactivated-ChB (Te1) E(RIMP2/Def2-TZVP)= -1610.5021978212 hartree 
N 3.12091 .58360 .0000

N -3.1209 - 1.58360 .0000

N $1.2603-0.42600 .0000$

$\mathrm{N}-1.26030 .42600 .0000$

C 3.55200 .29950 .0000

C $-3.5520-0.29950 .0000$

C $2.5744-0.76390 .0000$

C - 2.57440 .76390 .0000

Te 1.16141 .54430 .0000

$\mathrm{Te}-1.1614-1.54430 .0000$

C $4.9203-0.06420 .0000$

C -4.92030 .06420 .0000$

C $3.0122-2.10390 .0000$

C -3.01222 .10390 .0000$

C $5.3070-1.38000 .0000$

C -5.3070 1.38000 .0000

C $4.3460-2.41610 .0000$

C -4.34602 .41610 .0000$

F 5.84000 .90750 .0000

F -5.8400 -0.9075 0.0000

F 2.0805 -3.0730 0.0000

F -2.0805 3.07300 .0000

H $6.3649-1.61340 .0000$

$\mathrm{H}-6.36491 .61340 .0000$

H $4.6498-3.45570 .0000$

H -4.6498 3.4557 0.0000

\subsection{4,7-dichlorobenzo-1,2,5-telluradiazole (Te2)}

26

TeCl-dimer-nonactivated-ChB (Te2) E(RIMP2/Def2-TZVP) $=-3050.4152213089$ hartree N 3.14841 .57000 .0000

$\mathrm{N}-3.1484-1.57000 .0000$

N $1.2950-0.45200 .0000$

$\mathrm{N}-1.29500 .45200 .0000$

C 3.59000 .28770 .0000

C $-3.5900-0.28770 .0000$

C $2.6160-0.78540 .0000$

C -2.61600 .78540 .0000$

Te 1.19541 .51690 .0000

$\mathrm{Te}-1.1954-1.51690 .0000$

C $4.9676-0.04430 .0000$

C -4.96760 .04430 .0000$

C $3.0659-2.12390 .0000$

C -3.06592 .12390 .0000$ 
C $5.3621-1.36760 .0000$

C -5.36211 .36760 .0000$

C $4.4170-2.40670 .0000$

C -4.4170 2.40670 .0000

Cl 6.13501 .21600 .0000

Cl -6.1350 - 1.21600 .0000

Cl $1.9152-3.40850 .0000$

Cl -1.9152 3.4085 0.0000

H $6.4203-1.60210 .0000$

H -6.4203 1.60210 .0000

H $4.7436-3.43990 .0000$

H -4.7436 3.43990 .0000

26

TeCl-dimer-nonactivated-XB (Te2) E(RIMP2/Def2-TZVP)= -3050.3860998042 hartree N 2.93754 .38730 .0000

$\mathrm{N}-2.9375-4.38730 .0000$

N 1.05272 .32770 .0000

$\mathrm{N}-1.0527-2.32770 .0000$

C 3.36083 .08870 .0000

C $-3.3608-3.08870 .0000$

C 2.38462 .01980 .0000

C $-2.3846-2.01980 .0000$

Te 0.98724 .28000 .0000

$\mathrm{Te}-0.9872-4.28000 .0000$

C 4.73832 .76220 .0000

C $-4.7383-2.76220 .0000$

C 2.82930 .67500 .0000

C $-2.8293-0.67500 .0000$

C 5.13201 .43860 .0000

C $-5.1320-1.43860 .0000$

C 4.18370 .40250 .0000

C $-4.1837-0.40250 .0000$

Cl 5.90594 .02290 .0000

Cl -5.9059-4.0229 0.0000

Cl $1.6652-0.58540 .0000$

Cl -1.6652 0.58540 .0000

H 6.19031 .20450 .0000

H -6.1903 - 1.20450 .0000

H $4.5121-0.63050 .0000$

H - 4.51210 .63050 .0000

\subsection{4,7-dibromobenzo-1,2,5-telluradiazole (Te3)}

26

TeBr-dimer-nonactivated-ChB (Te3) E(RIMP2/Def2-TZVP)= -11501.9380295246 hartree 


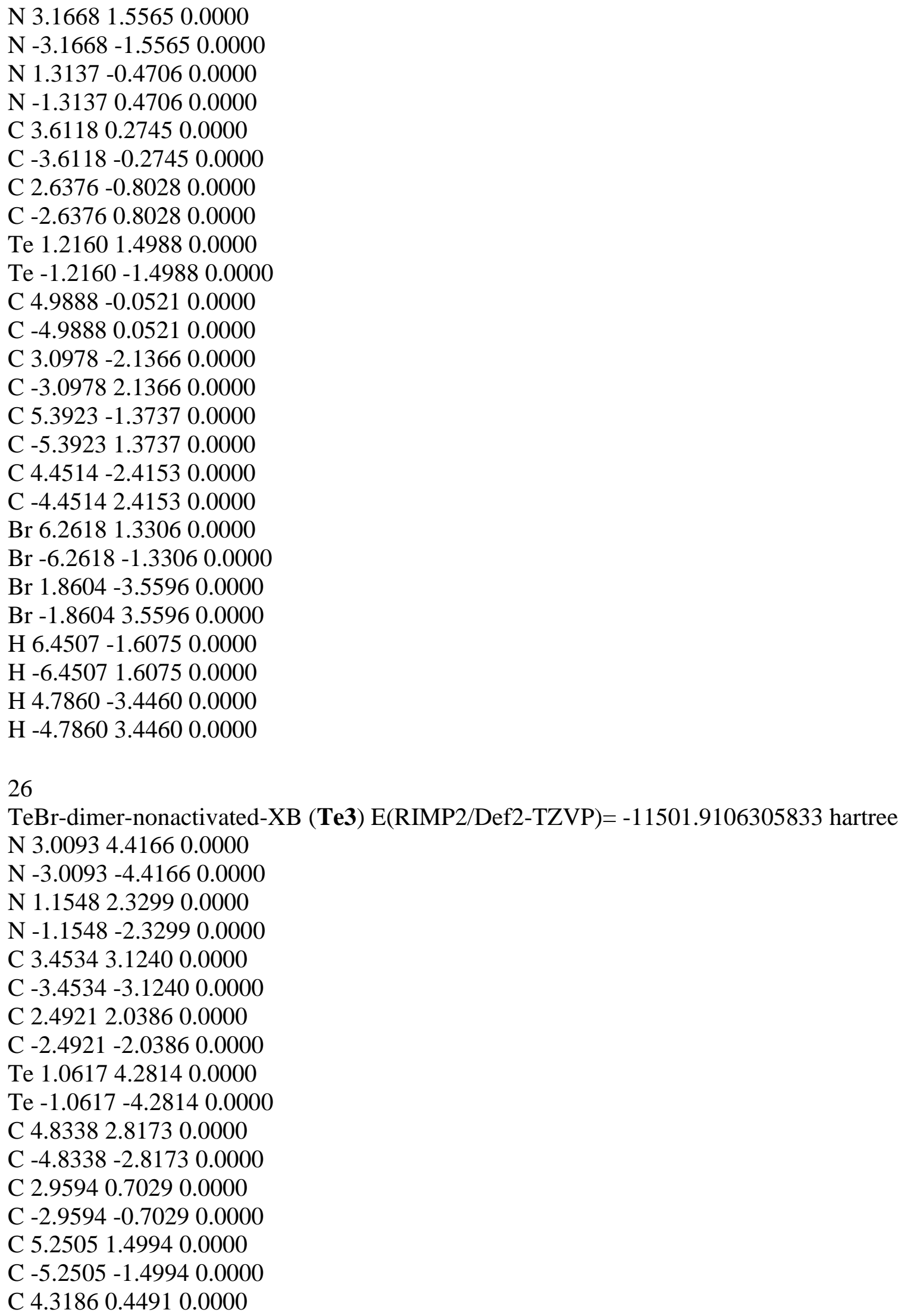


C $-4.3186-0.44910 .0000$

$\mathrm{Br} 6.09294 .21350 .0000$

Br $-6.0929-4.21350 .0000$

Br $1.7034-0.69410 .0000$

$\mathrm{Br}-1.70340 .69410 .0000$

H 6.31161 .27780 .0000

$\mathrm{H}-6.3116-1.27780 .0000$

H $4.6664-0.57760 .0000$

$\mathrm{H}-4.66640 .57760 .0000$

\subsection{4,7-diiodobenzo-1,2,5-telluradiazole (Te4)}

26

TeI-dimer-nonactivated-ChB (Te4) E(RIMP2/Def2-TZVP) $=-2398.8225588176$ hartree N 3.20011 .53200 .0000

$\mathrm{N}-3.2001-1.53200 .0000$

N $1.3481-0.50300 .0000$

$\mathrm{N}-1.34810 .50300 .0000$

C 3.64940 .24950 .0000

C -3.6494-0.2495 0.0000

C $2.6768-0.83260 .0000$

C -2.6768 0.83260.0000

Te 1.25211 .46650 .0000

$\mathrm{Te}-1.2521-1.46650 .0000$

C $5.0290-0.06180 .0000$

C -5.0290 0.06180 .0000

C $3.1451-2.16410 .0000$

C -3.14512 .16410 .0000$

C $5.4400-1.38380 .0000$

C -5.44001 .38380 .0000$

C $4.5053-2.42920 .0000$

C -4.50532 .42920 .0000$

I 6.42381 .48200 .0000

I -6.4238 -1.48200 .0000$

I $1.8108-3.76710 .0000$

I -1.81083 .76710 .0000$

H $6.4986-1.61840 .0000$

$\mathrm{H}-6.49861 .61840 .0000$

H $4.8540-3.45560 .0000$

$\mathrm{H}-4.85403 .45560 .0000$

26

TeI-dimer-nonactivated-XB (Te4) E(RIMP2/Def2-TZVP)= -2398.7975773736 hartree

N 3.13164 .46120 .0000

$\mathrm{N}-3.1316-4.46120 .0000$

N 1.31492 .34260 .0000 


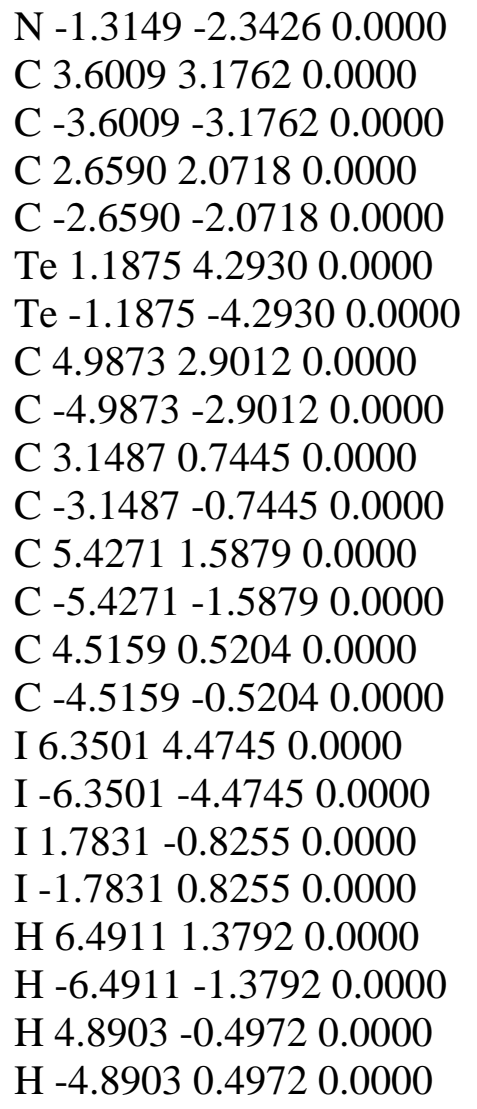

7.13 4,7-bis(fluoroethynyl)benzo-1,2,5-thiadiazole (S5)

34

SF-dimer-activated-ChB (S5) E(RIMP2/Def2-TZVP)= -2175.5516941072 hartree N 3.18551 .20640 .0000

$\mathrm{N}-3.1855-1.20640 .0000$

$\mathrm{N} 1.3557-0.51710 .0000$

$\mathrm{N}-1.35570 .51710 .0000$

C 3.6504-0.0745 0.0000

C -3.65040.0745 0.0000

C $2.6079-1.05290 .0000$

C - 2.60791 .05290 .0000

S 1.57451 .08750 .0000

$\mathrm{S}-1.5745-1.08750 .0000$

C $5.0116-0.46370 .0000$

C -5.01160 .46370 .0000$

C $2.9003-2.43720 .0000$

C -2.90032 .43720 .0000$

C $5.2713-1.83250 .0000$

C -5.27131 .83250 .0000$

C $4.2466-2.79230 .0000$

C -4.2466 2.79230.0000 


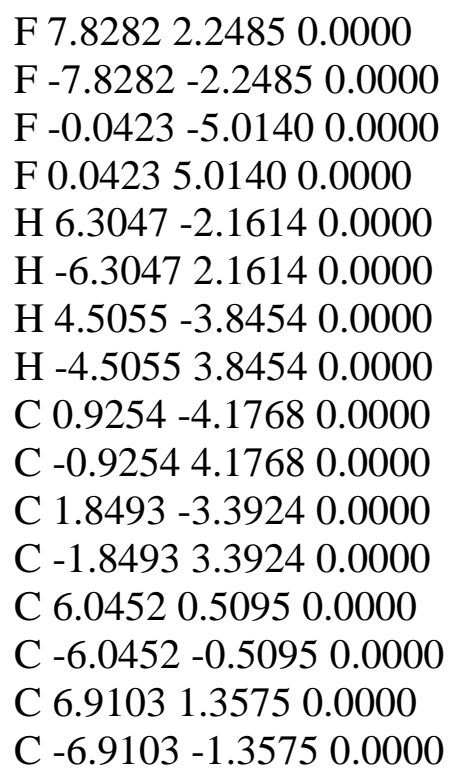

34

SF-dimer-activated-XB (S5) E(RIMP2/Def2-TZVP) $=-2175.5432015477$ hartree $\mathrm{N} 3.54185 .00890 .0000$

$\mathrm{N}-3.5418-5.00890 .0000$

$\mathrm{N} 1.84173 .14700 .0000$

$\mathrm{N}-1.8417-3.14700 .0000$

C 4.09793 .76300 .0000

C $-4.0979-3.76300 .0000$

C 3.13302 .70580 .0000

C $-3.1330-2.70580 .0000$

S 1.94934 .75610 .0000

S - $1.9493-4.75610 .0000$

C 5.48603 .48490 .0000

C $-5.4860-3.48490 .0000$

C 3.53661 .34860 .0000

C - $3.5366-1.34860 .0000$

C 5.85422 .14200 .0000

C $-5.8542-2.14200 .0000$

C 4.90811 .10550 .0000

C - $4.9081-1.10550 .0000$

F 8.07876 .41200 .0000

F -8.0787 -6.4120 0.0000

F $0.8714-1.51050 .0000$

F - 0.87141 .51050 .0000

H 6.91051 .89620 .0000

H -6.9105 -1.8962 0.0000

H 5.24920 .07610 .0000

H -5.2492 -0.0761 0.0000

C 6.43804 .53810 .0000 
C $-6.4380-4.53810 .0000$

C 7.23375 .45150 .0000

C - $7.2337-5.45150 .0000$

C 2.57720 .30280 .0000

C $-2.5772-0.30280 .0000$

C $1.7457-0.57940 .0000$

C - 1.74570 .57940 .0000

\subsection{4,7-bis(chloroethynyl)benzo-1,2,5-thiadiazole (S6)}

34

SCl-dimer-activated-ChB (S6) E(RIMP2/Def2-TZVP)= -3615.5237116298 hartree

N 3.18341 .24310 .0000

$\mathrm{N}-3.1834-1.24310 .0000$

$\mathrm{N} 1.3514-0.47830 .0000$

$\mathrm{N}-1.35140 .47830 .0000$

C $3.6458-0.03870 .0000$

C -3.64580 .03870 .0000$

C $2.6020-1.01420 .0000$

C -2.60201 .01420 .0000$

S 1.57071 .12650 .0000

S - $1.5707-1.12650 .0000$

C $5.0059-0.43620 .0000$

C -5.00590.43620.0000

C $2.8860-2.40130 .0000$

C -2.8860 2.40130 .0000

C $5.2589-1.80940 .0000$

C -5.2589 1.80940 .0000

C $4.2322-2.76480 .0000$

C -4.2322 2.76480 .0000

Cl 8.1075 2.4921 0.0000

$\mathrm{Cl}-8.1075-2.49210 .0000$

Cl -0.4611 -5.0429 0.0000

Cl 0.46115 .04290 .0000

H 6.2916 -2.1412 0.0000

$\mathrm{H}-6.29162 .14120 .0000$

H $4.4860-3.81920 .0000$

$\mathrm{H}-4.48603 .81920 .0000$

C $0.8438-4.06700 .0000$

C -0.84384 .06700 .0000$

C $1.8197-3.33190 .0000$

C - 1.81973 .33190 .0000

C 6.04310 .52640 .0000

C -6.0431 -0.5264 0.0000

C 6.92841 .36750 .0000

C -6.9284 -1.36750.0000 
34

SCl-dimer-activated-XB (S6) E(RIMP2/Def2-TZVP)= -3615.5204224955 hartree

N 3.65495.06970.0000

$\mathrm{N}-3.6549-5.06970 .0000$

$\mathrm{N} 1.97813 .18840 .0000$

$\mathrm{N}-1.9781-3.18840 .0000$

C 4.22563 .83070 .0000

C $-4.2256-3.83070 .0000$

C 3.27512 .76100 .0000

C - $3.2751-2.76100 .0000$

S 2.06584 .80050 .0000

S - $2.0658-4.80050 .0000$

C 5.61863 .57150 .0000

C $-5.6186-3.57150 .0000$

C 3.69671 .40730 .0000

C -3.6967-1.40730.0000

C 6.00482 .23110 .0000

C $-6.0048-2.23110 .0000$

C 5.07431 .18340 .0000

C -5.0743 -1.18340.0000

Cl 8.41986 .78820 .0000

$\mathrm{Cl}-8.4198-6.78820 .0000$

$\mathrm{Cl} 0.7255-1.64850 .0000$

$\mathrm{Cl}-0.72551 .64850 .0000$

H 7.0647 2.0008 0.0000

H -7.0647 -2.0008 0.0000

H 5.42790 .15810 .0000

H -5.4279 -0.1581 0.0000

C 6.55424 .63290 .0000

C -6.5542 -4.63290.0000

C 7.35435 .55530 .0000

C $-7.3543-5.55530 .0000$

C 2.75100 .35650 .0000

C - $2.7510-0.35650 .0000$

C $1.9040-0.52510 .0000$

C - 1.90400 .52510 .0000

\subsection{4,7-bis(bromoethynyl)benzo-1,2,5-thiadiazole (S7)}

34

SBr-dimer-activated-ChB (S7) E(RIMP2/Def2-TZVP)= -12067.0493815237 hartree N 3.18171 .24980 .0000

$\mathrm{N}-3.1817-1.24980 .0000$

$\mathrm{N} 1.3501-0.47230 .0000$

$\mathrm{N}-1.35010 .47230 .0000$ 


$$
\begin{array}{lll}
\text { C } 3.6442 & -0.0319 & 0.0000 \\
\text { C }-3.6442 & 0.0319 & 0.0000 \\
\text { C } 2.6006 & -1.0074 & 0.0000 \\
\text { C }-2.6006 & 1.0074 & 0.0000 \\
\text { S } 1.5686 & 1.1329 & 0.0000 \\
\text { S }-1.5686 & -1.1329 & 0.0000 \\
\text { C } 5.0042 & -0.4304 & 0.0000 \\
\text { C }-5.0042 & 0.4304 & 0.0000 \\
\text { C } 2.8843 & -2.3948 & 0.0000 \\
\text { C }-2.8843 & 2.3948 & 0.0000 \\
\text { C } 5.2572 & -1.8042 & 0.0000 \\
\text { C }-5.2572 & 1.8042 & 0.0000 \\
\text { C } 4.2306 & -2.7593 & 0.0000 \\
\text { C }-4.2306 & 2.7593 & 0.0000 \\
\text { Br } 8.2228 & 2.6033 & 0.0000 \\
\text { Br }-8.2228 & -2.6033 & 0.0000 \\
\text { Br }-0.6181 & -5.0919 & 0.0000 \\
\text { Br } 0.6181 & 5.0919 & 0.0000 \\
\text { H } 6.2899 & -2.1358 & 0.0000 \\
\text { H }-6.2899 & 2.1358 & 0.0000 \\
\text { H } 4.4841 & -3.8139 & 0.0000 \\
\text { H }-4.4841 & 3.8139 & 0.0000 \\
\text { C } 0.8309 & -4.0482 & 0.0000 \\
\text { C }-0.8309 & 4.0482 & 0.0000 \\
\text { C } 1.8152 & -3.3213 & 0.0000 \\
\text { C }-1.8152 & 3.3213 & 0.0000 \\
\text { C } 6.0414 & 0.5314 & 0.0000 \\
\text { C }-6.0414 & -0.5314 & 0.0000 \\
\text { C } 6.9299 & 1.3716 & 0.0000 \\
\text { C }-6.9299 & -1.3716 & 0.0000
\end{array}
$$

\section{4}

SBr-dimer-activated-XB (S7) E(RIMP2/Def2-TZVP)= -12067.0481261183 hartree N 3.7075 5.0916 0.0000

$\mathrm{N}$-3.7075 -5.09160.0000

$\mathrm{N} 2.04083 .20250 .0000$

$\mathrm{N}-2.0408-3.20250 .0000$

C 4.28443 .85560 .0000

C $-4.2844-3.85560 .0000$

C 3.34022 .78000 .0000

C -3.3402 -2.7800 0.0000

S 2.11994 .81590 .0000

S -2.1199 -4.81590.0000

C 5.67903 .60580 .0000

C $-5.6790-3.60580 .0000$

C 3.77111 .42870 .0000 


$$
\begin{aligned}
& \text { C }-3.7711-1.42870 .0000 \\
& \text { C } 6.07462 .26770 .0000 \\
& \text { C -6.0746 -2.2677 } 0.0000 \\
& \text { C } 5.15101 .21450 .0000 \\
& \text { C -5.1510 -1.21450.0000 } \\
& \text { Br 8.5565 } 6.96440 .0000 \\
& \mathrm{Br}-8.5565 \text {-6.9644 } 0.0000 \\
& \text { Br 0.6837 -1.7346 0.0000 } \\
& \text { Br }-0.68371 .73460 .0000 \\
& \text { H 7.1360 2.0445 } 0.0000 \\
& \mathrm{H}-7.1360-2.04450 .0000 \\
& \text { H } 5.51100 .19140 .0000 \\
& \text { H -5.5110 -0.1914 } 0.0000 \\
& \text { C } 6.60634 .67360 .0000 \\
& \text { C }-6.6063-4.67360 .0000 \\
& \text { C } 7.40105 .60310 .0000 \\
& \text { C - 7.4010 -5.60310.0000 } \\
& \text { C } 2.83550 .36980 .0000 \\
& \text { C - } 2.8355-0.36980 .0000 \\
& \text { C } 2.0026-0.52830 .0000 \\
& \text { C - } 2.00260 .52830 .0000
\end{aligned}
$$

7.16 4,7-bis(iodoethynyl)benzo-1,2,5-thiadiazole (S8)

34

SI-dimer-activated-ChB (S8) E(RIMP2/Def2-TZVP)= -2963.9514396291 hartree N 3.17781 .25350 .0000

$\mathrm{N}-3.1778-1.25350 .0000$

N $1.3481-0.47080 .0000$

$\mathrm{N}-1.34810 .47080 .0000$

C $3.6414-0.02780 .0000$

C -3.64140 .02780 .0000$

C $2.5989-1.00450 .0000$

C -2.59891 .00450 .0000$

S 1.56431 .13490 .0000

S - $1.5643-1.13490 .0000$

C $5.0020-0.42560 .0000$

C -5.0020 0.42560.0000

C $2.8833-2.39200 .0000$

C - 2.88332 .39200 .0000

C $5.2558-1.80000 .0000$

C -5.2558 1.80000 .0000

C $4.2306-2.75570 .0000$

C -4.2306 2.75570.0000

I 8.36122 .74610 .0000

I -8.3612 -2.7461 0.0000 


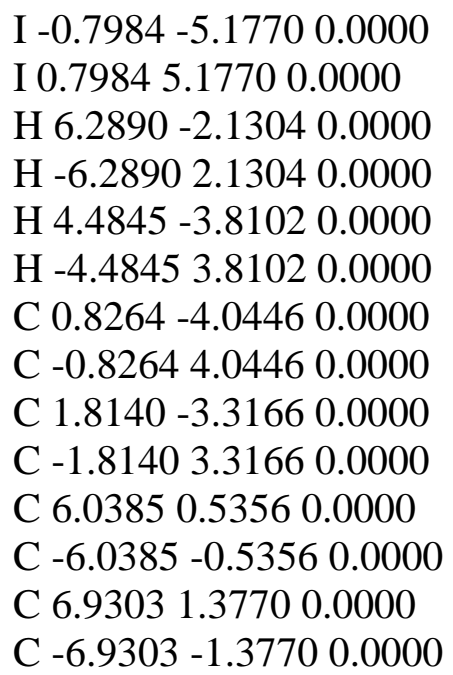

34

SI-dimer-activated-XB (S8) E(RIMP2/Def2-TZVP) $=-2963.9527174938$ hartree

N $6.15321 .6373-0.0000$

$\mathrm{N}-6.1532-1.63730 .0000$

N $3.67471 .1971-0.0000$

$\mathrm{N}-3.6747-1.19710 .0000$

C $5.83520 .3111-0.0000$

C $-5.8352-0.31110 .0000$

C $4.42630 .0546-0.0000$

C $-4.4263-0.05460 .0000$

S $4.74152 .4120-0.0000$

S - $4.7415-2.41200 .0000$

C $6.7751-0.7493-0.0000$

C -6.77510 .74930 .0000$

C $3.9256-1.27350 .0000$

C -3.9256 $1.2735-0.0000$

C $6.2548-2.0447-0.0000$

C -6.2548 2.04470 .0000

C $4.8780-2.2967-0.0000$

C -4.87802 .29670 .0000$

I 11.30700 .14620 .0000

I - $11.3070-0.1462-0.0000$

I $-0.6579-1.8381-0.0000$

I 0.65791 .83810 .0000

H $6.9489-2.8782-0.0000$

H -6.9489 2.87820 .0000

H $4.5246-3.3222-0.0000$

$\mathrm{H}-4.52463 .32220 .0000$

C $8.1635-0.4858-0.0000$

C -8.16350 .48580 .0000$

C $9.3665-0.24890 .0000$ 
C $-9.36650 .2489-0.0000$

C $2.5378-1.53490 .0000$

C $-2.53781 .5349-0.0000$

C $1.3296-1.76040 .0000$

C -1.32961 .76040 .0000$

\subsection{4,7-bis(fluoroethynyl)benzo-1,2,5-selenadiazole (Se5)}

34

SeF-dimer-activated-ChB (Se5) E(RIMP2/Def2-TZVP) $=-6180.1006708552$ hartree N 3.24261 .26400 .0000

$\mathrm{N}-3.2426-1.26400 .0000$

N $1.3057-0.53290 .0000$

$\mathrm{N}-1.30570 .53290 .0000$

C $3.6312-0.04090 .0000$

C -3.63120.04090.0000

C $2.5790-1.01530 .0000$

C -2.57901 .01530 .0000$

Se 1.46931 .24000 .0000

Se -1.4693 - 1.24000 .0000

C $4.9890-0.45520 .0000$

C -4.98900 .45520 .0000$

C $2.8724-2.40250 .0000$

C - 2.87242 .40250 .0000

C $5.2435-1.82470 .0000$

C -5.2435 1.82470 .0000

C $4.2135-2.77550 .0000$

C -4.21352 .77550 .0000$

F 7.8375 2.2251 0.0000

F -7.8375 -2.2251 0.0000

F - $0.0624-4.99180 .0000$

F 0.06244 .99180 .0000

H $6.2758-2.15740 .0000$

H -6.2758 2.1574 0.0000

H $4.4592-3.83180 .0000$

$\mathrm{H}-4.45923 .83180 .0000$

C $0.9020-4.14940 .0000$

C -0.90204 .14940 .0000$

C $1.8158-3.35270 .0000$

C -1.81583 .35270 .0000$

C 6.03260 .50750 .0000

C -6.0326 -0.5075 0.0000

C 6.90871 .34450 .0000

C -6.9087-1.3445 0.0000 
SeF-dimer-activated-XB (Se5) E(RIMP2/Def2-TZVP) $=-6180.0845330730$ hartree N 3.64665 .07050 .0000

$\mathrm{N}-3.6466-5.07050 .0000$

$\mathrm{N} 1.84593 .11240 .0000$

$\mathrm{N}-1.8459-3.11240 .0000$

C 4.12943 .79500 .0000

C $-4.1294-3.79500 .0000$

C 3.15762 .73790 .0000

C $-3.1576-2.73790 .0000$

Se 1.88524 .88370 .0000

Se $-1.8852-4.88370 .0000$

C 5.51783 .49870 .0000

C $-5.5178-3.49870 .0000$

C 3.56921 .37900 .0000

C - $3.5692-1.37900 .0000$

C 5.88682 .15660 .0000

C -5.8868 -2.1566 0.0000

C 4.93811 .12490 .0000

C $-4.9381-1.12490 .0000$

F 8.1287 6.41110.0000

F -8.1287 -6.4111 0.0000

F $0.8827-1.46150 .0000$

F - 0.88271 .46150 .0000

H 6.94321 .91110 .0000

$\mathrm{H}-6.9432-1.91110 .0000$

H 5.27120 .09280 .0000

H -5.2712 -0.0928 0.0000

C 6.47494 .54760 .0000

C $-6.4749-4.54760 .0000$

C 7.2776 5.45510.0000

C -7.2776 -5.4551 0.0000

C 2.60560 .33680 .0000

C -2.6056 -0.3368 0.0000

C $1.7662-0.53810 .0000$

C - 1.76620 .53810 .0000

\subsection{4,7-bis(chloroethynyl)benzo-1,2,5-selenadiazole (Se6)}

34

SeCl-dimer-activated-ChB (Se6) E(RIMP2/Def2-TZVP) $=-7620.0739262690$ hartree N 3.23771 .28970 .0000

$\mathrm{N}-3.2377-1.28970 .0000$

N $1.3022-0.50880 .0000$

$\mathrm{N}-1.30220 .50880 .0000$

C $3.6264-0.01520 .0000$

C -3.62640 .01520 .0000$ 
C $2.5752-0.98900 .0000$

C -2.57520.9890 0.0000

Se 1.46261 .26460 .0000

Se - $1.4626-1.26460 .0000$

C $4.9840-0.43360 .0000$

C -4.98400 .43360 .0000$

C $2.8644-2.37800 .0000$

C - 2.86442 .37800 .0000

C $5.2361-1.80700 .0000$

C -5.23611 .80700 .0000$

C $4.2067-2.75570 .0000$

C -4.2067 2.75570 .0000

Cl 8.10752 .47200 .0000

Cl -8.1075 -2.4720 0.0000

Cl -0.4597-5.0526 0.0000

$\mathrm{Cl} 0.45975 .05260 .0000$

H $6.2685-2.13980 .0000$

H -6.2685 2.13980 .0000

H $4.4503-3.81260 .0000$

H -4.45033 .81260 .0000$

C $0.8339-4.06070 .0000$

C -0.83394 .06070 .0000$

C $1.7970-3.30810 .0000$

C - 1.79703 .30810 .0000

C 6.02690 .52270 .0000

C $-6.0269-0.52270 .0000$

C 6.91991 .35590 .0000

C -6.9199-1.35590.0000

34

SeCl-dimer-activated-XB (Se6) E(RIMP2/Def2-TZVP) $=-7620.0623518106$ hartree

N 3.74195 .12080 .0000

$\mathrm{N}-3.7419-5.12080 .0000$

$\mathrm{N} 1.96253 .14530 .0000$

$\mathrm{N}-1.9625-3.14530 .0000$

C 4.23753 .85030 .0000

C $-4.2375-3.85030 .0000$

C 3.27862 .78190 .0000

C $-3.2786-2.78190 .0000$

Se 1.98304 .91830 .0000

Se $-1.9830-4.91830 .0000$

C 5.63043 .57150 .0000

C $-5.6304-3.57150 .0000$

C 3.70691 .42640 .0000

C -3.7069-1.4264 0.0000

C 6.01632 .23140 .0000 


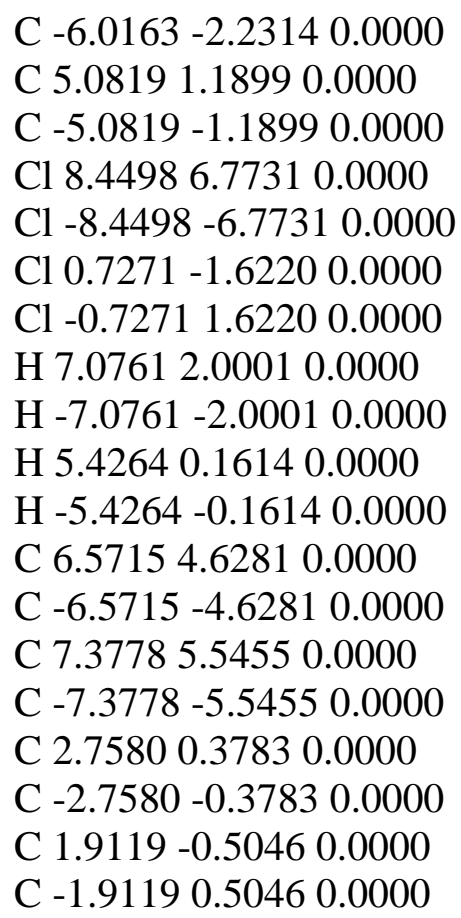

7.19 4,7-bis(bromoethynyl)benzo-1,2,5-selenadiazole (Se7)

34

SeBr-dimer-activated-ChB (Se7) E(RIMP2/Def2-TZVP) $=-16071.5999096583$ hartree N 3.47900 .17510 .0000

$\mathrm{N}-3.4790-0.1751-0.0000$

$\mathrm{N} 1.0660-0.90080 .0000$

$\mathrm{N}-1.06600 .9008-0.0000$

C $3.4247-1.1853-0.0000$

C -3.42471 .18530 .0000$

C $2.1150-1.76680 .0000$

C $-2.11501 .7668-0.0000$

Se 1.79070 .72580 .0000

Se $-1.7907-0.7258-0.0000$

C $4.5734-2.02120 .0000$

C $-4.57342 .0212-0.0000$

C $1.9392-3.17480 .0000$

C - $1.93923 .1748-0.0000$

C $4.3674-3.40290 .0000$

C -4.3674 $3.4029-0.0000$

C $3.0869-3.96750 .0000$

C -3.0869 $3.9675-0.0000$

Br 8.6142 -0.2217 0.0000

$\mathrm{Br}-8.61420 .2217-0.0000$

$\mathrm{Br}-2.2322-4.64650 .0000$

Br 2.23224 .64650 .0000 
$\begin{array}{llll}\text { H } & 5.2369 & -4.0516 & -0.0000 \\ \text { H }-5.2369 & 4.0516 & 0.0000 \\ \text { H } 2.9750 & -5.0464 & 0.0000 \\ \text { H }-2.9750 & 5.0464 & -0.0000 \\ \text { C }-0.5317 & -4.0998 & 0.0000 \\ \text { C } 0.5317 & 4.0998 & -0.0000 \\ \text { C } & 0.6275 & -3.7061 & 0.0000 \\ \text { C }-0.6275 & 3.7061 & -0.0000 \\ \text { C } 5.8695 & -1.4547 & 0.0000 \\ \text { C }-5.8695 & 1.4547 & 0.0000 \\ \text { C } 6.9869 & -0.9571 & 0.0000 \\ \text { C }-6.9869 & 0.9571 & -0.00000\end{array}$

34

SeBr-dimer-activated-XB (Se7) E(RIMP2/Def2-TZVP) $=-16071.5902640486$ hartree

N 6.23161 .39850 .0000

$\mathrm{N}-6.2316-1.3985-0.0000$

N $3.59571 .0611-0.0000$

$\mathrm{N}-3.5957-1.06110 .0000$

C $5.77890 .1121-0.0000$

C $-5.7789-0.11210 .0000$

C $4.3553-0.07430 .0000$

C $-4.35530 .0743-0.0000$

Se 4.76752 .39300 .0000

Se $-4.7675-2.3930-0.0000$

C $6.6553-1.0058-0.0000$

C -6.65531 .00580 .0000$

C $3.7984-1.38280 .0000$

C $-3.79841 .3828-0.0000$

C $6.0764-2.2750-0.0000$

C -6.0764 2.2750 0.0000

C $4.6898-2.4573-0.0000$

C -4.68982 .45730 .0000$

Br $11.0344-0.38400 .0000$

$\mathrm{Br}-11.03440 .38400 .0000$

Br 0.6082 1.7366 0.0000

Br -0.6082 - $1.7366-0.0000$

H $6.7309-3.14010 .0000$

H -6.7309 $3.1401-0.0000$

H $4.2816-3.4622-0.0000$

$\mathrm{H}-4.28163 .46220 .0000$

C $8.0567-0.81500 .0000$

C $-8.05670 .8150-0.0000$

C $9.2677-0.64340 .0000$

C -9.2677 $0.6434-0.0000$

C $2.3971-1.5652-0.0000$ 
C - 2.39711 .56520 .0000

C $1.1797-1.70260 .0000$

C $-1.17971 .7026-0.0000$

7.20 4,7-bis(iodoethynyl)benzo-1,2,5-selenadiazole (Se8)

34

SeI-dimer-activated-ChB (Se8) E(RIMP2/Def2-TZVP) $=-6968.5022356591$ hartree N 3.23331 .29470 .0000

$\mathrm{N}-3.2333-1.29470 .0000$

$\mathrm{N} 1.3003-0.50650 .0000$

$\mathrm{N}-1.30030 .50650 .0000$

C $3.6233-0.00980 .0000$

C -3.62330 .00980 .0000$

C $2.5735-0.98510 .0000$

C - 2.57350 .98510 .0000

Se 1.45731 .26760 .0000

Se $-1.4573-1.26760 .0000$

C $4.9813-0.42760 .0000$

C -4.98130 .42760 .0000$

C $2.8640-2.37420 .0000$

C -2.8640 2.37420.0000

C 5.2351-1.80220.0000

C -5.23511 .80220 .0000$

C $4.2078-2.75150 .0000$

C -4.20782 .75150 .0000$

I 8.35962 .72380 .0000

I -8.3596 -2.7238 0.0000

I $-0.7661-5.23200 .0000$

I 0.76615 .23200 .0000

H $6.2682-2.13310 .0000$

$\mathrm{H}-6.26822 .13310 .0000$

H 4.4516 -3.8084 0.0000

$\mathrm{H}-4.45163 .80840 .0000$

C $0.8290-4.05730 .0000$

C -0.82904 .05730 .0000$

C $1.7965-3.30180 .0000$

C -1.79653 .30180 .0000$

C 6.02290 .52790 .0000

C $-6.0229-0.52790 .0000$

C 6.92141 .36260 .0000

C -6.9214 -1.36260.0000

34

SeI-dimer-activated-XB (Se8) E(RIMP2/Def2-TZVP) $=-6968.4950833387$ hartree N 3.85895 .17500 .0000 
$\mathrm{N}-3.8589-5.17500 .0000$

N 2.09483 .19150 .0000

$\mathrm{N}-2.0948-3.19150 .0000$

C 4.36273 .90770 .0000

C - $4.3627-3.90770 .0000$

C 3.41332 .82930 .0000

C -3.4133 -2.8293 0.0000

Se 2.10274 .96680 .0000

Se $-2.1027-4.96680 .0000$

C 5.75903 .64580 .0000

C $-5.7590-3.64580 .0000$

C 3.85711 .47730 .0000

C $-3.8571-1.47730 .0000$

C 6.16002 .30900 .0000

C $-6.1600-2.30900 .0000$

C 5.23781 .25940 .0000

C - $5.2378-1.25940 .0000$

I 8.76837 .15080 .0000

I -8.7683 -7.1508 0.0000

I $0.6275-1.82350 .0000$

I - 0.62751 .82350 .0000

H 7.2224 2.08990 .0000

H -7.2224 -2.0899 0.0000

H 5.59200 .23410 .0000

H -5.5920 -0.2341 0.0000

C 6.68604 .71240 .0000

C $-6.6860-4.71240 .0000$

C 7.4872 5.6409 0.0000

C - $7.4872-5.64090 .0000$

C 2.93470 .40790 .0000

C - $2.9347-0.40790 .0000$

C $2.1418-0.53180 .0000$

C -2.1418 0.53180.0000

\subsection{4,7-bis(fluoroethynyl)benzo-1,2,5-telluradiazole (Te5)}

34

TeF-dimer-activated-ChB (Te5) E(RIMP2/Def2-TZVP)= -1914.3791644165 hartree N 3.26791 .29680 .0000

$\mathrm{N}-3.2679-1.29680 .0000$

N $1.2463-0.55750 .0000$

$\mathrm{N}-1.24630 .55750 .0000$

C $3.5945-0.02150 .0000$

C -3.59450 .02150 .0000$

C $2.5343-1.00190 .0000$

C - 2.53431 .00190 .0000 
Te 1.31531 .41420 .0000

$\mathrm{Te}-1.3153-1.41420 .0000$

C $4.9504-0.45760 .0000$

C - 4.95040 .45760 .0000

C $2.8412-2.38880 .0000$

C - 2.84122 .38880 .0000

C $5.2084-1.82560 .0000$

C -5.2084 1.82560 .0000

C $4.1788-2.77320 .0000$

C -4.1788 2.77320 .0000

F 7.8232 2.1994 0.0000

F - 7.8232 -2.1994 0.0000

F $-0.0096-5.07420 .0000$

F 0.00965 .07420 .0000

H 6.2412 -2.1571 0.0000

H -6.2412 2.1571 0.0000

H $4.4170-3.83130 .0000$

H -4.41703 .83130 .0000$

C $0.9267-4.19940 .0000$

C -0.92674 .19940 .0000$

C $1.7950-3.35220 .0000$

C - 1.79503 .35220 .0000

C 5.99960 .49950 .0000

C -5.9996 -0.4995 0.0000

C 6.88581 .32620 .0000

C -6.8858 - 1.32620 .0000

34

TeF-dimer-activated-XB (Te5) E(RIMP2/Def2-TZVP) $=-1914.3480021173$ hartree

N 3.74335 .12970 .0000

$\mathrm{N}-3.7433-5.12970 .0000$

$\mathrm{N} 1.84313 .08290 .0000$

$\mathrm{N}-1.8431-3.08290 .0000$

C 4.15543 .82620 .0000

C $-4.1554-3.82620 .0000$

C 3.17392 .76880 .0000

C $-3.1739-2.76880 .0000$

Te 1.79015 .03720 .0000

$\mathrm{Te}-1.7901-5.03720 .0000$

C 5.54263 .50820 .0000

C $-5.5426-3.50820 .0000$

C 3.59351 .40870 .0000

C - $3.5935-1.40870 .0000$

C 5.91172 .16630 .0000

C -5.9117 -2.16630.0000

C 4.95961 .14100 .0000 
C - $4.9596-1.14100 .0000$

F 8.18946 .39060 .0000

F -8.1894 -6.3906 0.0000

F $0.8977-1.42560 .0000$

F - 0.89771 .42560 .0000

H 6.96811 .92020 .0000

H -6.9681 -1.9202 0.0000

H 5.28350 .10590 .0000

H -5.2835 -0.1059 0.0000

C 6.50894 .54940 .0000

C $-6.5089-4.54940 .0000$

C 7.32585 .44450 .0000

C - $7.3258-5.44450 .0000$

C 2.62630 .36900 .0000

C - $2.6263-0.36900 .0000$

C $1.7851-0.50430 .0000$

C - 1.78510 .50430 .0000

\subsection{4,7-bis(chloroethynyl)benzo-1,2,5-telluradiazole (Te6)}

34

TeCl-dimer-activated-ChB (Te6) E(RIMP2/Def2-TZVP) $=-3354.3536569884$ hartree N 3.26641 .30920 .0000

$\mathrm{N}-3.2664-1.30920 .0000$

N $1.2464-0.54710 .0000$

$\mathrm{N}-1.24640 .54710 .0000$

C $3.5935-0.00910 .0000$

C -3.59350 .00910 .0000$

C $2.5344-0.98970 .0000$

C - 2.53440 .98970 .0000

Te 1.31191 .42440 .0000

$\mathrm{Te}-1.3119-1.42440 .0000$

C $4.9496-0.44700 .0000$

C -4.94960.4470 0.0000

C $2.8403-2.37780 .0000$

C - 2.84032 .37780 .0000

C $5.2076-1.81840 .0000$

C -5.20761 .81840 .0000$

C $4.1801-2.76480 .0000$

C -4.1801 2.76480 .0000

Cl 8.09452 .43740 .0000

Cl -8.0945 -2.4374 0.0000

$\mathrm{Cl}-0.3387-5.22910 .0000$

Cl 0.33875 .22910 .0000

H $6.2411-2.14860 .0000$

H -6.2411 2.14860.0000 
H $4.4170-3.82330 .0000$
H -4.41703 .82330 .0000
C $0.8892-4.15600 .0000$
C -0.88924 .15600 .0000
C $1.7914-3.33030 .0000$
C -1.79143 .33030 .0000
C 5.99660 .50540 .0000
C $-5.9966-0.50540 .0000$
C 6.89831 .32950 .0000
C $-6.8983-1.32950 .0000$

34

TeCl-dimer-activated-XB (Te6) E(RIMP2/Def2-TZVP)= -3354.3265784533 hartree N 3.8214 5.1708 0.0000

$\mathrm{N}-3.8214-5.17080 .0000$

N 1.94263 .10620 .0000

$\mathrm{N}-1.9426-3.10620 .0000$

C 4.24613 .87100 .0000

C $-4.2461-3.87100 .0000$

C 3.27752 .80250 .0000

C -3.2775 -2.80250.0000

Te 1.87015 .06170 .0000

$\mathrm{Te}-1.8701-5.06170 .0000$

C 5.63793 .57050 .0000

C $-5.6379-3.57050 .0000$

C 3.71371 .44600 .0000

C -3.7137 -1.4460 0.0000

C 6.02412 .23040 .0000

C $-6.0241-2.23040 .0000$

C 5.08651 .19560 .0000

C -5.0865 -1.1956 0.0000

$\mathrm{Cl} 8.49196 .74300 .0000$

$\mathrm{Cl}-8.4919-6.74300 .0000$

$\mathrm{Cl} 0.7254-1.59600 .0000$

$\mathrm{Cl}-0.72541 .59600 .0000$

H 7.0839 1.99850.0000

H -7.0839 -1.9985 0.0000

H 5.42130 .16380 .0000

$\mathrm{H}-5.4213-0.16380 .0000$

C 6.58744 .62030 .0000

C -6.5874 -4.62030.0000

C 7.40635.5266 0.0000

C -7.4063 -5.52660.0000

C 2.76190 .39990 .0000

C -2.7619-0.3999 0.0000

C $1.9188-0.48620 .0000$ 
C -1.91880 .48620 .0000$

\subsection{4,7-bis(bromoethynyl)benzo-1,2,5-telluradiazole (Te7)}

34

TeBr-dimer-activated-ChB (Te7) E(RIMP2/Def2-TZVP) $=-11805.8799363601$ hartree N $3.5162-0.1926-0.0000$

$\mathrm{N}-3.51620 .19260 .0000$

N 1.00690 .91740 .0000

$\mathrm{N}-1.0069-0.9174-0.0000$

C $3.40251 .1611-0.0000$

C $-3.4025-1.16110 .0000$

C $2.08491 .7499-0.0000$

C $-2.0849-1.74990 .0000$

Te $1.7018-0.92860 .0000$

$\mathrm{Te}-1.70180 .9286-0.0000$

C $4.54562 .0117-0.0000$

C - $4.5456-2.01170 .0000$

C 1.92903 .16260 .0000

C - $1.9290-3.1626-0.0000$

C 4.35003 .39420 .0000

C $-4.3500-3.3942-0.0000$

C $3.07363 .9605-0.0000$

C $-3.0736-3.96050 .0000$

Br 8.5966 0.2324 0.0000

Br -8.5966 -0.2324 -0.0000

$\mathrm{Br}-2.15234 .87880 .0000$

Br $2.1523-4.8788-0.0000$

H $5.22334 .0381-0.0000$

H -5.2233 -4.0381 0.0000

H 2.95765 .03890 .0000

H - 2.9576 -5.0389 -0.0000

C -0.49394 .21380 .0000$

C $0.4939-4.2138-0.0000$

C $0.62953 .7258-0.0000$

C - $0.6295-3.72580 .0000$

C $5.84271 .4467-0.0000$

C -5.8427 -1.4467 0.0000

C $6.96470 .9590-0.0000$

C $-6.9647-0.95900 .0000$

34

TeBr-dimer-activated-XB (Te7) E(RIMP2/Def2-TZVP)= -11805.8548313997 hartree N 6.37791 .10350 .0000

$\mathrm{N}-6.3779-1.1035-0.0000$

N 3.59650 .89030 .0000 


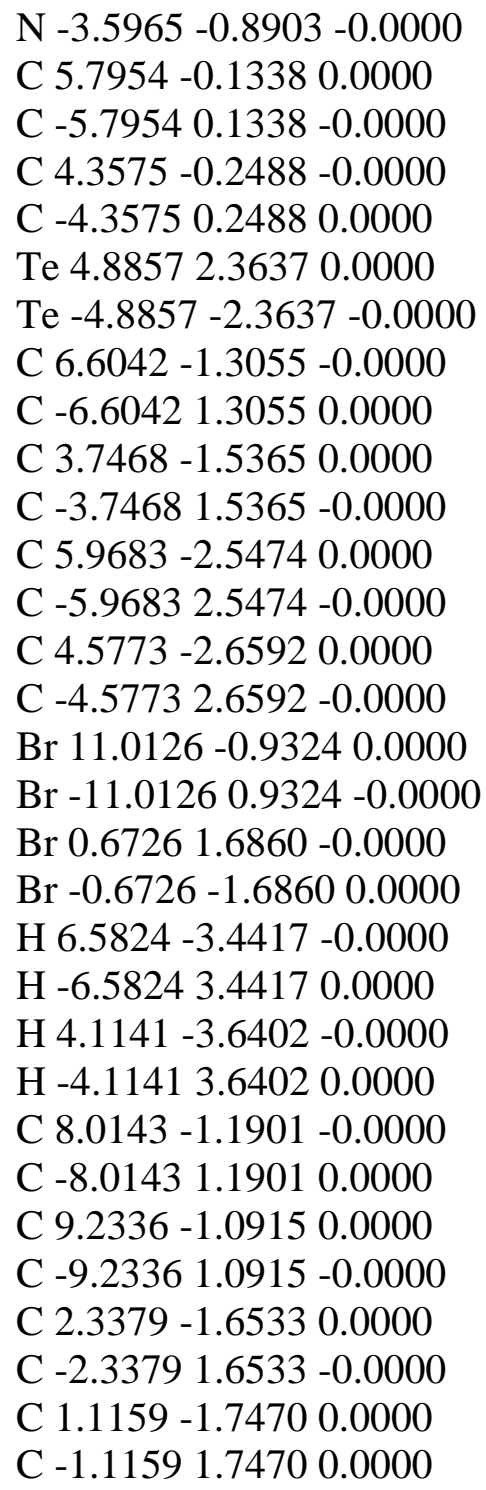

7.24 4,7-bis(iodoethynyl)benzo-1,2,5-telluradiazole (Te8)

34

TeI-dimer-activated-ChB (Te8) E(RIMP2/Def2-TZVP)= -2702.7824485262 hartree N 3.26351 .31500 .0000

$\mathrm{N}-3.2635-1.31500 .0000$

$\mathrm{N} 1.2466-0.54460 .0000$

$\mathrm{N}-1.24660 .54460 .0000$

C $3.5924-0.00300 .0000$

C -3.59240 .00300 .0000$

C $2.5351-0.98560 .0000$

C -2.53510.98560.0000

Te 1.30811 .42720 .0000

Te $-1.3081-1.42720 .0000$ 


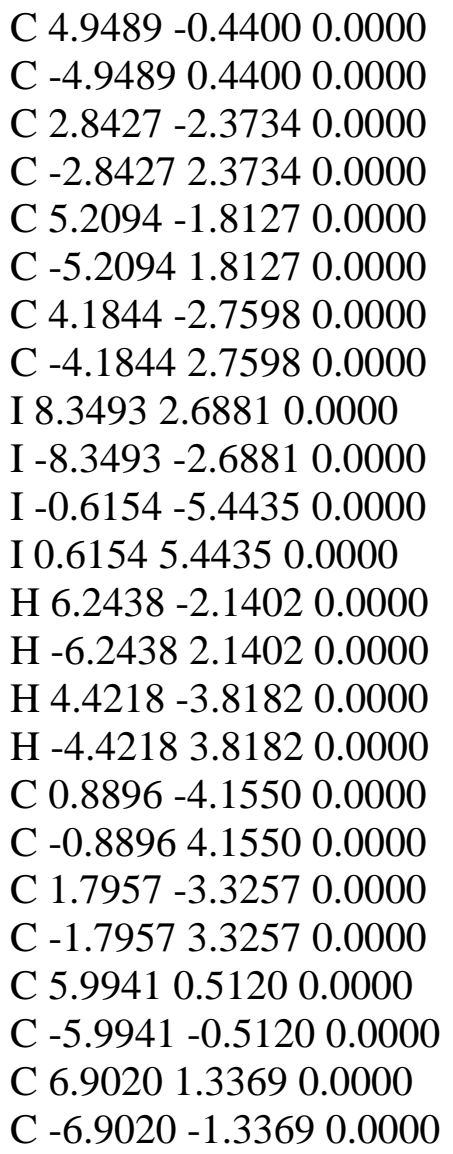

34

TeI-dimer-activated-XB (Te8) E(RIMP2/Def2-TZVP)= -2702.7600238770 hartree

N 3.9482 5.2061 0.0000

$\mathrm{N}-3.9482-5.2061-0.0000$

$\mathrm{N} 2.07453 .14510 .0000$

$\mathrm{N}-2.0745-3.1451-0.0000$

C 4.37433 .90640 .0000

C $-4.3743-3.9064-0.0000$

C 3.40972 .83270 .0000

C -3.4097 -2.8327 -0.0000

Te 1.99955 .10300 .0000

Te $-1.9995-5.1030-0.0000$

C 5.76803 .61580 .0000

C $-5.7680-3.6158-0.0000$

C 3.85441 .47770 .0000

C -3.8544 -1.4777 -0.0000

C $6.16272 .2769-0.0000$

C -6.1627-2.2769 0.0000

C 5.23211 .23870 .0000

C -5.2321 -1.2387-0.0000

I $8.83067 .0751-0.0000$ 

I -8.8306 -7.0751 0.0000
I $0.6033-1.8018-0.0000$
I - -0.60331 .80180 .0000$
H 7.2240 2.05180 .0000
H -7.2240 -2.0518 - 0.0000
H 5.57130 .20840 .0000
H -5.5713 -0.2084 -0.0000
C 6.70884 .67090 .0000
C $-6.7088-4.6709-0.0000$
C 7.5269 5.5847 0.0000
C - $7.5269-5.5847-0.0000$
C $2.92650 .4121-0.0000$
C $-2.9265-0.41210 .0000$
C $2.1422-0.5357-0.0000$
C -2.14220 .53570 .00$ 


\section{References:}

1. We acknowledge the NSF-MRI grant CHE-2018414, which was used to purchase the single-crystal X-ray diffractometer and associated software employed in this study.

2. We acknowledge the NSF-MRI grant CHE-0923449, which was used to purchase the single-crystal $\mathrm{X}$-ray diffractometer and associated software employed in this study.

3. Dolomanov, O. V.; Bourhis, L. J.; Gildea, R. J.; Howard, J. A. K.; Puschmann, H., OLEX2: a complete structure solution, refinement and analysis program. Journal of Applied Crystallography 2009, 42 (2), 339-341.

4. Sheldrick, G., SHELXT - Integrated space-group and crystal-structure determination. Acta Crystallographica Section A 2015, 71 (1), 3-8.

5. Sheldrick, G., Crystal structure refinement with SHELXL. Acta Crystallographica Section C 2015, 71 (1), 3-8.

6. Peterson, K. A.; Shepler, B. C.; Figgen, D.; Stoll, H., On the Spectroscopic and Thermochemical Properties of $\mathrm{ClO}, \mathrm{BrO}, \mathrm{IO}$, and Their Anions. The Journal of Physical Chemistry A 2006, 110 (51), 13877-13883.

7. DaSilveira Neto, B. A.; Lopes, A. S. A.; Ebeling, G.; Gonçalves, R. S.; Costa, V. E. U.; Quina, F. H.; Dupont, J., Photophysical and electrochemical properties of $\pi$-extended molecular 2,1,3benzothiadiazoles. Tetrahedron 2005, 61 (46), 10975-10982.

8. Pilgram, K.; Zupan, M.; Skiles, R., Bromination of 2,1,3-benzothiadiazoles. Journal of Heterocyclic Chemistry 1970, 7 (3), 629-633.

9. Tsubata, Y.; Suzuki, T.; Miyashi, T.; Yamashita, Y., Single-component organic conductors based on neutral radicals containing the pyrazino-TCNQ skeleton. The Journal of Organic Chemistry 1992, 57 (25), 6749-6755.

10. Sonogashira, K.; Tohda, Y.; Hagihara, N., A convenient synthesis of acetylenes: catalytic substitutions of acetylenic hydrogen with bromoalkenes, iodoarenes and bromopyridines.

Tetrahedron Letters 1975, 16 (50), 4467-4470.

11. Nishikawa, T.; Shibuya, S.; Hosokawa, S.; Isobe, M., One Pot Synthesis of Haloacetylenes from Trimethylsilylacetylenes. Synlett 1994, 1994 (07), 485-486.

12. Lindner, B. D.; Coombs, B. A.; Schaffroth, M.; Engelhart, J. U.; Tverskoy, O.; Rominger, F.; Hamburger, M.; Bunz, U. H. F., From Thia- to Selenadiazoles: Changing Interaction Priority. Organic Letters 2013, 15 (3), 666-669.

13. Caddick, S.; Delisser, V. M.; Doyle, V. E.; Khan, S.; Avent, A. G.; Vile, S., Studies toward the synthesis of natural and unnatural dienediynes 1 . Approaches to a functionalised bicyclic ring system. Tetrahedron 1999, 55 (9), 2737-2754.

14. Denmark, S. E.; Yang, S.-M., Sequential ring-closing metathesis/Pd-catalyzed, Si-assisted cross-coupling reactions: general synthesis of highly substituted unsaturated alcohols and medium-sized rings containing a 1,3-cis-cis diene unit. Tetrahedron 2004, 60 (43), 9695-9708. 